NIST Technical Note 2162

\title{
Velocity and Temperature Structure of Medium-Scale Pool Fires
}

\author{
Kunhyuk Sung \\ Ryan Falkenstein-Smith \\ Anthony Hamins
}

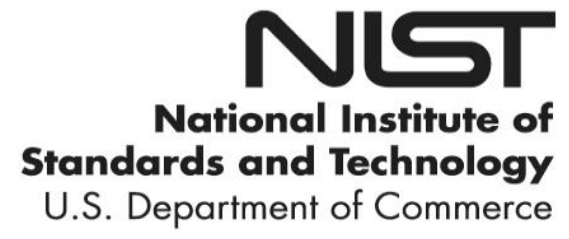


NIST Technical Note 2162

\title{
Velocity and Temperature Structure of Medium-Scale Pool Fires
}

\author{
Kunhyuk Sung \\ Ryan Falkenstein-Smith \\ Anthony Hamins \\ Fire Research Division \\ Engineering Laboratory
}

This publication is available free of charge from:

https://doi.org/10.6028/NIST.TN.2162

June 2021

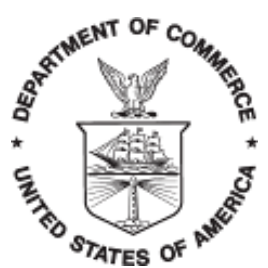

U.S. Department of Commerce Gina M. Raimondo, Secretary

National Institute of Standards and Technology

James K. Olthoff, Performing the Non-Exclusive Functions and Duties of the Under Secretary of Commerce for Standards and Technology \& Director, National Institute of Standards and Technology 
Certain commercial entities, equipment, or materials may be identified in this document in order to describe an experimental procedure or concept adequately. Such identification is not intended to imply recommendation or endorsement by the National Institute of Standards and Technology, nor is it intended to imply that the entities, materials, or equipment are necessarily the best available for the purpose.

National Institute of Standards and Technology Technical Note 2162

Natl. Inst. Stand. Technol. Tech. Note 2162, 63 pages (June 2021) CODEN: NTNOEF

This publication is available free of charge from: https://doi.org/10.6028/NIST.TN.2162 


\begin{abstract}
A series of measurements was conducted using a bidirectional probe to characterize the upward speed in the plumes of medium-scale pool fires burning a variety of gaseous and liquid fuels. Time-averaged local measurements of the upward velocity using a bidirectional probe were conducted in the plumes of methanol, ethanol, and acetone pool fires burning in a $30 \mathrm{~cm}$ diameter liquid pool burner and methane and propane gaseous pool fires established on a $37 \mathrm{~cm}$ diameter gas burner.

The bidirectional probes were connected to multiple pressure transducers with various time responses, ranging from $10 \mathrm{~ms}$ to $160 \mathrm{~ms}$. A $25 \mu \mathrm{m}$ wire diameter, bare-bead, Type $\mathrm{R}$ or $\mathrm{S}$, thermocouple with an approximately spherical bead of diameter $125 \mu \mathrm{m}$ was positioned about $0.5 \mathrm{~cm}$ upstream of the probe. The time series of temperature was corrected for radiative loss only. The Bernoulli equation was solved using the time series of pressure, the "corrected" time series of gas temperature, and the instantaneous $k_{p}$ factor based on the Reynolds number (and its properties) calculated from the instantaneous velocity and temperature. Thermocouple temperature measurements with and without the bidirectional probe present showed negligible impact of the probe on the temperature measurement results. The experiments were typically repeated 2 to 3 times and the results were repeatable to within a few percent. The results showed that the upward velocity increased with distance above the plume for about 1 to 2 diameters above the fuel surface and then decreased with distance. The upward component of the velocity on the plume centerline in the methanol pool fire compared favorably to previous measurements and followed the general trends of Baum and McCaffrey's plume theory.

A single location radiative heat flux measurement was used to determine the radiative fraction $\left(\chi_{\text {rad }}\right)$ in $30 \mathrm{~cm}$ diameter methanol pool fires. The results were favorably compared to previous measurements using multi-location and single-location heat flux measurements. The mean and standard deviation of $\chi_{\text {rad }}$, considering the single and multi-location measurements in the literature and this study is equal to $0.22 \pm 0.02$.
\end{abstract}

KEYWORDS: bidirectional probe; plume velocity; gas temperature; pool fires; radiative fraction

This publication is available free of charge from: https://doi.org/10.6028/NIST.TN.2162 


\section{TABLE OF CONTENTS}

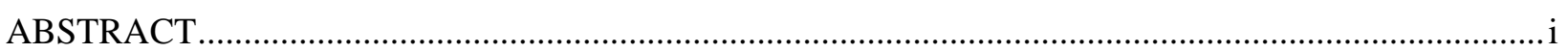

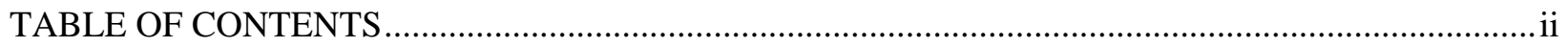

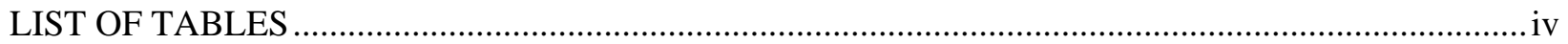

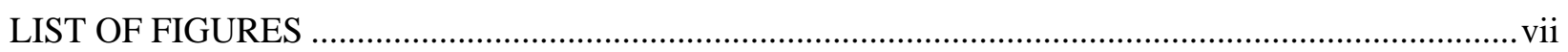

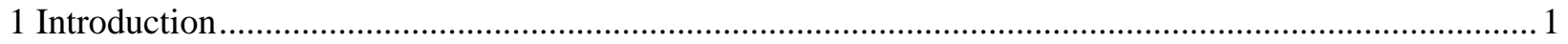

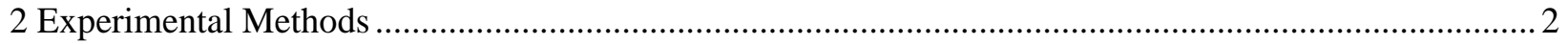

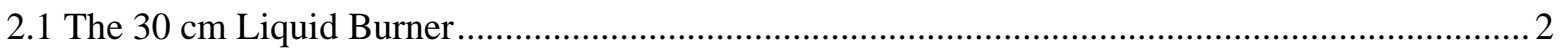

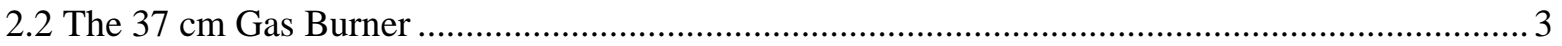

2.3 Thermocouple Temperature Measurements............................................................................... 3

2.3.1 Gas Temperature Determination: Energy Balance at the Thermocouple Bead ..................5

2.4 Bidirectional Probe Measurement............................................................................................ 5

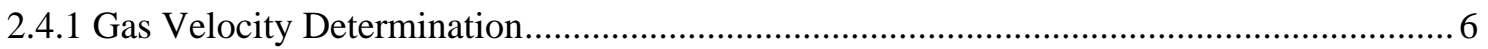

2.5 Single Location Heat Flux Measurement and Estimate of Radiative Fraction ............................. 8

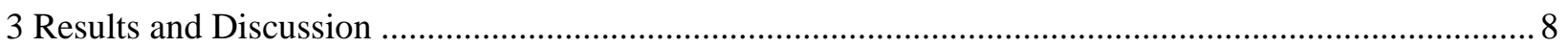

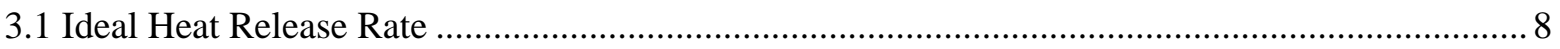

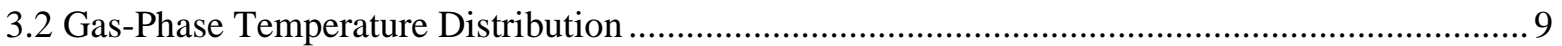

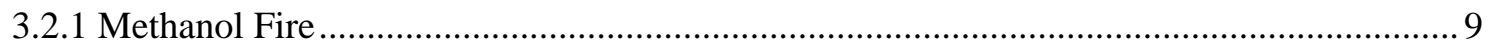

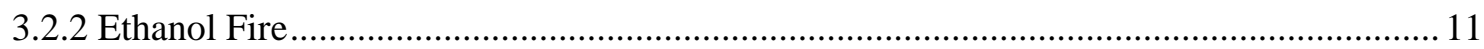

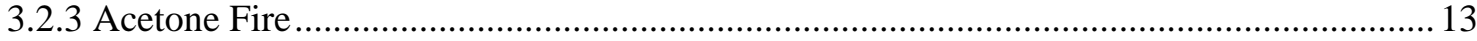

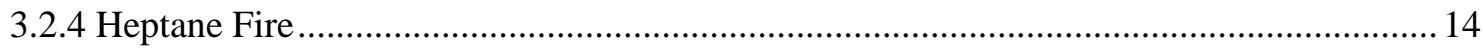

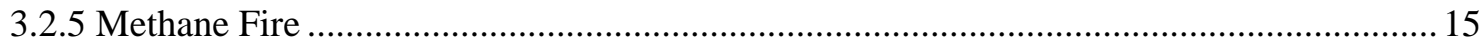

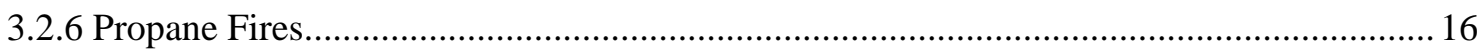

3.3 Upward Component of Velocity Profile along the Fire Centerline …....................................... 17

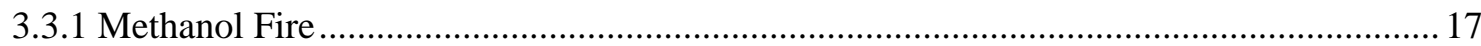

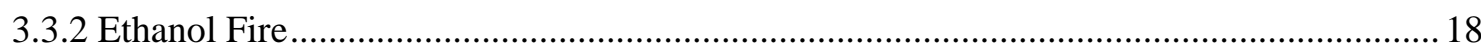

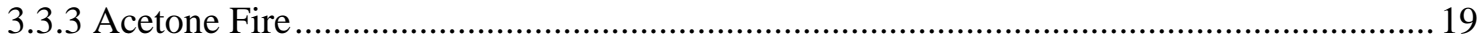

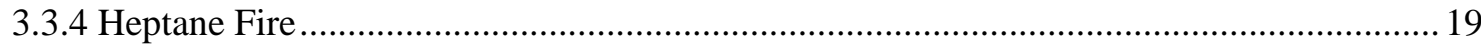

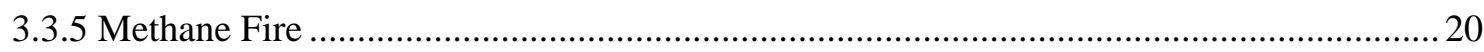

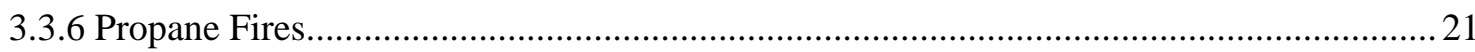

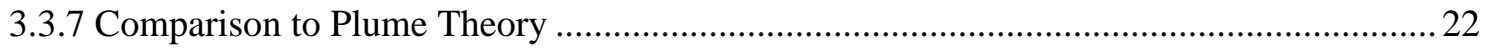

ii

This publication is available free of charge from: https://doi.org/10.6028/NIST.TN.2162 


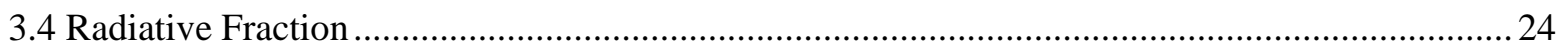

3.4.1 Single location radiative fraction measurements in the $30 \mathrm{~cm}$ methanol fire ................... 24

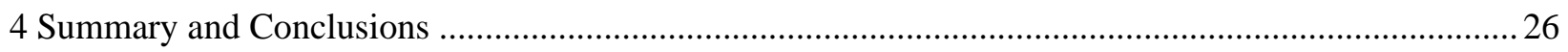

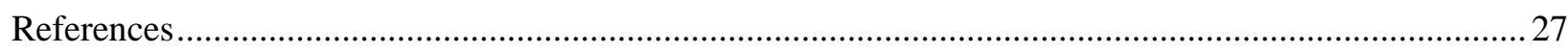

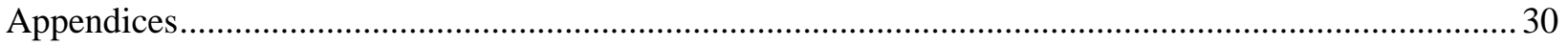

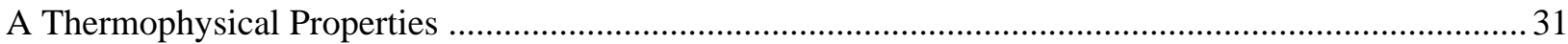

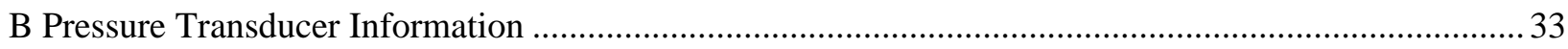

B.1 Pressure Transducer Response Time ….................................................................................. 33

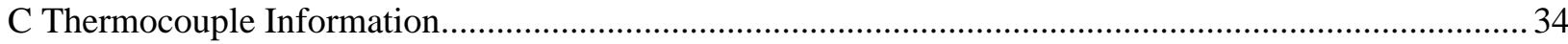

D Effect of Bidirectional Probe on Temperature Measurements ........................................................... 34

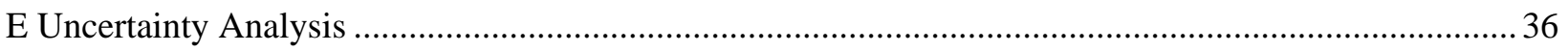

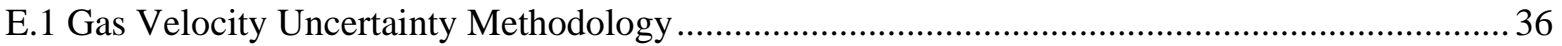

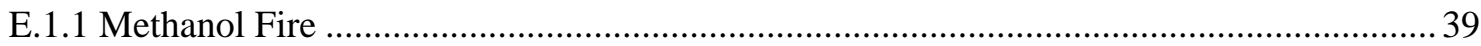

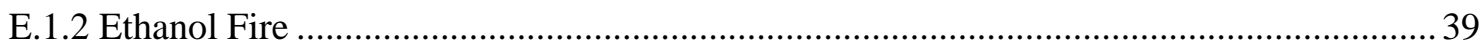

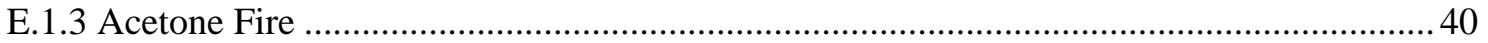

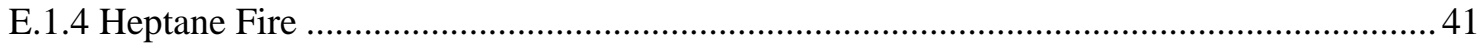

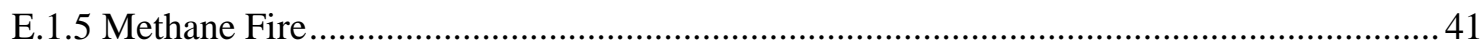

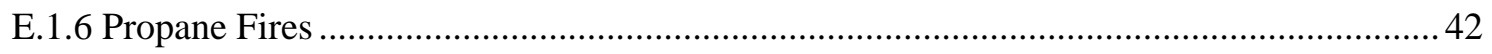

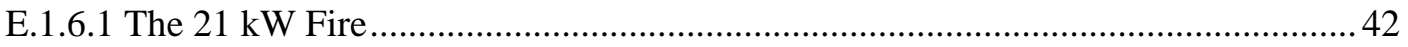

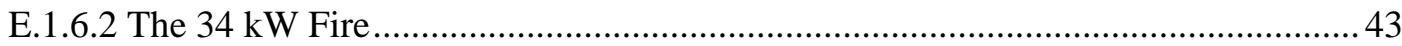

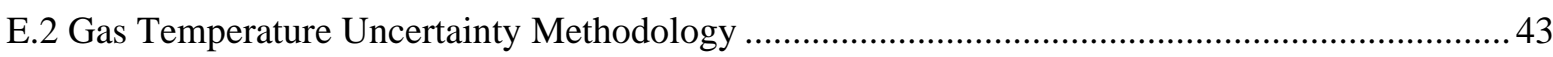

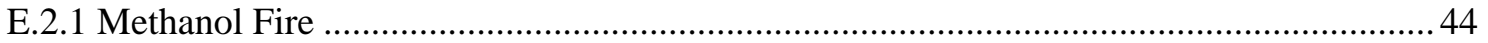

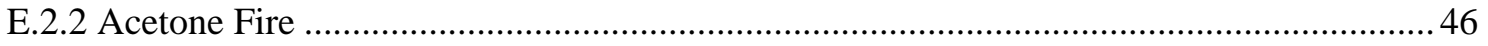

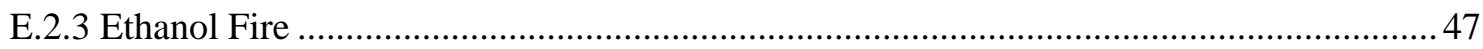

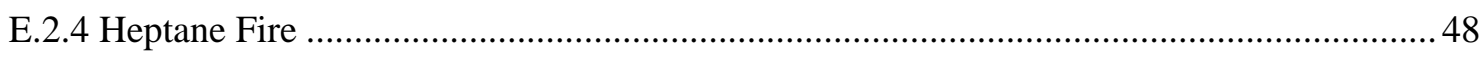

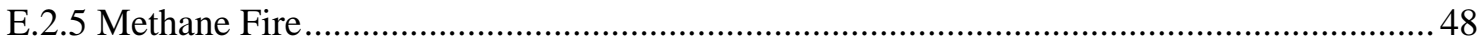

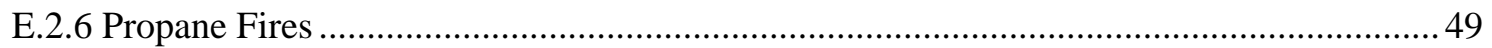

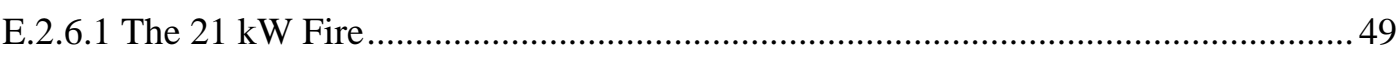

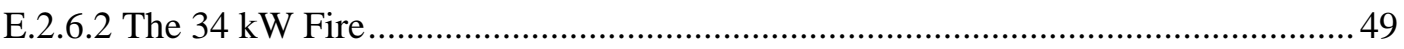

E.3 Uncertainty of Ideal Heat Release Rate .................................................................................... 50

E.4 Uncertainty of the Radiative Fraction Estimate Based on a Single Point Measurement ..............50

iii

This publication is available free of charge from: https://doi.org/10.6028/NIST.TN.2162 


\section{LIST OF TABLES}

Table 1 . Summary of the data acquisition sampling rate $\left(f_{s}\right)$, temperature measurement positions and thermocouple number and type used in the experiments (see Appendix $C$ for the wire and bead diameter).

Table 2. List of the lower (or net) heat of combustion $\left(\Delta H_{c}\right)$, the pool diameter $(D)$, the measured mass flux $\left(\dot{m}^{\prime \prime}\right)$, and the ideal heat release rate $\left(\dot{Q}=\dot{m}^{\prime \prime} \Delta H_{c}\right)$ averaged over the $N$ experiments conducted as part of this study. The uncertainty is presented as the expanded combined uncertainty, representing a $95 \%$ confidence interval.

Table 3. Baum and McCaffrey's [33] plume correlation parameters, which depend on the buoyant diffusion flame region.

Table 4. Summary of value and location of the measured peak upward axial velocity

Table 5. Mass loss, ideal heat release rate, heat flux gauge locations, fluxes and calculated radiative fractions for four tests with gauges various radial distances $(r)$ directed towards the fire and located at a vertical position, $z=15 \mathrm{~cm}$. The uncertainties are expressed as standard deviations (SD) of the measurements.

Table 6. Summary of previous measurements of $\chi_{\text {rad }}$ from single and multi-location measurements and $\chi_{r}$ in $30 \mathrm{~cm}$ methanol pool fires. .25

Table A1. Thermochemical properties of liquid and gaseous fuels at $20^{\circ} \mathrm{C}$ [27]. ................................31

Table A2. Thermophysical properties of platinum as a function of temperature. ..................................... 31

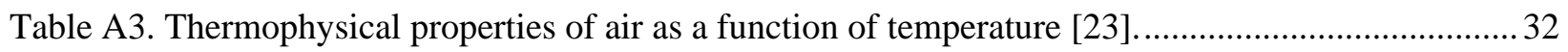

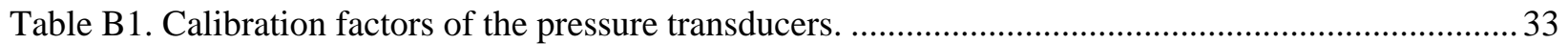

Table C1. Thermocouple type, and wire and bead diameters. .34

Table D1. Mean gas temperature measured using thermocouples without the bidirectional probe

$\left(T_{g, a l o n e}\right)$ present and with the thermocouple positioned below the bidirectional probe $\left(T_{g, T C 5}\right)$ in methanol, acetone and ethanol pool fires. The deviation of the mean gas temperature at each position is compared to the expanded combined uncertainty of the mean gas temperature measured using thermocouples without the bidirectional probe present $\left(U_{c}\left(T_{g, a l o n e}\right)\right)$. .35

Table E1. Pooled mean gas velocity $\left(\bar{V}_{g}\right)$ and standard deviation $\left(\sigma_{V_{g}}\right)$ as a function of axial distance above the burner in the $30 \mathrm{~cm}$ methanol pool fire. The expanded combined uncertainty of the mean gas velocity $\left(U_{c}\left(\bar{V}_{g}\right)\right)$ is also shown in which the uncertainty represents a $95 \%$ confidence interval.

Table E2. Pooled mean gas velocity $\left(\bar{V}_{g}\right)$ and standard deviation $\left(\sigma_{V_{g}}\right)$ as a function of axial distance above the burner in the $30 \mathrm{~cm}$ ethanol pool fire. The expanded combined uncertainty of the mean gas velocity $\left(U_{c}\left(\bar{V}_{g}\right)\right)$ is also shown in which the uncertainty represents a $95 \%$ confidence interval. 
Table E3. Pooled mean gas velocity $\left(\bar{V}_{g}\right)$ and standard deviation $\left(\sigma_{V_{g}}\right)$ as a function of axial distance above the burner in the $30 \mathrm{~cm}$ acetone pool fire. The expanded combined uncertainty of the mean gas velocity $\left(U_{c}\left(\bar{V}_{g}\right)\right)$ is also shown in which the uncertainty represents a $95 \%$ confidence interval.

Table E4. Pooled mean gas velocity $\left(\bar{V}_{g}\right)$ and standard deviation $\left(\sigma_{V_{g}}\right)$ as a function of axial distance above the burner in the $30 \mathrm{~cm}$ heptane pool fire. The expanded combined uncertainty of the mean gas velocity $\left(U_{c}\left(\bar{V}_{g}\right)\right)$ is also shown in which the uncertainty represents a $95 \%$ confidence interval.

Table E5. Pooled mean gas velocity $\left(\bar{V}_{g}\right)$ and standard deviation $\left(\sigma_{V_{g}}\right)$ as a function of axial distance above the burner in the methane gas fire. The expanded combined uncertainty of the mean gas velocity $\left(U_{c}\left(\bar{V}_{g}\right)\right)$ is also shown in which the uncertainty represents a $95 \%$ confidence interval. 41

Table E6. Pooled mean gas velocity $\left(\bar{V}_{g}\right)$ and standard deviation $\left(\sigma_{V_{g}}\right)$ as a function of axial distance above the burner in the $21 \mathrm{~kW}$ propane gas fire. The expanded combined uncertainty of the mean gas velocity $\left(U_{c}\left(\bar{V}_{g}\right)\right)$ is also shown in which the uncertainty represents a $95 \%$ confidence interval.

Table E7. Pooled mean gas velocity $\left(\bar{V}_{g}\right)$ and standard deviation $\left(\sigma_{V_{g}}\right)$ as a function of axial distance above the burner in the $34 \mathrm{~kW}$ propane gas fire. The expanded combined uncertainty of the mean gas velocity $\left(U_{c}\left(\bar{V}_{g}\right)\right)$ is also shown in which the uncertainty represents a $95 \%$ confidence interval.

Table E8. Pooled mean and RMS of the gas temperature as a function of the axial distance above the burner in the $30 \mathrm{~cm}$ methanol pool fire; those expanded combined uncertainties are also shown in which uncertainty represents a $95 \%$ confidence interval.

Table E9. Pooled mean temperature as a function of the radial distance from the burner at $z=40 \mathrm{~cm}, 50$ $\mathrm{cm}$ and $60 \mathrm{~cm}$ in the $30 \mathrm{~cm}$ methanol pool fire. The expanded combined uncertainty is also shown in which uncertainty represents a $95 \%$ confidence interval.

Table E10. Pooled mean temperature as a function of the axial distance above the burner in the $30 \mathrm{~cm}$ acetone pool fire. The expanded combined uncertainty is also shown in which uncertainty represents a $95 \%$ confidence interval

Table E11. Pooled mean temperature as a function of the axial distance above the burner in the $30 \mathrm{~cm}$ ethanol pool fire. The expanded combined uncertainty is also shown in which uncertainty represents a $95 \%$ confidence interval.

Table E12. Pooled mean gas temperature near the downstream face of the probe as a function of axial distance above the burner in the $30 \mathrm{~cm}$ heptane pool fire. The expanded combined uncertainty is also shown in which the uncertainty represents a $95 \%$ confidence interval.

Table E13. Pooled mean temperature as a function of the axial distance above the burner in the methane gas fire. The expanded combined uncertainty is also shown in which uncertainty represents a $95 \%$

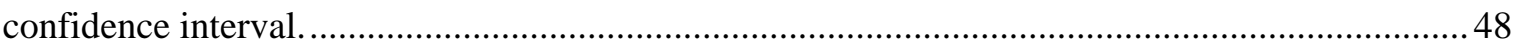


Table E14. Pooled mean gas temperature near the downstream face of the probe as a function of axial distance above the burner in the $21 \mathrm{~kW}$ propane gas fire. The expanded combined uncertainty is also shown in which the uncertainty represents a $95 \%$ confidence interval. ................................. 49

Table E15. Pooled mean gas temperature near the downstream face of the probe as a function of axial distance above the burner in the $34 \mathrm{~kW}$ propane gas fire. The expanded combined uncertainty is also shown in which the uncertainty represents a $95 \%$ confidence interval. 


\section{LIST OF FIGURES}

Figure 1. The round, $30 \mathrm{~cm}$ diameter, water-cooled, steel burner with fuel level indicator and fuel overflow section.

Figure 2. The $37 \mathrm{~cm}$ diameter, water-cooled, gas burner in the fire compartment. The bidirectional probe and Type $\mathrm{S}$ thermocouple were attached to a horizontal rod mounted on the vertical moving traverse.

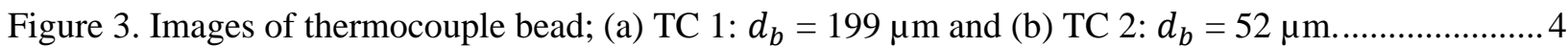

Figure 4. Photograph of a bidirectional probe with a $25 \mu \mathrm{m}$ diameter wire, bare-bead, Type $S$, thermocouple a few $\mathrm{cm}$ above the gas burner.

Figure 5. Schematic drawing of the determination of the radiative fraction using a single-point heat flux measurement.

Figure 6. Mean and RMS of the gas temperature profile as a function of the axial distance above the burner along the centerline in the $30 \mathrm{~cm}$ methanol pool fire; (a) depending on the thermocouple type and sampling frequency, (b) the pooled mean and RMS values.

Figure 7. The pooled mean gas temperature as a function of the radial distance from the burner center at $Z$ $=40 \mathrm{~cm}, 50 \mathrm{~cm}$, and $60 \mathrm{~cm}$ in the $30 \mathrm{~cm}$ methanol pool fire. The error bars indicate the combined uncertainty, representing a $95 \%$ confidence interval.

Figure 8. Mean and RMS of the axial gas temperature profiles as a function of distance above the burner normalized by $\dot{Q}^{2 / 5}$ and compared with the previous results in $30 \mathrm{~cm}$ methanol pool fires.

Figure 9. mean gas temperature as a function of the axial distance above the burner in the $30 \mathrm{~cm}$ ethanol pool fire; (a) mean gas temperature measured using the $n^{\text {th }}$ thermocouple $\left(\bar{T}_{g, n}\right)$, (b) the pooled mean gas temperature $\left(\bar{T}_{g}\right)$. The error bars indicate the combined uncertainty, representing a $95 \%$ confidence interval.

Figure 10. Mean gas temperature as a function of axial distance above the fuel surface normalized by $\dot{Q}^{2 / 5}$ in the $30 \mathrm{~cm}$ ethanol pool fire, and compared with the previous results from Ref. [31]. The error bars indicate the combined uncertainty, representing a $95 \%$ confidence interval.

Figure 11. mean gas temperature as a function of the axial distance above the burner in the $30 \mathrm{~cm}$ acetone pool fire; (a) mean gas temperature measured using the $n^{\text {th }}$ thermocouple $\left(\bar{T}_{g, n}\right)$, (b) the pooled mean gas temperature $\left(\bar{T}_{g}\right)$. The error bars indicate the combined uncertainty, representing a $95 \%$ confidence interval.

Figure 12. Mean gas temperature as a function of axial distance above the fuel surface normalized by $\dot{Q}^{2 / 5}$ in the $30 \mathrm{~cm}$ acetone pool fire, and compared with the measurements by Weckman and Strong [8]. The error bars indicate the combined uncertainty, representing a $95 \%$ confidence interval. 
Figure 13. mean gas temperature as a function of the axial distance above the burner in the $30 \mathrm{~cm}$ heptane pool fire; (a) mean gas temperature measured using the $n^{\text {th }}$ thermocouple $\left(\bar{T}_{g, n}\right)$, (b) the pooled mean gas temperature $\left(\bar{T}_{g}\right)$. The error bars indicate the combined uncertainty, representing a $95 \%$ confidence interval.

Figure 14. mean gas temperature as a function of the axial distance above the burner in the methane gas fire; (a) mean gas temperature measured using the $n^{\text {th }}$ thermocouple $\left(\bar{T}_{g, n}\right)$, (b) the pooled mean gas temperature $\left(\bar{T}_{g}\right)$. The error bars indicate the combined uncertainty, representing a $95 \%$ confidence interval.

Figure 15. Pooled mean gas temperature as a function of the axial distance above the burner in the $21 \mathrm{~kW}$ propane gas fire. The error bars indicate the combined uncertainty, representing a $95 \%$ confidence interval. 16

Figure 16. Pooled mean gas temperature as a function of the axial distance above the burner in the $34 \mathrm{~kW}$ propane gas fire. The error bars indicate the combined uncertainty, representing a $95 \%$ confidence interval.

Figure 17. Mean gas velocities in the upward direction as a function of axial distance above the burner in the $30 \mathrm{~cm}$ methanol pool fire; (a) mean gas velocity measured using the $n^{\text {th }}$ pressure transducers $\left(\bar{V}_{g, n}\right)$, (b) pooled mean gas velocity $\left(\bar{V}_{g}\right)$. Measurements reported by Weckman and Strong [8] in a $30 \mathrm{~cm}$ methanol pool fire also shown. The error bars indicate the combined uncertainty representing a $95 \%$ confidence interval.

Figure 18. Mean gas velocities in the upward direction as a function of axial distance above the burner in the $30 \mathrm{~cm}$ ethanol pool fire; (a) mean gas velocity measured using the $n^{\text {th }}$ pressure transducers $\left(\bar{V}_{g, n}\right)$, (b) pooled mean gas velocity $\left(\bar{V}_{g}\right)$. The error bars indicate the combined uncertainty, representing a $95 \%$ confidence interval.

Figure 19. Mean gas velocities in the upward direction as a function of axial distance above the burner in the $30 \mathrm{~cm}$ acetone pool fire; (a) mean gas velocity measured using the $n^{\text {th }}$ pressure transducers $\left(\bar{V}_{g, n}\right)$, (b) pooled mean gas velocity $\left(\bar{V}_{g}\right)$. The error bars indicate the combined uncertainty, representing a $95 \%$ confidence interval.

Figure 20. Mean gas velocities in the upward direction as a function of axial distance above the burner in the $30 \mathrm{~cm}$ heptane pool fire; (a) mean gas velocity measured using the $n^{\text {th }}$ pressure transducers $\left(\bar{V}_{g, n}\right)$, (b) pooled mean gas velocity $\left(\bar{V}_{g}\right)$. The error bars indicate the combined uncertainty, representing a $95 \%$ confidence interval.

Figure 21. Pooled mean gas velocity in the upward direction $\left(\bar{V}_{g}\right)$ as a function of axial distance above the burner in the $37 \mathrm{~cm}$ methane gas burner fire. The error bars indicate the combined uncertainty, representing a $95 \%$ confidence interval.

Figure 22. Mean gas velocities in the upward direction as a function of axial distance above the burner in the $21 \mathrm{~kW}$ propane gas fire; (a) mean gas velocity measured using the $n^{\text {th }}$ pressure transducers $\left(\bar{V}_{g, n}\right)$, (b) pooled mean gas velocity $\left(\bar{V}_{g}\right)$. The error bars indicate the combined uncertainty, representing a $95 \%$ confidence interval.

$$
\text { viii }
$$

This publication is available free of charge from: https://doi.org/10.6028/NIST.TN.2162 
Figure 23. Mean gas velocities in the upward direction as a function of axial distance above the burner in the $34 \mathrm{~kW}$ propane gas fire; (a) mean gas velocity measured using the $n^{\text {th }}$ pressure transducers $\left(\bar{V}_{g, n}\right)$, (b) pooled mean gas velocity $\left(\bar{V}_{g}\right)$. The error bars indicate the combined uncertainty, representing a $95 \%$ confidence interval. .

Figure 24. Dimensionless mean gas velocity $\left(V_{g} / \sqrt{g D^{*}}\right)$ as a function of dimensionless axial distance above the burner $\left(z / D^{*}\right)$, compared with Baum and McCaffrey plume theory (solid line) in the pool fires; (a) the acetone fire, (b) the ethanol fire, (c) the methanol fire, (d) the heptane fire, (e) the methane gas fire, (f) the $21 \mathrm{~kW}$ propane gas fire, and (g) the $34 \mathrm{~kW}$ propane gas fire. The hollow circle and solid triangle symbols represent the present study and Weckman's results [8, 32]. The error bars indicate the uncertainty, representing a $95 \%$ confidence interval.

Figure B1. Normalized pressure difference measured with Setra-717 as a function of time. 34 


\section{Introduction}

This report describes a series of experiments to characterize medium-scale pool fires. This study is part of a larger body of work characterizing the structure and dynamics of pool fires [1]. The goal of this study is to improve the understanding of fire phenomena and support the development and validation of computational fluid dynamics fire models such as the Fire Dynamics Simulator (FDS). This work also supports recent efforts by the International Association of Fire Safety Science (IAFSS) Working Group on Measurement and Computation of Fire Phenomena (the MaCFP Working Group), an international community of fire scientists working to advance predictive fire models, by addressing critical gaps in knowledge that hinder accurate modeling predictions. The Working Group coordinates research between fire experimentalists and modelers [2-4]. Among the topics selected for investigation are pool fires.

Pool fires are a convenient testbed for model validation due to their well-defined boundary conditions, including the isothermal, flat, and horizontal fuel surface. In this paper, the axial velocity distribution is measured in $30 \mathrm{~cm}$ diameter liquid and $37 \mathrm{~cm}$ diameter gaseous pool fires steadily burning in a wellventilated, quiescent environment. The rate of evaporation in a pool of burning liquid is controlled by heat transfer to the liquid pool, which is primarily controlled by gas-phase heat transfer processes involving convection and radiation. Thus, heat and mass transfer in a pool fire are coupled, and the mass burning rate $(\dot{m})$ of a pool fire depends on the total heat feedback to the pool surface $\left(\dot{Q}_{s}\right)$. In medium and largescale pool fires, radiative heat transfer is the dominant mechanism of heat feedback to the fuel surface. An analysis of the heat feedback to $30 \mathrm{~cm}$ diameter methanol, ethanol, and acetone pool fires is given in Ref. [5]. This paper presents new measurement results, complementing the flame structure information presented in other studies. A series of pool fires burning methane, propane, methanol, ethanol, acetone, and heptane are considered. These fuels were selected to complement previously studies that examined the structure, and the heat and mass transfer processes in these fires [1, 5-11].

A focus of this study is to characterize the vertical velocity profile above the pool centerline in mediumscale pool fires. There are few practical diagnostic options to quantify the velocity in a fire. Although a number of combustion studies and some fire studies have successfully employed various optical methods (alone or in combination with other measurements) to quantify the local velocity field [12-16], they are expensive and not particularly simple to implement, requiring particle seeding and sophisticated equipment. They may be limited in terms of capability particularly in the presence of soot. An effective and practical approach to velocity characterization in soot-laden fires is the use of a bidirectional probe $[17,18]$. Other measurements conducted as part of this study include the gas phase temperature distribution. Measurements were conducted using fine-wire, bare-bead, platinum thermocouples corrected for radiative loss and thermal inertia effects. The radiative fraction in methanol pool fires is estimated using a single location heat flux measurement.

This report is broken into several sections. Section 2 describes the experimental methods and apparatus including the pool burners and instrumentation used to measure the gas phase velocity and temperature, as well as the radiative heat flux emitted by the fire. Section 3 discusses the results and compares the measurements to previous studies and to theory and correlations in the technical literature. Section 4 summarizes the conclusions of the report. The Appendices present information characterizing the fuel properties, the instrumentation, detailed of the analysis of measurement uncertainty, and measurement results regarding the effect of the presence of the bidirectional probe on the thermocouple temperature measurements.

This publication is available free of charge from: https://doi.org/10.6028/NIST.TN.2162 


\section{Experimental Methods}

Methanol, acetone, ethanol and heptane pool fire experiments were conducted using high-purity fuels. Thermochemical properties of the fuels are listed in Appendix A. Experiments were conducted under a canopy hood surrounded by a cubic enclosure, about $3 \mathrm{~m}$ on a side, made of a double layer wire-mesh screen $(6 \mathrm{mesh} / \mathrm{cm}$ with $83 \%$ porosity) to reduce the impact of air currents and room ventilation. The effect of ambient convective currents on the fire was minimized by closing all inlet vents in the lab. The exhaust flow was maintained below about $1 \mathrm{~kg} / \mathrm{s}$, helping to avoid perturbations (such as flame lean) and minimizing the influence of the exhaust on fire behavior.

Steady-state burning conditions were established before measurements were initiated. A warm-up period of 10 min was required for the mass burning rate to be steady. Since back diffusion of water slowly accumulates in the fuel pool, fresh fuel was used for all experiments using the liquid fuels.

\subsection{The $30 \mathrm{~cm}$ Liquid Burner}

A circular pan with an inner diameter $(D)$ of $0.30 \mathrm{~m}$, a depth of $0.15 \mathrm{~m}$, and a wall thickness of $0.0013 \mathrm{~m}$ held the liquid fuels. An image of the burner is seen in Figure 1. The bottom of the burner was watercooled with thermocouples used to monitor the water temperature. The burner was mounted on cinder blocks such that the burner was about $0.3 \mathrm{~m}$ above the floor. A fuel overflow section included for safety was positioned $10 \mathrm{~cm}$ below the burner rim and extended $2.5 \mathrm{~cm}$ in the radial direction beyond the fuel reservoir outer wall. The fuel inlet was insulated and covered with a reflective foil to prevent preheating the fuel. A baffle situated in the fuel pool just above the fuel entry port ensured that the upward momentum of fuel entering the liquid pool was eliminated, which reduced mixing in the fuel pool. The level was verified throughout the experiment by visually observing a video feed of the tiny tip of a sharpened ( $2 \mathrm{~mm}$ diameter) pointer that formed a barely discernable dimple on the fuel surface. The fuel level indicator is seen towards the left of the burner in Figure 1. A camera with optical zoom focused on the fuel level at the pointer, allowing observation of the fuel level.

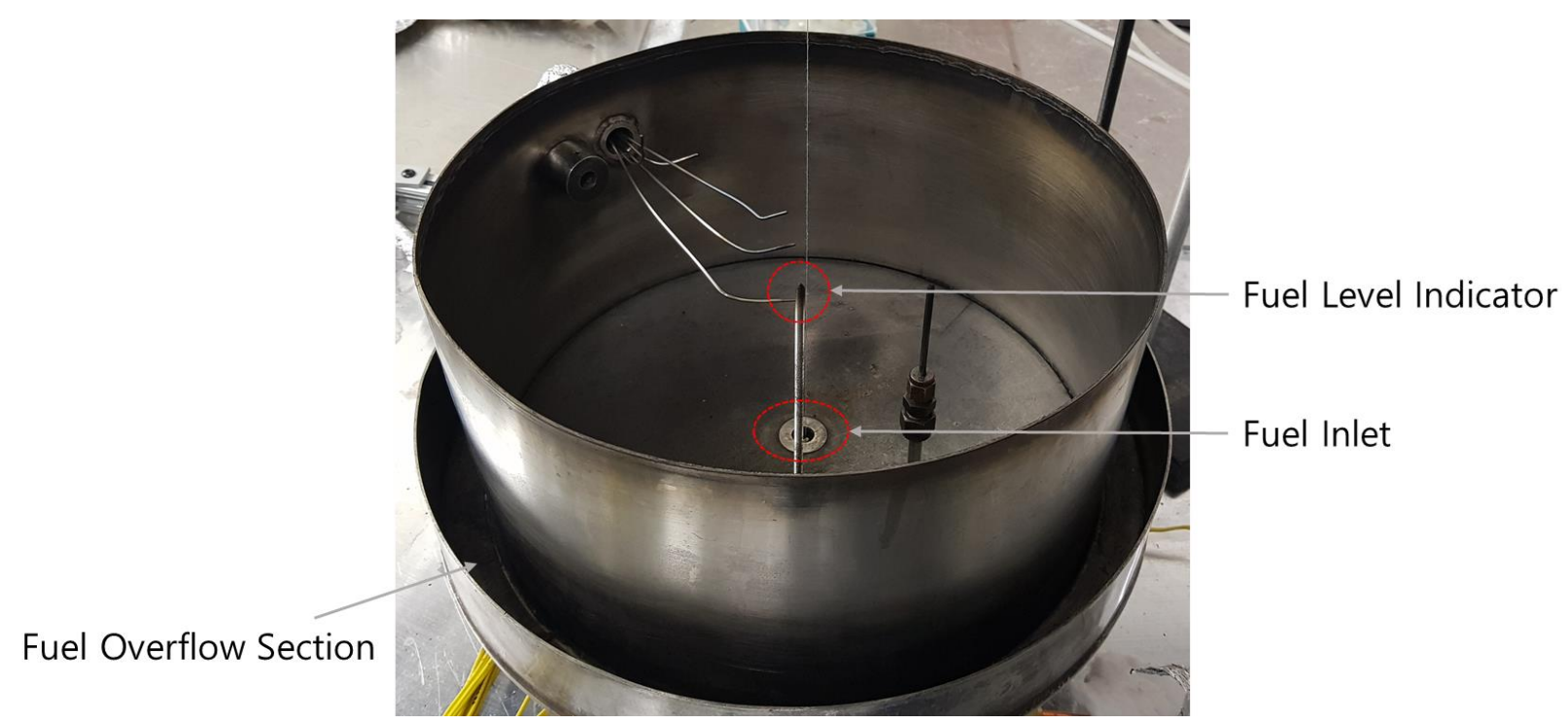

Figure 1 . The round, $30 \mathrm{~cm}$ diameter, water-cooled, steel burner with fuel level indicator and fuel overflow section.

This publication is available free of charge from: https://doi.org/10.6028/NIST.TN.2162 
Fuel to the burner was gravity fed from a reservoir on a mass load cell raised $2 \mathrm{~m}$ above the floor. The mass burning rate was measured by monitoring the mass loss in the $20 \mathrm{~L}$ methanol reservoir feeding the liquid pool, using a calibrated load cell. During the experiments, the level of the fuel was maintained $1 \mathrm{~cm}$ below the burner rim by regulating the fuel supply from the reservoir to the burner.

\subsection{The $37 \mathrm{~cm}$ Gas Burner}

The gaseous pool fires were established in a $37 \mathrm{~cm}$ diameter circular burner as seen in Figure 2. The bottom and sides of the burner was cooled by circulating water to maintain a constant temperature during the experiments. Fuel to the gas burner is controlled via a mass flow controller located outside of the enclosure.

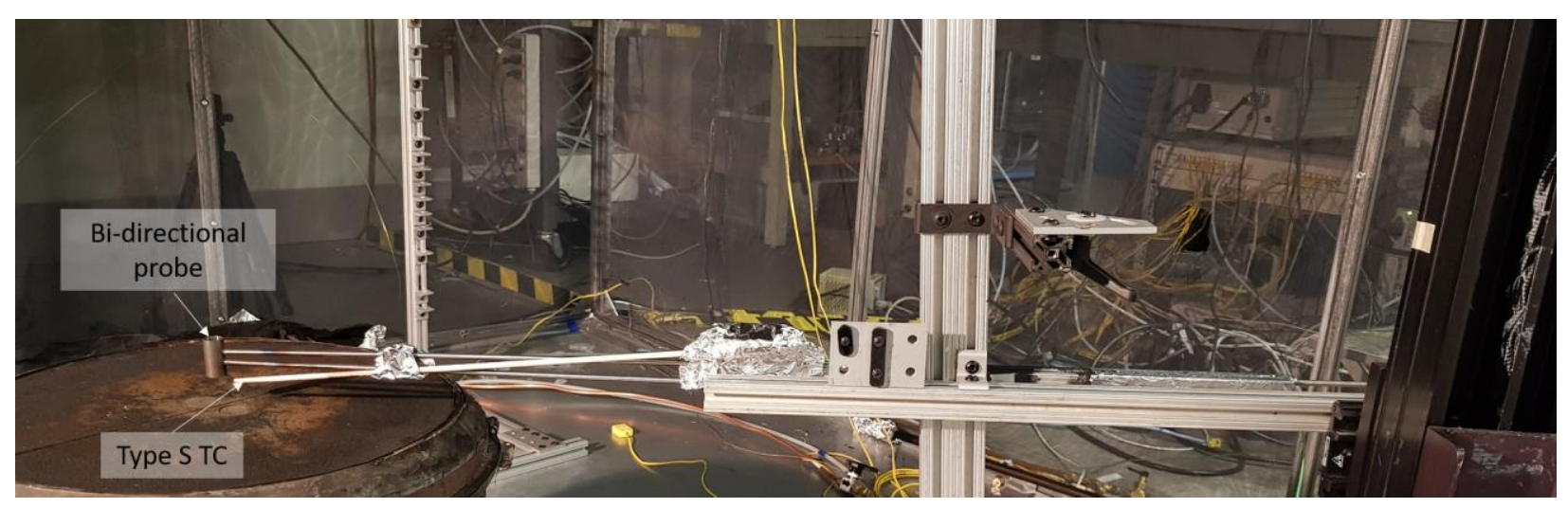

Figure 2. The $37 \mathrm{~cm}$ diameter, water-cooled, gas burner in the fire compartment. The bidirectional probe and Type $\mathrm{S}$ thermocouple were attached to a horizontal rod mounted on the vertical moving traverse.

\subsection{Thermocouple Temperature Measurements}

The local temperature was measured using Type S (Pt with $10 \% \mathrm{Rh} / \mathrm{Pt})$ or Type $\mathrm{R}(\mathrm{Pt}$ with $13 \% \mathrm{Rh} / \mathrm{Pt})$, bare-bead thermocouples with wire diameters varying from $13 \mu \mathrm{m}$ to $50 \mu \mathrm{m}$ (see Table $\mathrm{C} 1$ in Appendix $C$ ). The selection of the diameter of a fine wire thermocouple must consider trade-offs between the durability of the instrument and measurement needs. The finer the wire, the smaller the radiative exchange with the environment and the faster the measurement time response, but the more fragile the thermocouple. The thermocouple bead was approximately spherical as determined using an optical microscope. Figure 3 shows images of the thermocouple bead. The thermocouple bead diameter $\left(d_{b}\right)$ is estimated using an image processing software (Image-J). The bead diameters varied from about $52 \mu \mathrm{m}$ to $199 \mu \mathrm{m}$ (see Table C1 in Appendix C).

A computer-controlled translation device was used to adjust the position of the thermocouple along a vertical axis. The vertical translation device was mounted on a horizontal rail to adjust the position of the thermocouple in the radial direction. The thermocouple assembly, lead wires and connections were insulated and covered with aluminum foil. 

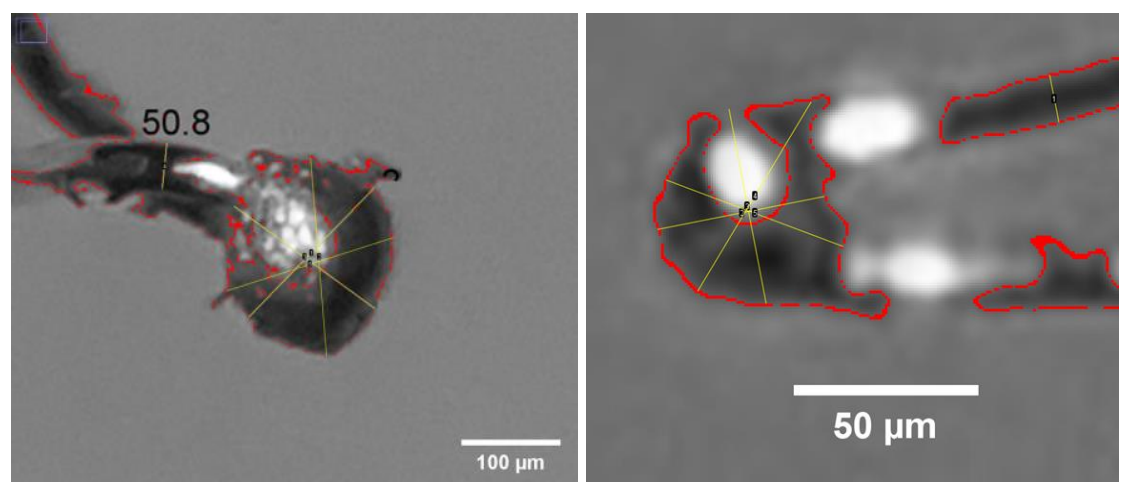

Figure 3. Images of thermocouple bead; (a) TC 1: $d_{b}=199 \mu \mathrm{m}$ and (b) TC 2: $d_{b}=52 \mu \mathrm{m}$.

Table 1 lists the information on the thermocouple bead diameter, type and data acquisition sampling rate for the thermocouple employed in each experiment. Information on each of the five thermocouples, including thermocouple type, and wire and bead diameter can be found in Table $\mathrm{C} 1$. The measured signal was acquired at the sampling rate presented in Table 1 for $120 \mathrm{~s}$ at each position. The temperature was typically measured three times at each location, sometime more, and always at least two times at each location.

Table 1. Summary of the data acquisition sampling rate $\left(f_{s}\right)$, temperature measurement positions and thermocouple number and type used in the experiments (see Appendix $C$ for the wire and bead diameter).

\begin{tabular}{cccccc}
\hline Fuel & $\begin{array}{c}\text { Thermocouple } \\
\text { Number* }\end{array}$ & $\begin{array}{c}\text { Thermocouple } \\
\text { type }\end{array}$ & $\begin{array}{c}\mathbf{z} \\
\text { [cm] }\end{array}$ & $\begin{array}{c}\boldsymbol{r} \\
\text { [cm] }\end{array}$ & $\begin{array}{c}\boldsymbol{f}_{\boldsymbol{s}} \\
{[\mathbf{H z}]}\end{array}$ \\
\hline Acetone & $5^{\dagger}$ & $\mathrm{S}$ & 2 to 130 & 0 & 250 \\
Acetone & 3 & $\mathrm{R}$ & 2 to 60 & 0 & 120 \\
Acetone & 4 & $\mathrm{~S}$ & 2 to 100 & 0 & 250 \\
Ethanol & $5^{\dagger}$ & $\mathrm{S}$ & 2 to 100 & 0 & 250 \\
Ethanol & 1 & $\mathrm{~S}$ & 1 to 60 & 0 & 250 \\
Heptane & $5^{\dagger}$ & $\mathrm{S}$ & 30 to 140 & 0 & 250 \\
Methanol & $5^{\dagger}$ & $\mathrm{S}$ & 3 to 112 & 0 & 250 \\
Methanol & 2 & $\mathrm{~S}$ & -1 to 110 & 0 & 1000 \\
Methanol & 1 & $\mathrm{~S}$ & 1 to 60 & 0 & 250 \\
Methanol & 6 & $\mathrm{~S}$ & 40 to 60 & -5 to 18 & 60 \\
Methane & $5^{\dagger}$ & $\mathrm{S}$ & 4 to 10 & 0 & 200 \\
Methane & $5^{\dagger}$ & $\mathrm{S}$ & 20 to 88 & 0 & 20 \\
Methane & 3 & $\mathrm{R}$ & 1 to 75 & 0 & 1000 \\
Methane & 2 & $\mathrm{~S}$ & 1 to 60 & 0 & 1000 \\
Propane, $21 \mathrm{~kW}$ & $5^{\dagger}$ & $\mathrm{S}$ & 1 to 100 & 0 & 500 \\
Propane, $34 \mathrm{~kW}$ & $5^{\dagger}$ & $\mathrm{S}$ & 4 to 75 & 0 & 200 \\
Propane, $34 \mathrm{~kW}$ & $5^{\dagger}$ & $\mathrm{S}$ & 100 to 115 & 0 & 500 \\
\hline
\end{tabular}

* Additional information on each of the thermocouples, including wire and bead diameter, can be found in Table C1. ${ }^{\dagger}$ during experiments using TC 5, the thermocouple was positioned about $5 \mathrm{~mm}$ upstream of the bidirectional probe. 


\subsubsection{Gas Temperature Determination: Energy Balance at the Thermocouple Bead}

The energy balance on a thermocouple bead consists of convective, radiative and conductive heat transfer. The details of the energy balance on the thermocouple bead and assumptions are explained in Ref. [19]. Following Ref. [19], the conductive heat transfer between the spherical bead and the lead wire is assumed to be negligible. Considering the energy balance at the thermocouple bead, the instantaneous gas temperature $T_{g}(t)$ is estimated as:

$$
T_{g}(t)=T_{b}(t)+\tau \frac{d T_{b}(t)}{d t}+\frac{\epsilon \sigma}{h}\left(T_{b}^{4}(t)-T_{s u r r}^{4}\right)
$$

where $T_{b}(t)$ is the instantaneous thermocouple bead temperature, $h$ is the convective heat transfer coefficient of the gas flow near the bead, $\sigma$ is the Stefan-Boltzmann constant $\left(5.67 \cdot 10^{-8} \mathrm{~W} / \mathrm{m}^{2} / \mathrm{K}^{4}\right)$, and $\epsilon$ is the thermocouple emissivity. The mean and expanded combined uncertainty of ambient temperature during the experiment was $298 \mathrm{~K} \pm 5 \mathrm{~K}$, which is taken as the surrounding temperature, $T_{\text {surr }}$. In Eq. 1 , the second and third terms on the right side represent the thermal inertia and radiative loss corrections, respectively. Here, the flame is taken as optically thin based on estimates using the updated RADCAL software [20], which is a radiation subroutine in Ref. [21]. The thermocouple emissivity was taken as that of platinum based on inspection after each experiment. Assuming a spherical bead shape, the time constant $(\tau)$ is estimated as:

$$
\tau=\frac{\rho_{b} c_{p, b} d_{b}^{2}}{6 \mathrm{Nu} \lambda_{g}}
$$

where $\rho_{b}$ and $c_{p, b}$ is the density and specific heat of the thermocouple, respectively, which is assumed to be purely platinum. In Eqs. 1 - 2, the convective heat transfer coefficient is defined as $h=\mathrm{Nu} \cdot \lambda_{g} / d_{b}$, where $\lambda_{g}$ is the thermal conductivity of the gas and $d_{b}$ is the thermocouple bead diameter. The Nusselt number $(\mathrm{Nu})$ is empirically associated with the Reynolds and Prandtl numbers. The Ranz-Marshall model [22] applies the following Nusselt number correlation for convective heat transfer:

$$
\mathrm{Nu}=2.0+0.6 \operatorname{Re}_{d}^{1 / 2} \operatorname{Pr}^{1 / 3} ; \quad 0<\operatorname{Re}_{d}<200
$$

The temperature-dependent gas properties are taken as those of air [23]. The temperature-dependent emissivity and thermophysical properties of platinum are taken from Refs. [24, 25] and are listed in Appendix A.

\subsection{Bidirectional Probe Measurement}

A bidirectional probe was located above the burner centerline. The external and internal diameters of the probe were $15.9 \mathrm{~mm}$ and $13.6 \mathrm{~mm}$, respectively. The pressure difference between the front and rear of the probe was measured with multiple pressure transducers, each with a different instrument response time. As many as three transducers were used for any single time series measurement. A Type $S, 25 \mu \mathrm{m}$ wire diameter, bare-bead, thermocouple was positioned $5 \mathrm{~mm}$ upstream of the probe as seen in Figure 4 . This position was based on being as close to the probe as practical while preventing damage to the fine thermocouple by the fire, which tended to move the thermocouple downstream towards the bidirectional

This publication is available free of charge from: https://doi.org/10.6028/NIST.TN.2162 
probe when instruments were inserted into the upward moving fire plume. The thermocouple bead was nearly spherical with a bead diameter of approximately $125 \mu \mathrm{m}$ as determined by optical microscopy. The percentage temperature difference between the mean gas temperature measurements with and without the bidirectional probe in the fire is $4 \%$ on-average, which is less than the mean of the expanded combined uncertainty of the mean gas temperature measured using thermocouples without a nearby bidirectional probe (see Appendix $D$ ). Thus, the presence of the probe is regarded as having a negligible impact on the thermocouple measurement.

Voltage signals from the pressure transducers and the thermocouples were obtained using a DAQ (Model: SCXI-1600, National instrument Inc). Detailed information about the pressure transducers' calibration factors and response time are provided in Appendix $B$. The data sampling rates of the voltage and the temperature ranged from $20 \mathrm{~Hz}$ to $500 \mathrm{~Hz}$. Data was acquired for $2 \mathrm{~min}$ at each position along the axial centerline above the burner.
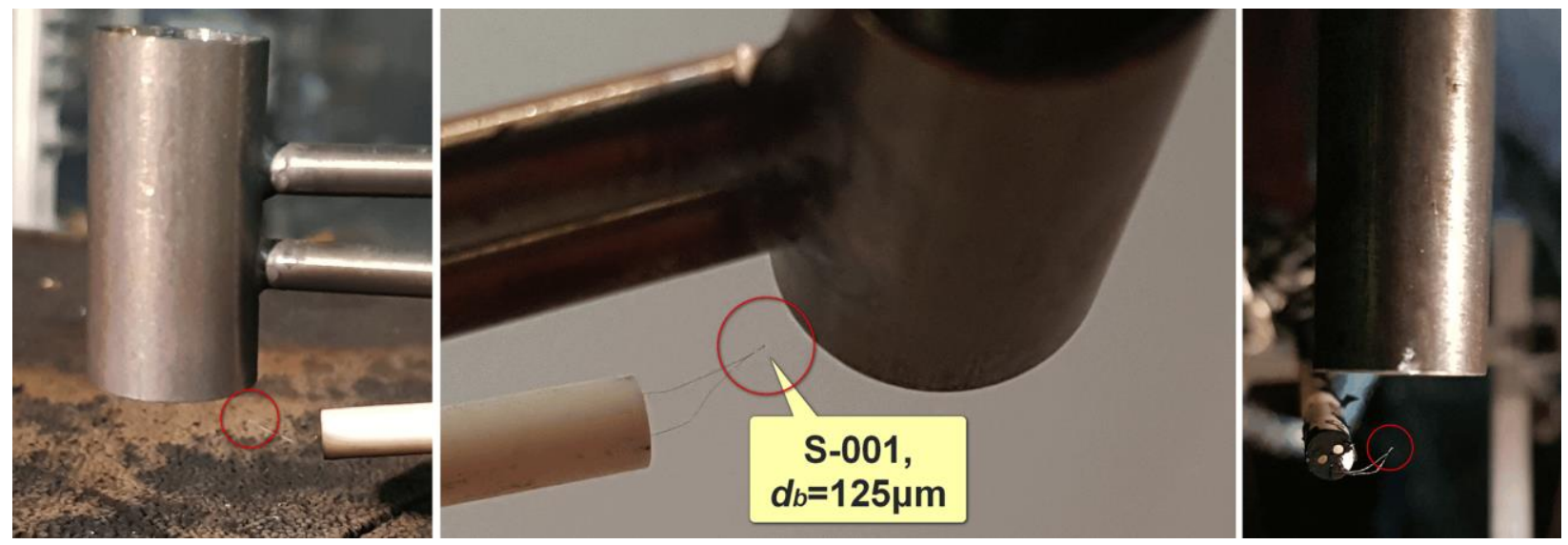

Figure 4. Photograph of a bidirectional probe with a $25 \mu \mathrm{m}$ diameter wire, bare-bead, Type $S$, thermocouple a few $\mathrm{cm}$ above the gas burner.

\subsubsection{Gas Velocity Determination}

The instantaneous gas velocity in the upward direction $\left(V_{g}(t)\right)$ is estimated from measurement of the pressure difference across the bidirectional probe and the simultaneously measured gas temperature near the upstream face of the probe, applying the velocity model for a bidirectional probe [17] as:

$$
V_{g}(t)=\frac{1}{k_{p}(t)} \sqrt{\frac{2 \Delta P_{c}(t)}{\rho(t)}}
$$

where $k_{p}(t)$ is the instantaneous probe constant, and $\Delta P_{c}(t)$ and $\rho(t)$ are the instantaneous corrected pressure difference and gas density, respectively. The gas density $\rho(t)$ is determined from thermocouple 
temperature measurements using a fine, bare-bead, Type $S$ thermocouple corrected for radiative loss and the assumption ${ }^{*}$ that the gas constant corresponds to that of air.

The instantaneous measured pressure difference $(\Delta P(t))$ is corrected to consider the pressure transducer time response, which is treated in a manner similar to the inertia correction in the thermocouple measurement (see Eq. 1). The instantaneous corrected pressure difference $\left(\Delta P_{c}(t)\right)$ is defined as:

$$
\Delta P_{c}(t)=\Delta P(t)+\tau_{p} \frac{d(\Delta P(t))}{d t}
$$

where the second term on the right side of the equation is the instantaneous time-response correction term. Solving for the correction term, the time derivative of the pressure difference is calculated using a second-order polynomial fit using three consecutive data points in the pressure difference time series. The parameter, $\tau_{p}$, is the pressure transducer response time, which is experimentally determined by applying a step function of pressure difference as discussed in Appendix $B$.

The value of the parameter $k_{p}(t)$ in Eq. 4, depends on several factors, including the Reynolds number, probe shape, and flow approach angle. Reference [17] provides a polynomial curve fit for low Reynolds number flows $\left(40<\operatorname{Re}_{p}<3800\right)$ with a standard uncertainty of $5 \%$, which is given as:

$$
\begin{aligned}
k_{p}(t)= & 1.53-1.37 \cdot 10^{-3} \operatorname{Re}_{p}(t)+1.69 \cdot 10^{-6} \operatorname{Re}_{p}^{2}(t)+9.71 \cdot 10^{-10} \operatorname{Re}_{p}^{3}(t) \\
& +2.56 \cdot 10^{-13} \operatorname{Re}_{p}^{4}(t)-2.48 \cdot 10^{-17} \operatorname{Re}_{p}^{5}(t)
\end{aligned}
$$

where $\operatorname{Re}_{p}(t)$ is defined as $V_{g}(t) d_{p} / v(t)$, and the parameters $d_{p}$ and $v(t)$ are the bidirectional probe diameter and the instantaneous kinematic viscosity of the gas. In this study, the mean Reynolds number $\left(\overline{\operatorname{Re}}_{p}\right)$ varied from about 100 to 1500 , depending on the distance from the burner surface. The temperature-dependent gas properties in Eqs. 4 - 6 are taken as those of air [23], calculated using the polynomial fits presented in Appendix A. The instantaneous thermocouple temperature corrected for radiative loss was determined following the procedure outlined in Section 2.3.1 with the results presented in Section 3.2.

In this study, the time series datasets of the bidirectional probe pressure difference were acquired at each measurement location, using multiple pressure transducers with the measurements typically repeated 2 to 3 times and as often as 10 times. The temperature and velocity measurement results are discussed in Section 3 below with the details of the uncertainty analysis presented in Appendix E.

\footnotetext{
* This assumption is better away from the burner. An estimate of the efficacy of the assumption can be determined considering the square root of the ratio of the mean molecular weight of gas species to that of air as a function of position (see Eq. 4), which can be estimated from the mean species concentrations and temperatures along the fuel centerline reported in Ref. [1]. For example, in the $30 \mathrm{~cm}$ methanol pool fire, the assumption is good to better than $5 \%$ of the mean velocity result near the fuel surface. For locations larger than one-half pool diameter above the fire, the assumption is good to better than $2 \%$ of the mean velocity result.
}

This publication is available free of charge from: https://doi.org/10.6028/NIST.TN.2162 


\subsection{Single Location Heat Flux Measurement and Estimate of Radiative Fraction}

The radiative fraction of the $30 \mathrm{~cm}$ diameter methanol pool fire is estimated from a single location measurement of the heat flux. The measurements are compared to previous measurements including those based on both single and multi-heat flux gauges. Figure 5 shows a schematic drawing of the single-point heat flux gauge measurement used to estimate the radiative fraction. A gauge is located at a distance $(r)$ from the pool center and at a vertical position $(z)$ above the burner rim.

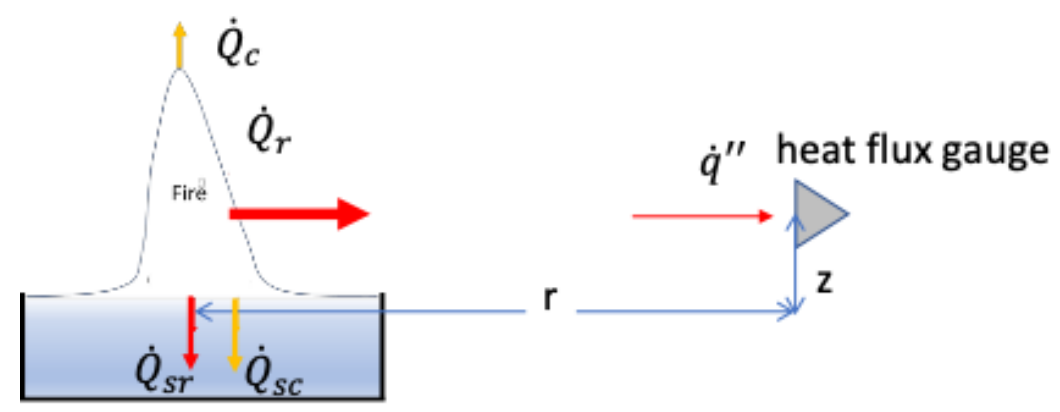

Figure 5. Schematic drawing of the determination of the radiative fraction using a single-point heat flux measurement.

In the figure, the convective energy transferred to the fuel surface is $\dot{Q}_{s c}$. The total energy radiated by the fire to the surroundings is denoted as $\dot{Q}_{r}$, whereas the energy radiated back to the fuel surface is denoted as $\dot{Q}_{s r}$. The total energy radiated by the fire $\left(\dot{Q}_{r a d}\right)$ is the sum of the energy radiated to the surroundings and to the fuel surface:

$$
\dot{Q}_{r a d}=\dot{Q}_{r}+\dot{Q}_{s r}
$$

For suitably far distances from the fire, the radiative fraction, $\chi_{\text {rad }}$, can be determined from a single measurement of the radiative heat flux as:

$$
\chi_{\text {rad }}=\frac{\dot{Q}_{r a d}}{\dot{m} H_{c}}=\frac{4 \pi r^{2} \dot{q}^{\prime \prime}}{\dot{m} H_{c}}
$$

where $\left(\dot{q}^{\prime \prime}\right)$ is the radiative heat flux measured at a distance $r$ from the fire, $\dot{m}$ is the fuel mass burning rate, and $H_{c}$ is the fuel's net heat of combustion (assuming water as a gaseous product). Here, fire symmetry and radiative isotropy are assumed. The product, $\dot{m} H_{c}$, is the ideal heat release rate of the fire. According to Modak [26], an accurate single location measurement of radiative fraction is appropriate for distances greater than 5 times the diameter of the pool from the fire.

\section{Results and Discussion}

\subsection{Ideal Heat Release Rate}

The ideal heat release rate $(\dot{Q})$ i.e., $\dot{m} \Delta H_{c}$ was estimated from the mass burning rate $(\dot{m})$, where $\Delta H_{c}$ is the net heat of combustion listed in Table A1. The fuel pool diameter, the measured mass burning flux 
and the ideal heat release rate, and the actual heat release rate from calorimetry measured via oxygen consumption calorimetry are presented in Table 2 .

Table 2. List of the lower (or net) heat of combustion $\left(\Delta H_{c}\right)$, the pool diameter $(D)$, the measured mass flux $\left(\dot{m}^{\prime \prime}\right)$, and the ideal heat release rate $\left(\dot{Q}=\dot{m}^{\prime \prime} \Delta H_{c}\right)$ averaged over the $N$ experiments conducted as part of this study. The uncertainty is presented as the expanded combined uncertainty, representing a $95 \%$ confidence interval.

\begin{tabular}{|c|c|c|c|c|c|c|}
\hline & Fuel & $\begin{array}{c}\Delta H_{c} \\
{[\mathbf{k J} / \mathbf{k g}]^{\dagger}}\end{array}$ & $\begin{array}{c}D \\
{[\mathrm{~m}]}\end{array}$ & $\begin{array}{c}\dot{m}^{\prime \prime} \\
{\left[\mathrm{g} / \mathrm{m}^{2}-\mathrm{s}\right]}\end{array}$ & $\begin{array}{c}\dot{Q} \\
{[\mathrm{~kW}]}\end{array}$ & $\begin{array}{c}\text { Experiments } \\
N\end{array}$ \\
\hline \multirow{4}{*}{ 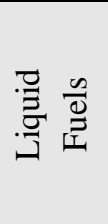 } & Methanol & $19.90 \pm 0.1$ & $0.301 \pm 0.2 *$ & $12.4 \pm 2.8$ & $17.5 \pm 2.0$ & 25 \\
\hline & Ethanol & $26.82 \pm 0.1$ & $0.301 \pm 0.2 *$ & $13.9 \pm 2.5$ & $26.7 \pm 2.4$ & 24 \\
\hline & Acetone & $28.52 \pm 0.1$ & $0.301 \pm 0.2 *$ & $17.7 \pm 6.0$ & $35.9 \pm 6.1$ & 9 \\
\hline & Heptane & $44.56 \pm 0.1$ & $0.301 \pm 0.2 *$ & $36.8 \pm 3.7$ & $116 \pm 12$ & 2 \\
\hline \multirow{3}{*}{ 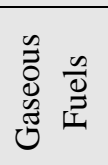 } & Methane & $50.03 \pm 0.1$ & $0.37 \pm 0.5$ & $6.41 \pm 0.1$ & $34.5 \pm 0.5$ & $* *$ \\
\hline & Propane & $46.33 \pm 0.1$ & $0.37 \pm 0.5$ & $4.16 \pm 0.12$ & $20.7 \pm 0.6$ & $* *$ \\
\hline & Propane & $46.33 \pm 0.1$ & $0.37 \pm 0.5$ & $6.91 \pm 0.1$ & $34.4 \pm 0.5$ & $* *$ \\
\hline
\end{tabular}

$\dagger$ from Ref. [27].

* The inner pool diameter is specified.

** The gaseous fuel flows were set, not measured.

\subsection{Gas-Phase Temperature Distribution}

The gas temperature profiles measured using the various thermocouple types and data acquisition sampling rate (listed in Table 1) are plotted and compared with previous studies. The pooled (or ensemble) mean gas temperature at a particular measurement position $\left(\bar{T}_{g}\right)$ is estimated by averaging the mean gas temperatures from all thermocouple data. The pooled root mean square (RMS) of the gas temperature at a particular location $\left(\sigma_{T_{g}}\right)$ is estimated by taking the RMS of the various standard deviation values of the gas temperature from all of the thermocouple time series datasets. The uncertainties of the pooled mean and RMS gas temperatures are discussed in Appendix E.2.

\subsubsection{Methanol Fire}

Figure 6 shows the mean and RMS of the gas temperature as a function of distance above the burner along the centerline in the $30 \mathrm{~cm}$ methanol pool fire. The maximum value of the mean temperature was about $1315 \mathrm{~K}$, which occurred about $0.1 \mathrm{~m}$ above the fuel surface. The temperature gradient near the fuel surface is steep. At $1 \mathrm{~cm}$ above the fuel surface, the gas temperature was about $922 \mathrm{~K} \pm 293 \mathrm{~K}$. The temperature at two locations on the fuel surface was measured to be approximately the boiling point of methanol, $338 \mathrm{~K}$, yielding a temperature gradient near the fuel surface of about $584 \mathrm{~K} / \mathrm{cm} \pm 293 \mathrm{~K} / \mathrm{cm}$. Figure $6 \mathrm{~b}$ also shows the mean and RMS measurements by Weckman and Strong [8], which are in general agreement with the present study.

This publication is available free of charge from: https://doi.org/10.6028/NIST.TN.2162 

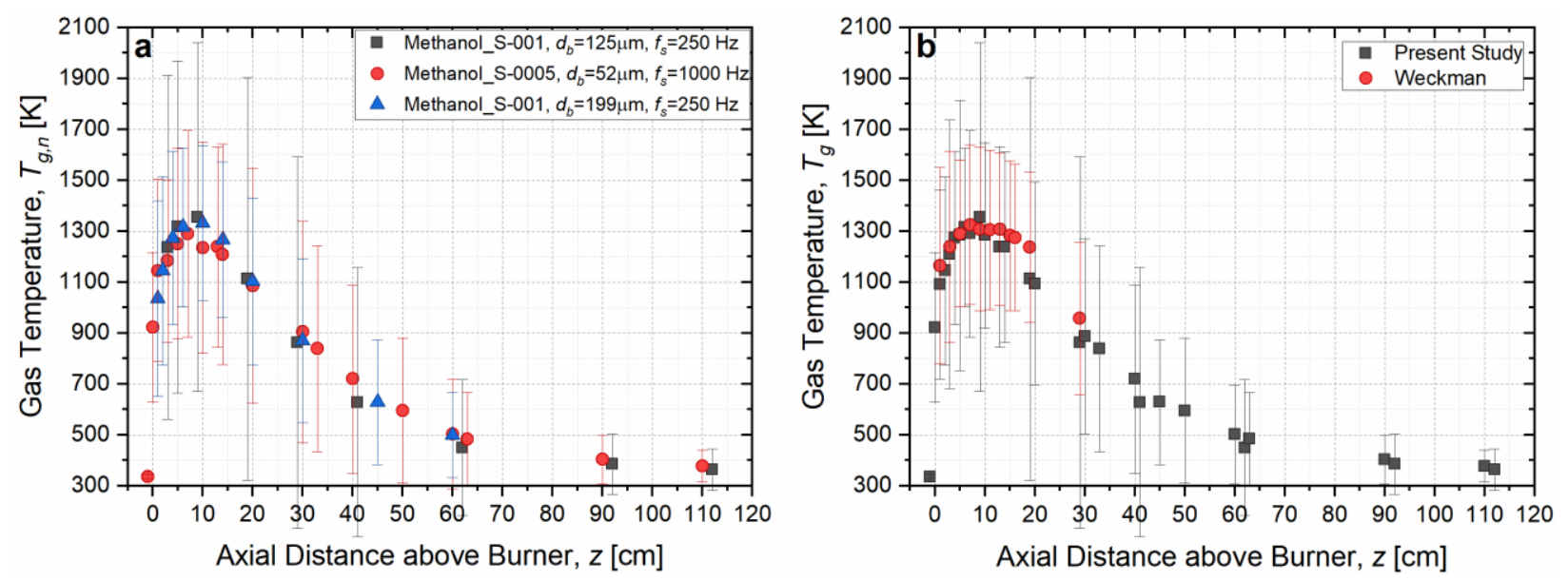

Figure 6. Mean and RMS of the gas temperature profile as a function of the axial distance above the burner along the centerline in the $30 \mathrm{~cm}$ methanol pool fire; (a) depending on the thermocouple type and sampling frequency, (b) the pooled mean and RMS values.

Figure 7 shows the pooled mean gas temperature as a function of radial distance from the burner at $z=40$ $\mathrm{cm}, 50 \mathrm{~cm}$ and $60 \mathrm{~cm}$ in the $30 \mathrm{~cm}$ methanol pool fire. The error bars indicate the combined uncertainty, representing a $95 \%$ confidence interval (see Appendix E.2 for a description of the uncertainty components).

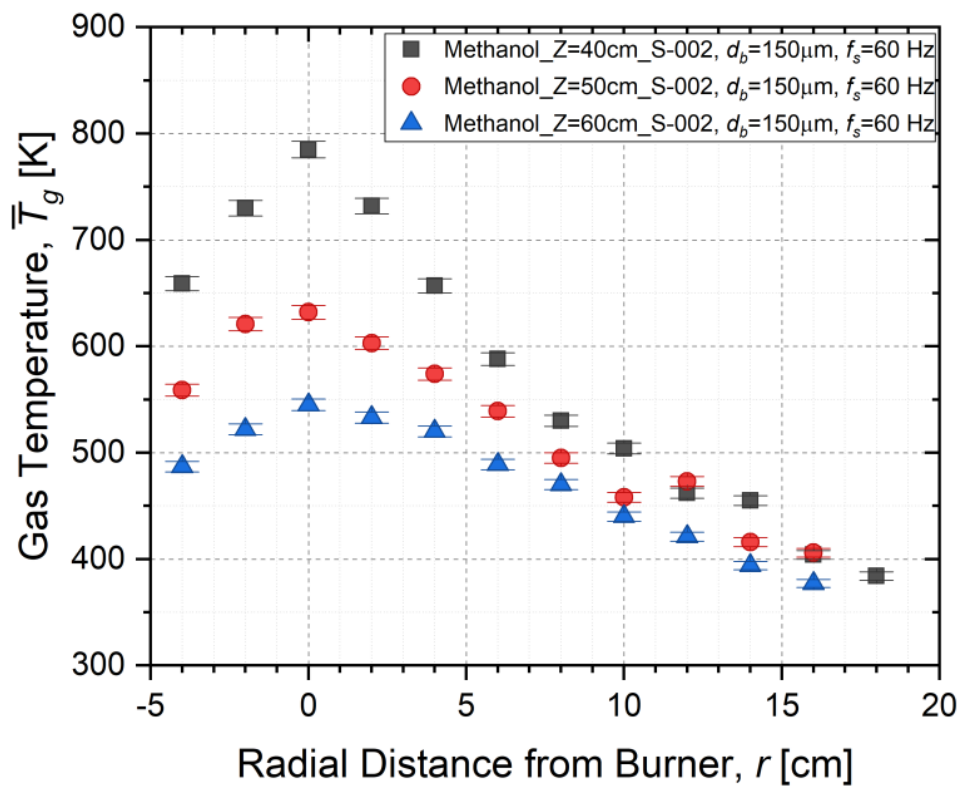

Figure 7. The pooled mean gas temperature as a function of the radial distance from the burner center at $Z$ $=40 \mathrm{~cm}, 50 \mathrm{~cm}$, and $60 \mathrm{~cm}$ in the $30 \mathrm{~cm}$ methanol pool fire. The error bars indicate the combined uncertainty, representing a $95 \%$ confidence interval.

Figure 8 shows the pooled mean and RMS of the temperature centerline profile as a function of the scaled axial distance above the burner. Here, a Froude number type scaling is used to help collapse the results.

This publication is available free of charge from: https://doi.org/10.6028/NIST.TN.2162 
The measurements are compared to previous measurements in $30 \mathrm{~cm}$ diameter methanol pool fires from Refs. [8, 28, 29] and a 1 m diameter methanol pool fire from Ref. [30]. Weckman and Strong [8] measured temperature in a $30.2 \mathrm{~cm}$ inner diameter methanol pool fire with a lip height of $1 \mathrm{~cm}$ using a 50 $\mu \mathrm{m}$ wire diameter, bare-bead, Type $\mathrm{S}(\mathrm{Pt}, 10 \% \mathrm{Rh} / \mathrm{Pt}$ ), thermocouple similar to the thermocouples used in this study. The measurements from Ref. [28] are also shown, where temperature was measured using a $75 \mu \mathrm{m}$ wire diameter, bare-bead, Type $\mathrm{S}$ thermocouple in the steadily burning, NIST, $30.1 \mathrm{~cm}$ diameter methanol pool fire with a $0.5 \mathrm{~cm}$ lip. The radiation corrected thermocouple measurements in Wang et al. [29] are also shown, which used a $50 \mu \mathrm{m}$ wire diameter, bare-bead, Type $\mathrm{S}$ thermocouple in the steadily burning $30.1 \mathrm{~cm}$ diameter methanol pool fire with a $1 \mathrm{~cm}$ lip height. Sung et al. [30] measured temperature in a $100.6 \mathrm{~cm}$ diameter methanol pool fire with a lip height of $1 \mathrm{~cm}$ using a $50 \mu \mathrm{m}$ diameter, bare-bead, Type $\mathrm{S}$ thermocouple and calculated the corrected gas temperature, considering the radiative loss and thermal inertia effects. A comparison of the results in Figure 8 shows that the temperature profiles as a function of axial distance above the burner normalized by $\dot{Q}^{2 / 5}$ are quite similar. The scatter in the results provide a gauge of the repeatability of the measurement. Small differences in the experimental details could easily cause scatter of this magnitude.

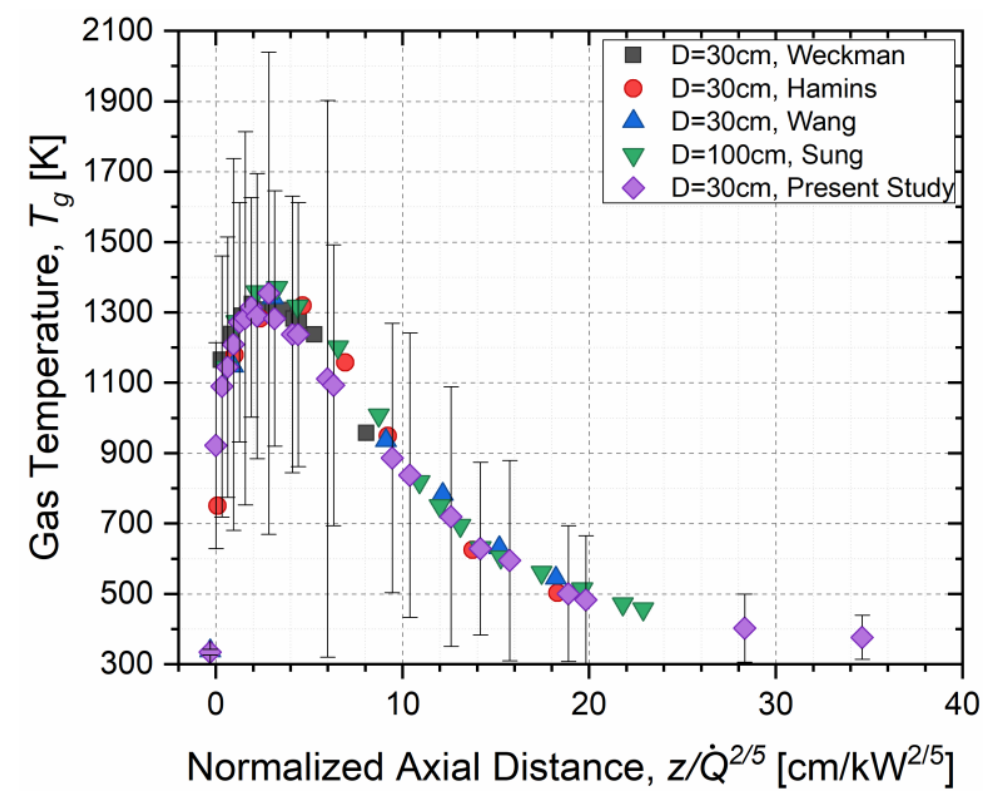

Figure 8. Mean and RMS of the axial gas temperature profiles as a function of distance above the burner normalized by $\dot{Q}^{2 / 5}$ and compared with the previous results in $30 \mathrm{~cm}$ methanol pool fires.

\subsubsection{Ethanol Fire}

Figure 9 shows the mean gas temperature measured using various thermocouples as well as the pooled mean gas temperature as function of axial distance above the burner in the $30 \mathrm{~cm}$ ethanol pool fire. The error bars indicate the combined uncertainty, representing a $95 \%$ confidence interval (see Appendix E.2 for a description of the uncertainty components).

This publication is available free of charge from: https://doi.org/10.6028/NIST.TN.2162 

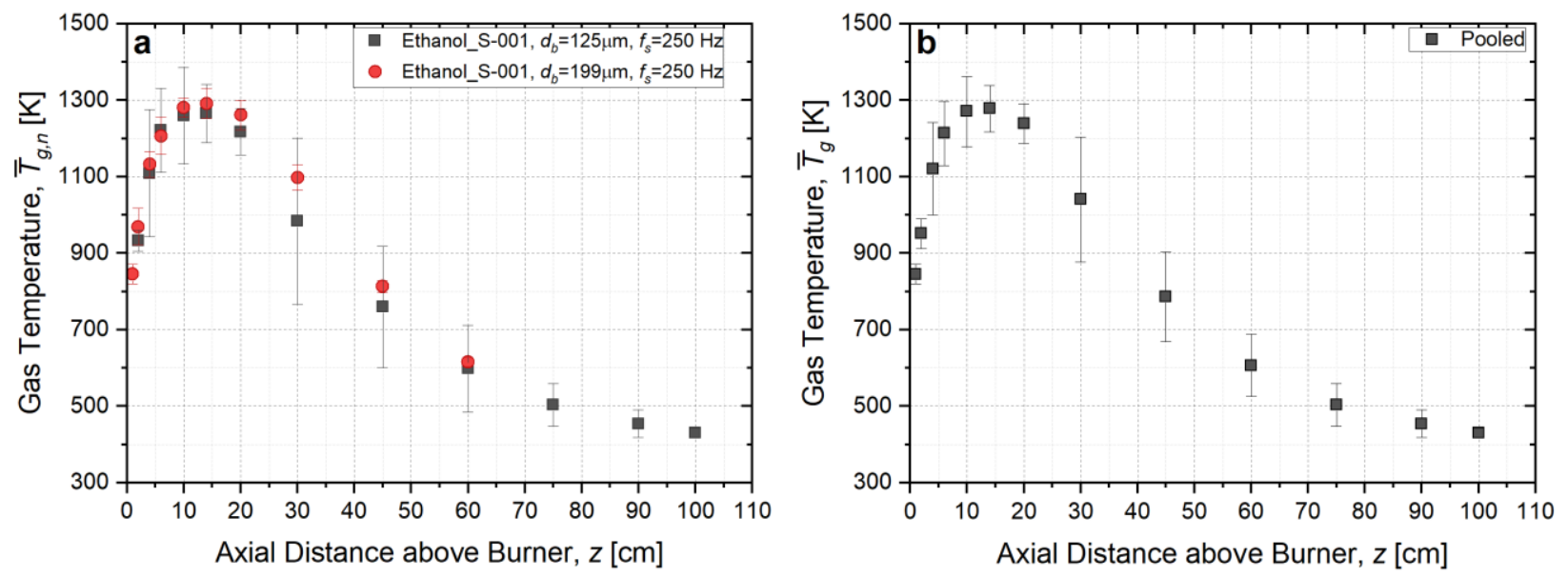

Figure 9. mean gas temperature as a function of the axial distance above the burner in the $30 \mathrm{~cm}$ ethanol pool fire; (a) mean gas temperature measured using the $n^{\text {th }}$ thermocouple $\left(\bar{T}_{g, n}\right)$, (b) the pooled mean gas temperature $\left(\bar{T}_{g}\right)$. The error bars indicate the combined uncertainty, representing a $95 \%$ confidence interval.

Figure 10 shows the mean gas temperature as a function of axial distance above the fuel surface normalized by $\dot{Q}^{2 / 5}$, and compared with previous results [31]. Fischer et al. [31] conducted measurements in a $50 \mathrm{~cm}$ diameter ethanol pool fire with a lip height of $1 \mathrm{~cm}$. The ideal heat release rate calculated from the measured mass burning flux $\left(13.8 \mathrm{~g} / \mathrm{m}^{2} \mathrm{~s} \pm 0.5 \mathrm{~g} / \mathrm{m}^{2} \mathrm{~s}\right)$ was $72.8 \mathrm{~kW}$. Temperature was measured using a $75 \mu \mathrm{m}$ wire diameter, bare-bead, Type $\mathrm{K}$ thermocouple with a bead diameter of $100 \mu \mathrm{m}$. The thermocouple temperature was corrected considering radiative loss and thermal inertia effects [31]. A comparison of the results shows the temperature profiles agree with the axial distance normalized by $\dot{Q}^{2 / 5}$. 


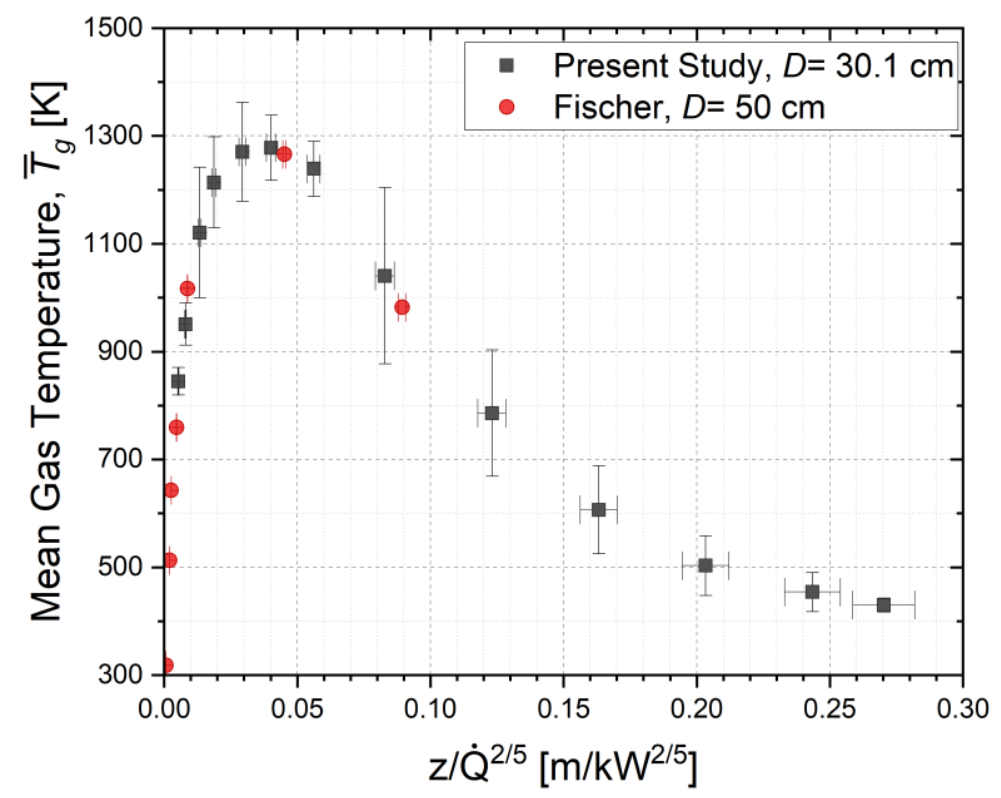

Figure 10. Mean gas temperature as a function of axial distance above the fuel surface normalized by $\dot{Q}^{2 / 5}$ in the $30 \mathrm{~cm}$ ethanol pool fire, and compared with the previous results from Ref. [31]. The error bars indicate the combined uncertainty, representing a $95 \%$ confidence interval.

\subsubsection{Acetone Fire}

Figure 11 shows the mean gas temperature measured using various thermocouples as well as the pooled mean gas temperature as function of axial distance above the burner in the $30 \mathrm{~cm}$ acetone pool fire. The error bars indicate the combined uncertainty, representing a $95 \%$ confidence interval (see Appendix E.2 for a description of the uncertainty components).
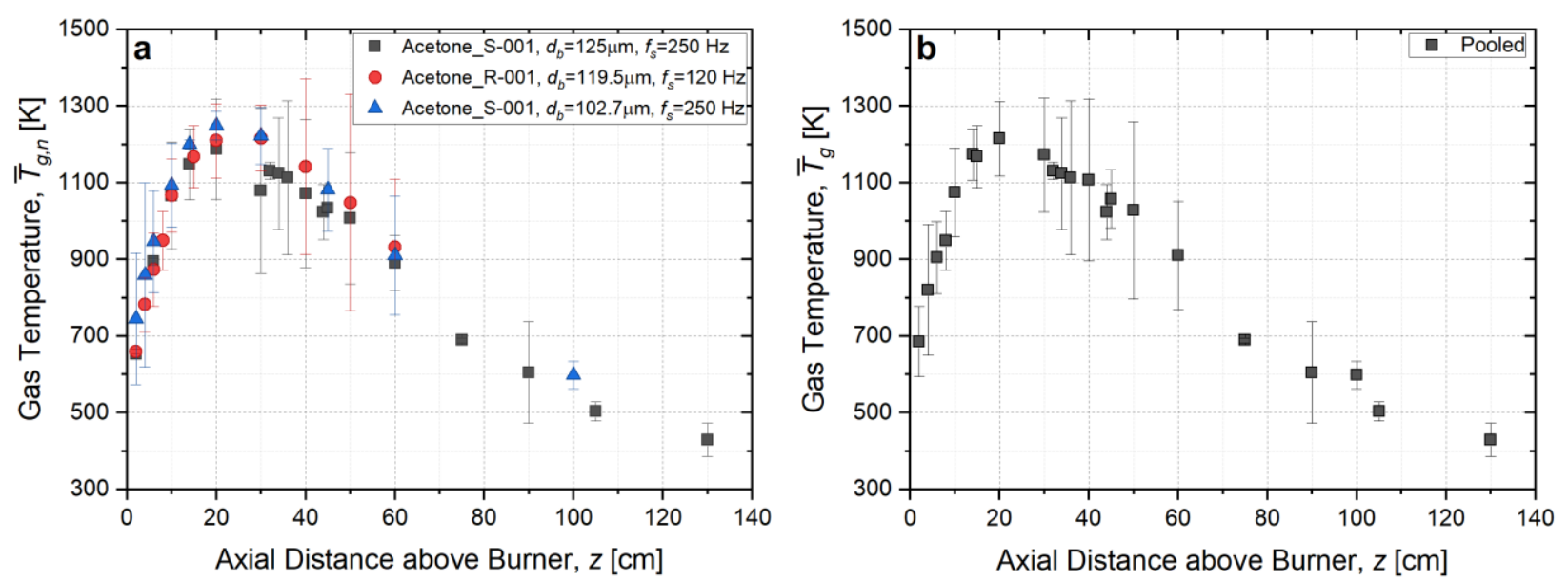

Figure 11. mean gas temperature as a function of the axial distance above the burner in the $30 \mathrm{~cm}$ acetone pool fire; (a) mean gas temperature measured using the $n^{\text {th }}$ thermocouple $\left(\bar{T}_{g, n}\right)$, (b) the pooled mean gas temperature $\left(\bar{T}_{g}\right)$. The error bars indicate the combined uncertainty, representing a $95 \%$ confidence interval.

This publication is available free of charge from: https://doi.org/10.6028/NIST.TN.2162 
Figure 12 shows the mean gas temperature as a function of axial distance above the fuel surface normalized by $\dot{Q}^{2 / 5}$, and compared with previous measurements also in a $30 \mathrm{~cm}$ acetone pool fire [8]. A comparison of the results shows the temperature profiles are in general agreement.

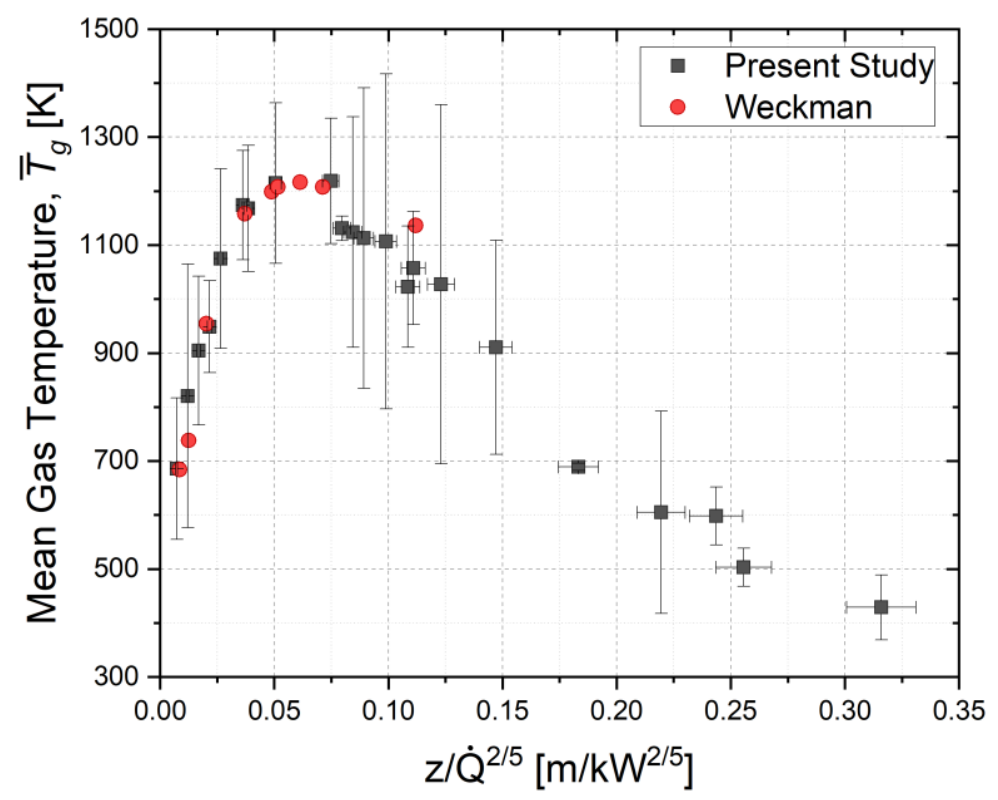

Figure 12. Mean gas temperature as a function of axial distance above the fuel surface normalized by $\dot{Q}^{2 / 5}$ in the $30 \mathrm{~cm}$ acetone pool fire, and compared with the measurements by Weckman and Strong [8]. The error bars indicate the combined uncertainty, representing a $95 \%$ confidence interval.

\subsubsection{Heptane Fire}

Figure 13 shows the pooled mean gas temperature as function of axial distance above the burner in the 30 $\mathrm{cm}$ heptane pool fire. The error bars indicate the combined uncertainty, representing a $95 \%$ confidence interval. The uncertainty components are described in Appendix E.2. 


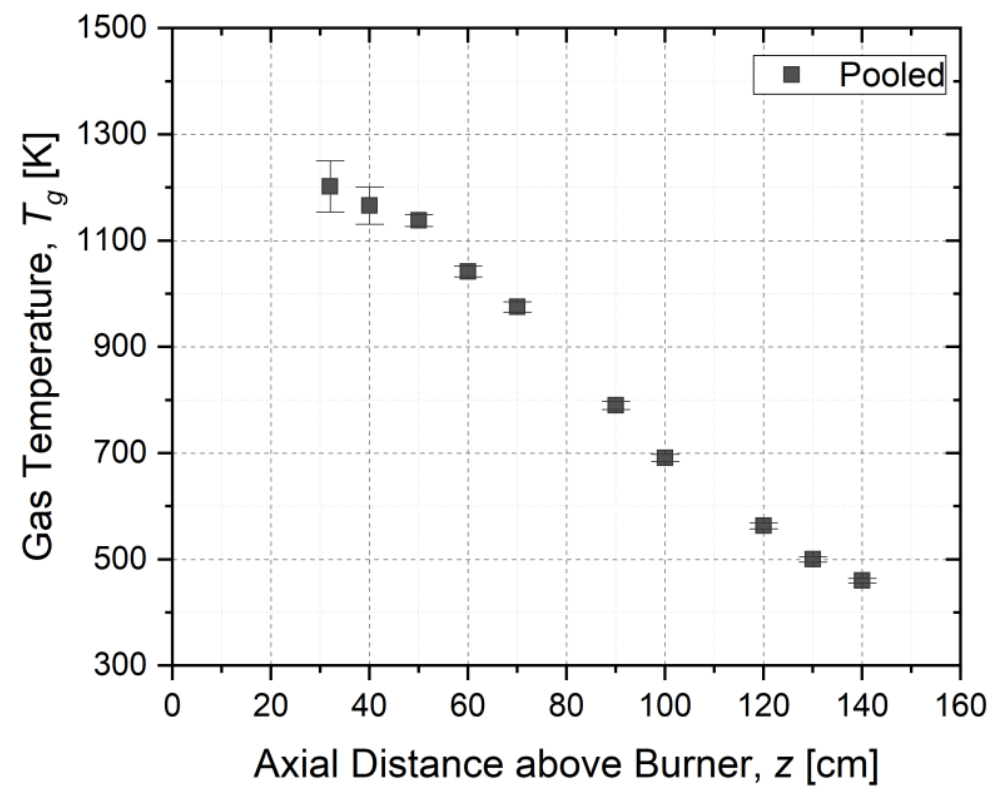

Figure 13. mean gas temperature as a function of the axial distance above the burner in the $30 \mathrm{~cm}$ heptane pool fire; (a) mean gas temperature measured using the $n^{\text {th }}$ thermocouple $\left(\bar{T}_{g, n}\right)$, (b) the pooled mean gas temperature $\left(\bar{T}_{g}\right)$. The error bars indicate the combined uncertainty, representing a $95 \%$ confidence interval.

\subsubsection{Methane Fire}

Figure 14 shows the mean gas temperature measured using various thermocouples as well as the pooled mean gas temperature as function of axial distance above the burner in the methane gas fire. The error bars indicate the combined uncertainty, representing a $95 \%$ confidence interval (see Appendix E. 2 for a description of the uncertainty components). 

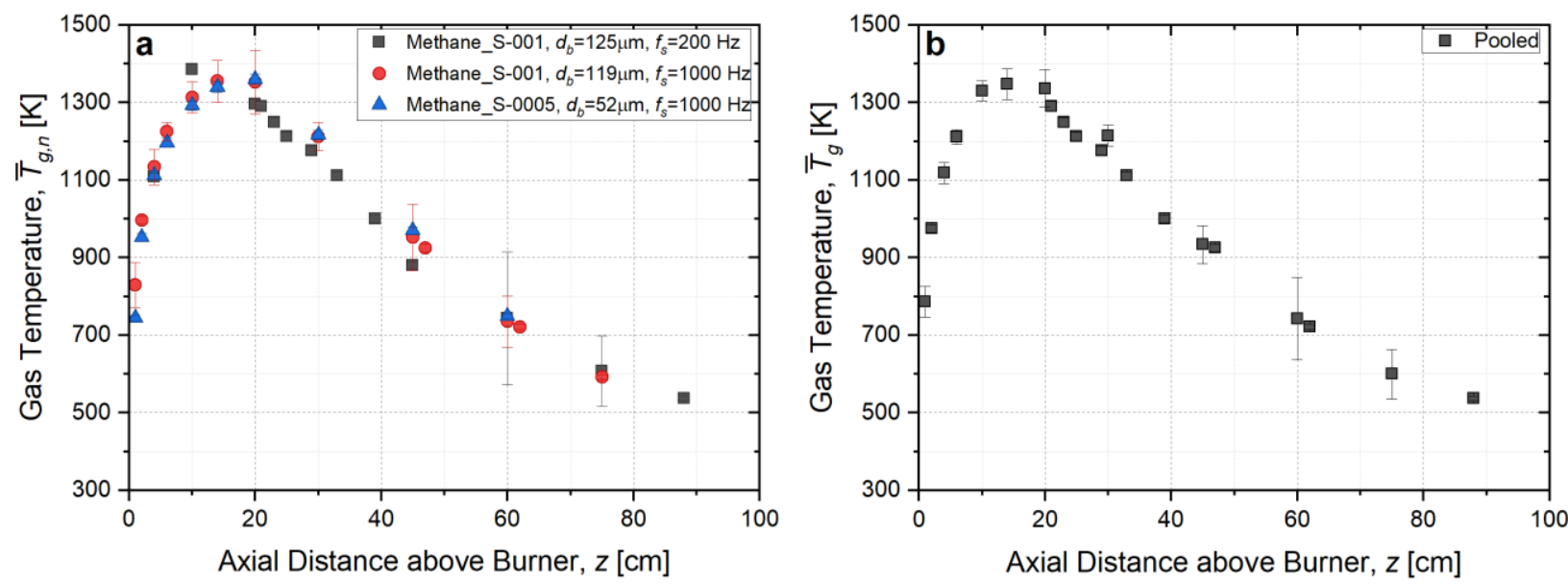

Figure 14. mean gas temperature as a function of the axial distance above the burner in the methane gas fire; (a) mean gas temperature measured using the $n^{\text {th }}$ thermocouple $\left(\bar{T}_{g, n}\right)$, (b) the pooled mean gas temperature $\left(\bar{T}_{g}\right)$. The error bars indicate the combined uncertainty, representing a $95 \%$ confidence interval.

\subsubsection{Propane Fires}

Figure 15 and Figure 16 show the pooled mean gas temperature as function of axial distance above the burner in the $21 \mathrm{~kW}$ and $34 \mathrm{~kW}$ propane gas fires. The error bars indicate the combined uncertainty, representing a $95 \%$ confidence interval. The uncertainty components are described in Appendix E.2.

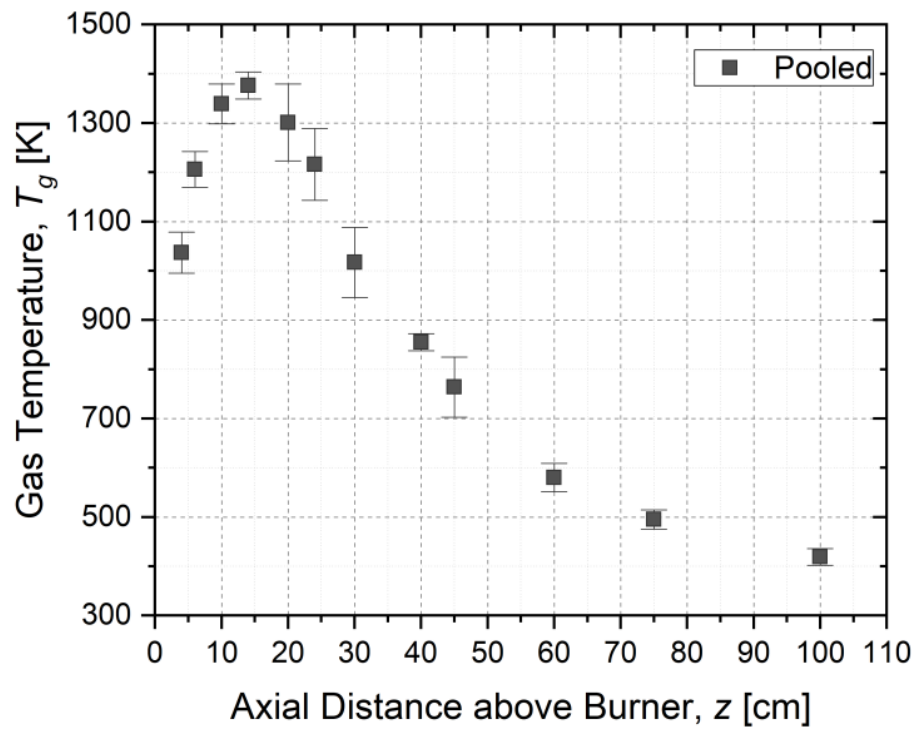

Figure 15. Pooled mean gas temperature as a function of the axial distance above the burner in the $21 \mathrm{~kW}$ propane gas fire. The error bars indicate the combined uncertainty, representing a $95 \%$ confidence interval. 


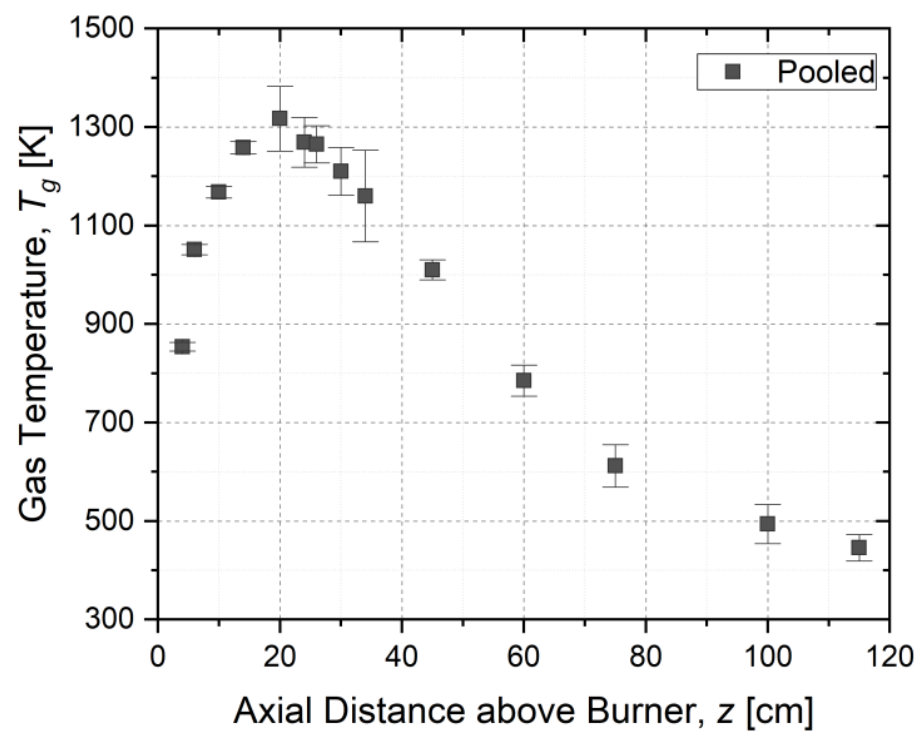

Figure 16. Pooled mean gas temperature as a function of the axial distance above the burner in the $34 \mathrm{~kW}$ propane gas fire. The error bars indicate the combined uncertainty, representing a $95 \%$ confidence interval.

\subsection{Upward Component of Velocity Profile along the Fire Centerline}

The upward component of velocity along the fire centerline for all of the fires tested is described in the following sections. The uncertainty analysis is provided in Appendix E.1.

\subsubsection{Methanol Fire}

Figure 17 shows the mean gas velocity measured using each pressure transducer and the pooled mean gas velocity as a function of axial distance above the burner in the $30 \mathrm{~cm}$ methanol fire. The error bars indicate the combined uncertainty of the mean gas velocity, representing a $95 \%$ confidence interval. Careful measurements reported by Weckman and Strong [8], who used laser doppler velocimetry (LDV) to determine the velocity field in the $30 \mathrm{~cm}$ methanol pool fire with a $1 \mathrm{~cm}$ lip height, are also shown and appear to be in agreement with the current measurements within experimental uncertainty. The current dataset represents an extension of Weckman's results [8] to locations more than four diameters downstream of the burner. 

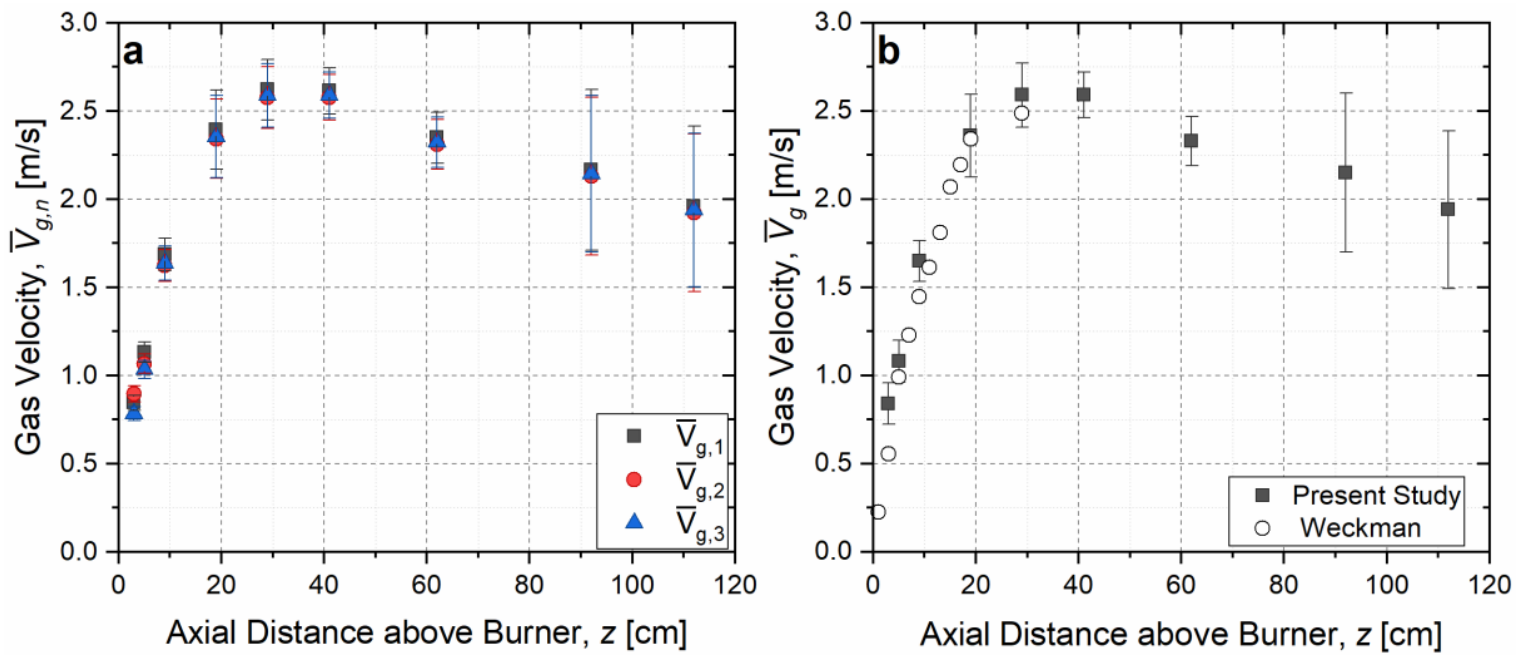

Figure 17. Mean gas velocities in the upward direction as a function of axial distance above the burner in the $30 \mathrm{~cm}$ methanol pool fire; (a) mean gas velocity measured using the $n^{\text {th }}$ pressure transducers $\left(\bar{V}_{g, n}\right)$, (b) pooled mean gas velocity $\left(\bar{V}_{g}\right)$. Measurements reported by Weckman and Strong [8] in a $30 \mathrm{~cm}$ methanol pool fire also shown. The error bars indicate the combined uncertainty representing a $95 \%$ confidence interval.

\subsubsection{Ethanol Fire}

Figure 18 shows the mean gas velocity measured using each pressure transducer and the pooled mean gas velocity as a function of axial distance above the burner in the $30 \mathrm{~cm}$ ethanol fire. The error bars indicate the combined uncertainty of the mean gas velocity, representing a $95 \%$ confidence interval.
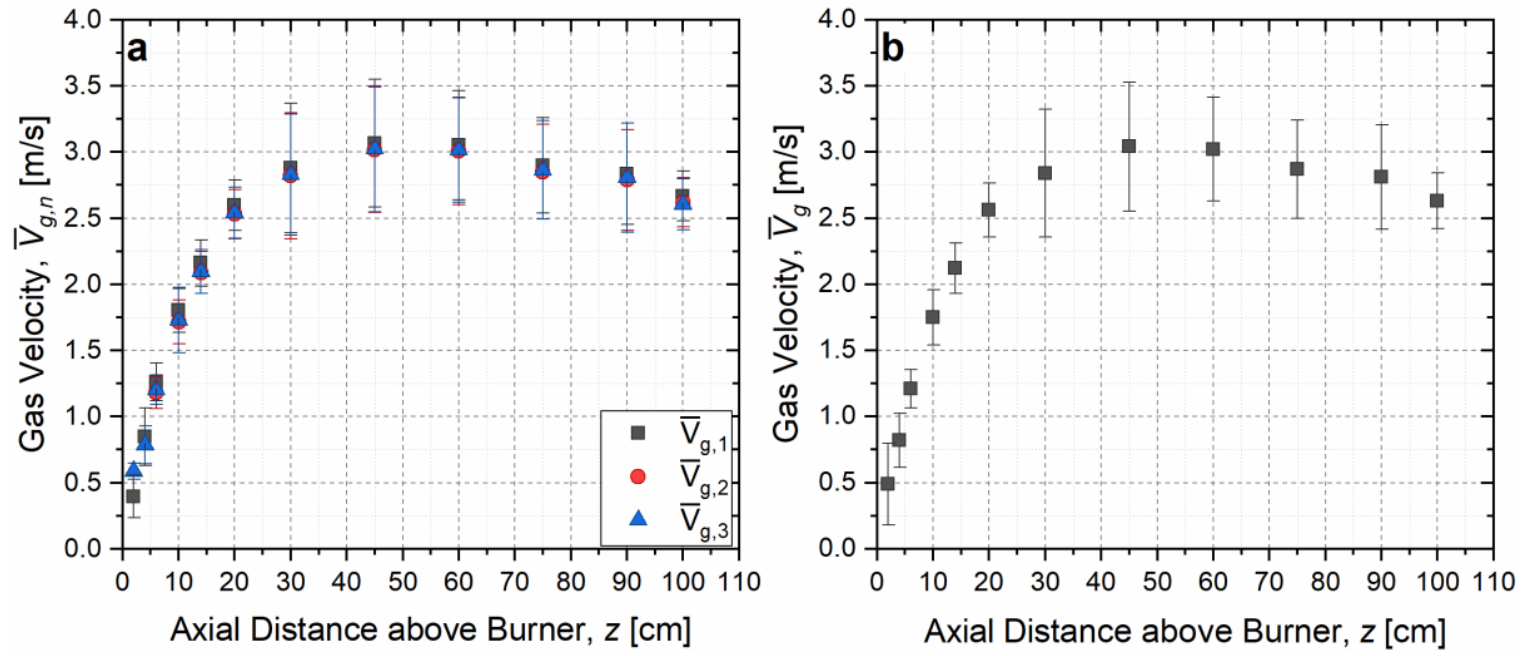

Figure 18. Mean gas velocities in the upward direction as a function of axial distance above the burner in the $30 \mathrm{~cm}$ ethanol pool fire; (a) mean gas velocity measured using the $n^{\text {th }}$ pressure transducers $\left(\bar{V}_{g, n}\right)$, (b) pooled mean gas velocity $\left(\bar{V}_{g}\right)$. The error bars indicate the combined uncertainty, representing a $95 \%$ confidence interval.

This publication is available free of charge from: https://doi.org/10.6028/NIST.TN.2162 


\subsubsection{Acetone Fire}

Figure 19 shows the mean gas velocity measured using each pressure transducer and the pooled mean gas velocity as a function of axial distance above the burner in the $30 \mathrm{~cm}$ acetone fire. The error bars indicate the combined uncertainty of the mean gas velocity, representing a $95 \%$ confidence interval. Results by Weckman [32] in the $30 \mathrm{~cm}$ acetone pool fire (also with a $1 \mathrm{~cm}$ lip height) determined using LDV analogous to Ref. [8] are also shown. The measurements are in agreement within experimental uncertainty. The current dataset represents an extension of Weckman's results [8] to locations more than four diameters downstream of the burner.
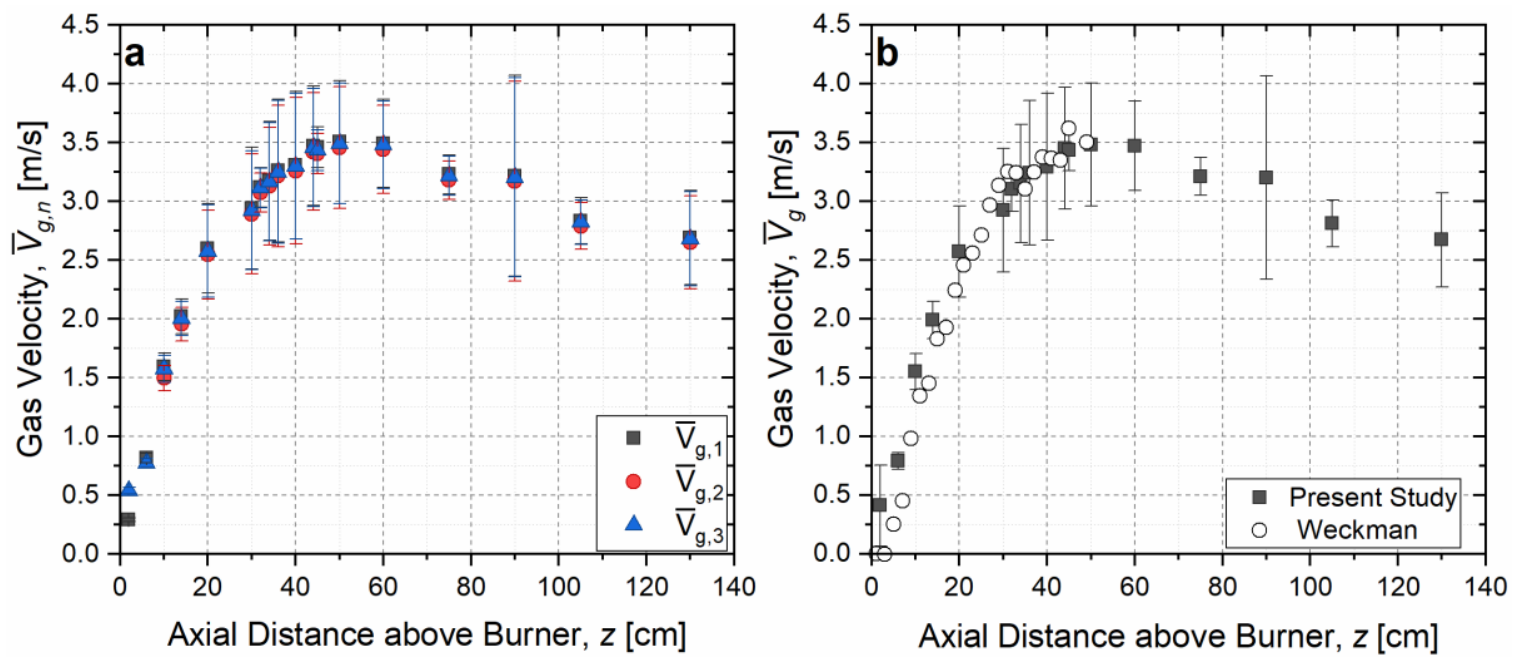

Figure 19. Mean gas velocities in the upward direction as a function of axial distance above the burner in the $30 \mathrm{~cm}$ acetone pool fire; (a) mean gas velocity measured using the $n^{\text {th }}$ pressure transducers $\left(\bar{V}_{g, n}\right)$, (b) pooled mean gas velocity $\left(\bar{V}_{g}\right)$. The error bars indicate the combined uncertainty, representing a $95 \%$ confidence interval.

\subsubsection{Heptane Fire}

Figure 20 shows the mean gas velocity measured using each pressure transducer and the pooled mean gas velocity as a function of axial distance above the burner in the $30 \mathrm{~cm}$ heptane fire. The error bars indicate the combined uncertainty of the mean gas velocity, representing a $95 \%$ confidence interval. 

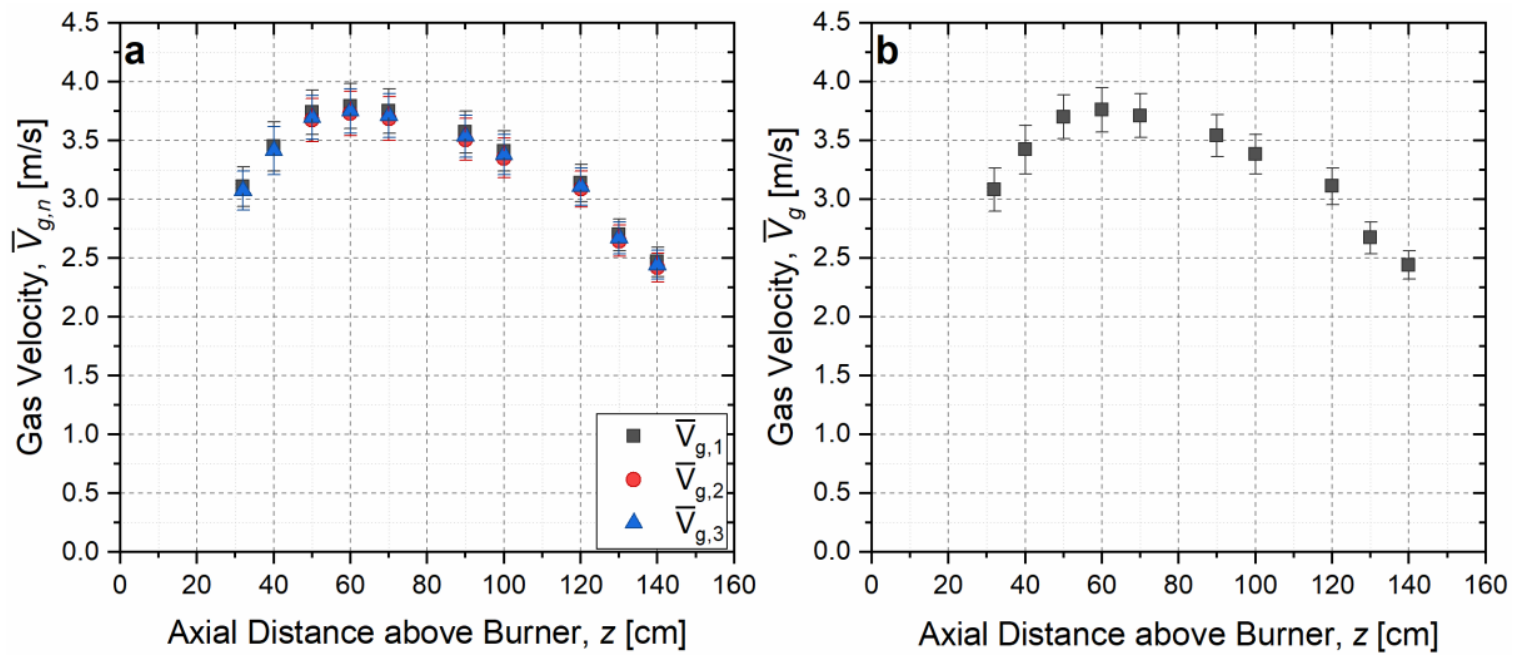

Figure 20. Mean gas velocities in the upward direction as a function of axial distance above the burner in the $30 \mathrm{~cm}$ heptane pool fire; (a) mean gas velocity measured using the $n^{\text {th }}$ pressure transducers $\left(\bar{V}_{g, n}\right)$, (b) pooled mean gas velocity $\left(\bar{V}_{g}\right)$. The error bars indicate the combined uncertainty, representing a $95 \%$ confidence interval.

\subsubsection{Methane Fire}

Figure 21 shows the mean gas velocity measured using each pressure transducer and the pooled mean gas velocity as a function of axial distance above the burner in the $30 \mathrm{~cm}$ methane fire. The error bars indicate the combined uncertainty of the mean gas velocity, representing a $95 \%$ confidence interval.

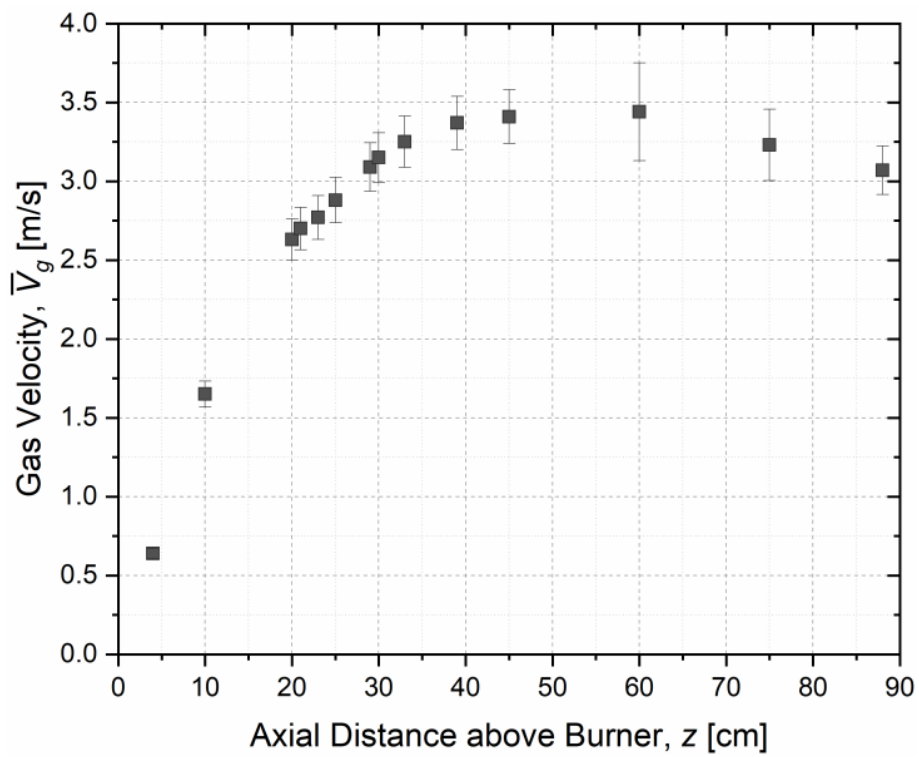

Figure 21. Pooled mean gas velocity in the upward direction $\left(\bar{V}_{g}\right)$ as a function of axial distance above the burner in the $37 \mathrm{~cm}$ methane gas burner fire. The error bars indicate the combined uncertainty, representing a $95 \%$ confidence interval.

This publication is available free of charge from: https://doi.org/10.6028/NIST.TN.2162 


\subsubsection{Propane Fires}

Figure 22 and Figure 23 show the mean gas velocity measured using each pressure transducer and the pooled mean gas velocity as a function of axial distance above the burner in the $21 \mathrm{~kW}$ and $34 \mathrm{~kW}$ propane gas fires, respectively. The error bars indicate the combined uncertainty of the mean gas velocity, representing a $95 \%$ confidence interval.
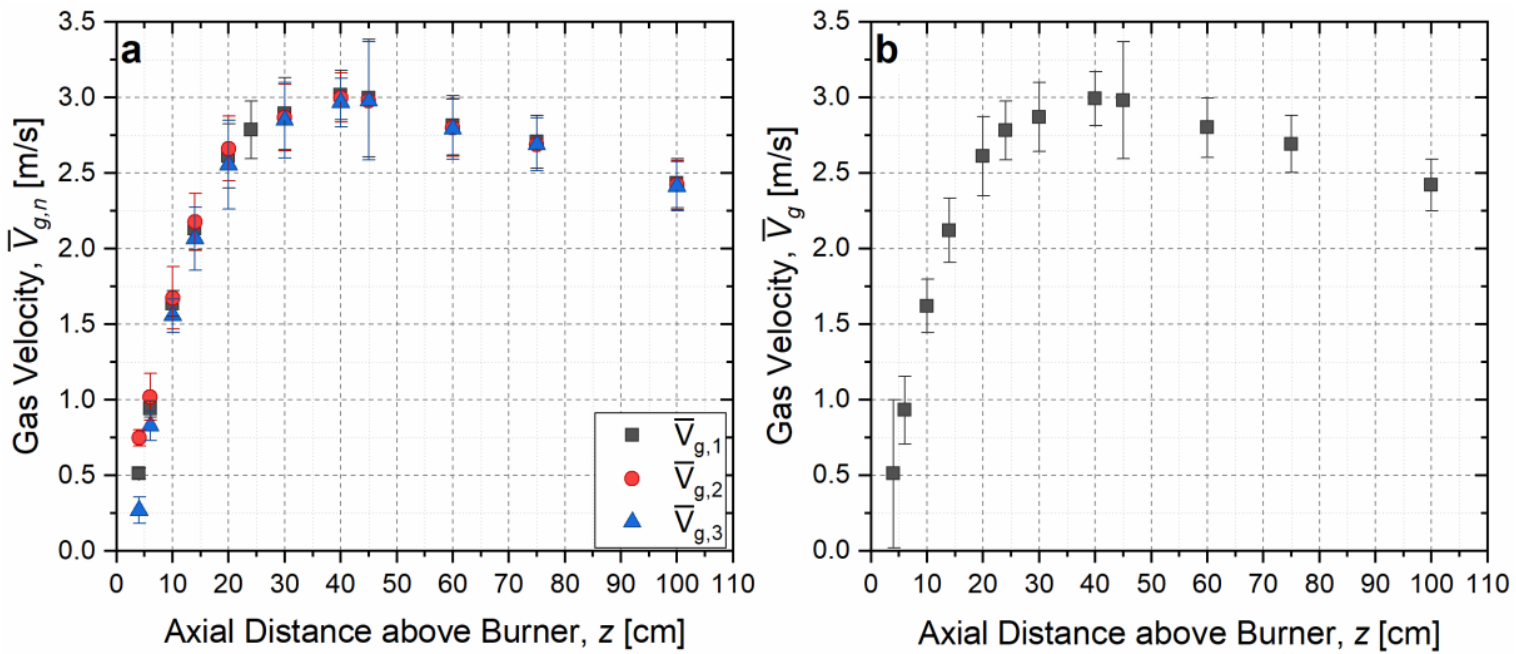

Figure 22. Mean gas velocities in the upward direction as a function of axial distance above the burner in the $21 \mathrm{~kW}$ propane gas fire; (a) mean gas velocity measured using the $n^{\text {th }}$ pressure transducers $\left(\bar{V}_{g, n}\right)$, (b) pooled mean gas velocity $\left(\bar{V}_{g}\right)$. The error bars indicate the combined uncertainty, representing a $95 \%$ confidence interval.
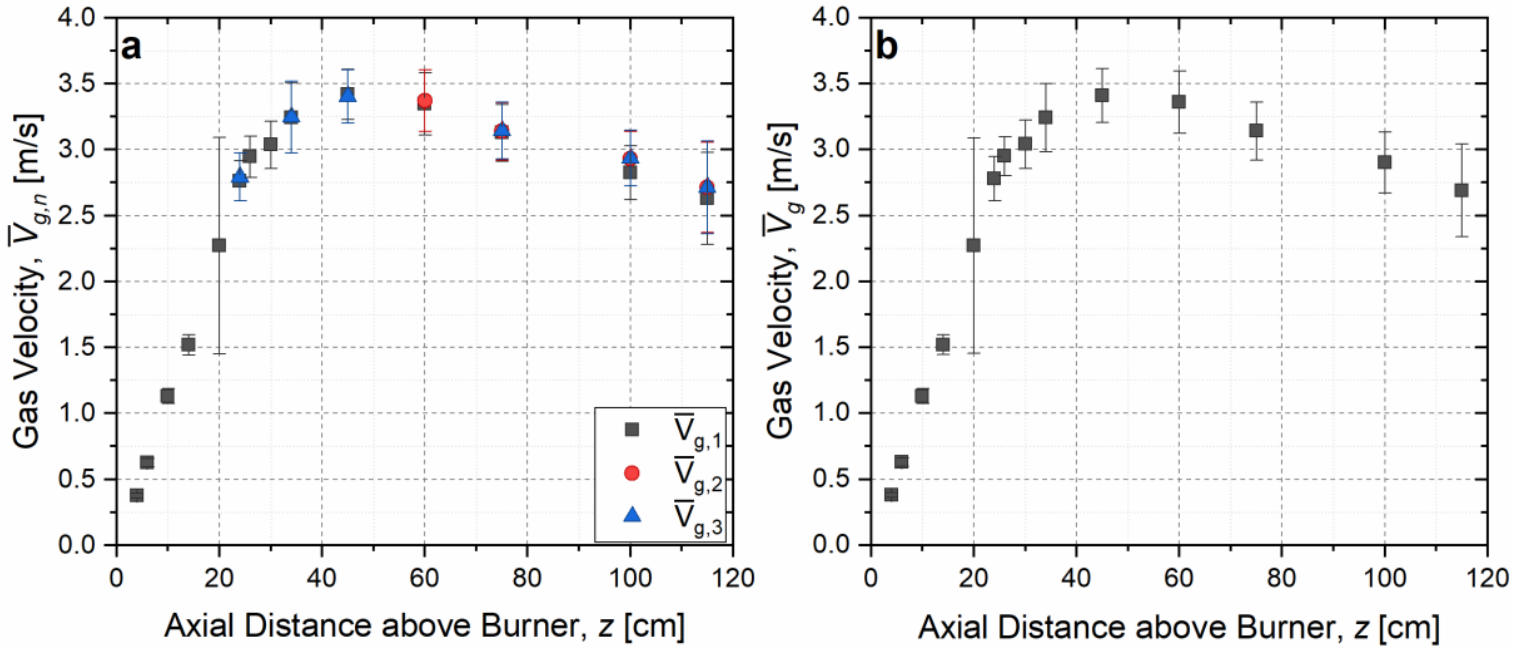

Figure 23. Mean gas velocities in the upward direction as a function of axial distance above the burner in the $34 \mathrm{~kW}$ propane gas fire; (a) mean gas velocity measured using the $n^{\text {th }}$ pressure transducers $\left(\bar{V}_{g, n}\right)$, (b) pooled mean gas velocity $\left(\bar{V}_{g}\right)$. The error bars indicate the combined uncertainty, representing a $95 \%$ confidence interval.

This publication is available free of charge from: https://doi.org/10.6028/NIST.TN.2162 


\subsubsection{Comparison to Plume Theory}

Baum and McCaffrey [33] developed a theoretical plume correlation based on kinematic relationships between the velocity, vorticity, and heat release field in an isolated fire plume, which is made nondimensional with $D^{*}$ in length scale and $\sqrt{g D^{*}}$ in velocity scale. The dimensionless upstream gas velocity along the centerline is defined as:

$$
\frac{V_{g}}{\sqrt{g D^{*}}}=A\left(\frac{Z}{D^{*}}\right)^{n}
$$

where $D^{*}$ is the plume scaling involving the heat release rate, defined by $\left(\dot{Q} /\left(\rho_{o} c_{p} T_{o} \sqrt{g}\right)\right)^{2 / 5}$; where $\dot{Q}$ is the ideal heat release rate, and $\rho_{o}$ and $c_{p}$ are the density and specific heat of air, respectively, at the ambient temperature $\left(T_{o}\right)$. In Eq. 9, the quantities $n$ and $A$ for each plume region, are defined by the range of $z / D^{*}$, and are given in Table 3. Details of the plume correlation and the distinct plume regions are described in Ref. [33].

Table 3. Baum and McCaffrey's [33] plume correlation parameters, which depend on the buoyant diffusion flame region.

\begin{tabular}{cccc}
\hline Plume Region & Range & $\boldsymbol{n}$ & $\boldsymbol{A}$ \\
\hline Flame & $0<z / D^{*}<1.32$ & $1 / 2$ & 2.18 \\
Intermittent & $1.32<z / D^{*}<3.30$ & 0 & 2.45 \\
Plume & $3.30<z / D^{*}$ & $-1 / 3$ & 3.64 \\
\hline
\end{tabular}

Figure 24 shows the dimensionless mean gas velocity $\left(V_{g} / \sqrt{g D^{*}}\right)$ as a function of the dimensionless axial distance above the burner $\left(z / D^{*}\right)$, compared with Baum and McCaffrey's plume theory (solid line) [33] in the pool fires. The hollow circle and solid triangle symbols represent the present study and Weckman's results [8], respectively. The error bars indicate the uncertainty, representing a $95 \%$ confidence interval. Baum and McCaffrey's correlation overpredicts at every measurement position in fires burning every fuel. On the other hand, the velocity profile structure for the distinct plume regions follows the trends of Baum and McCaffery's correlation. 

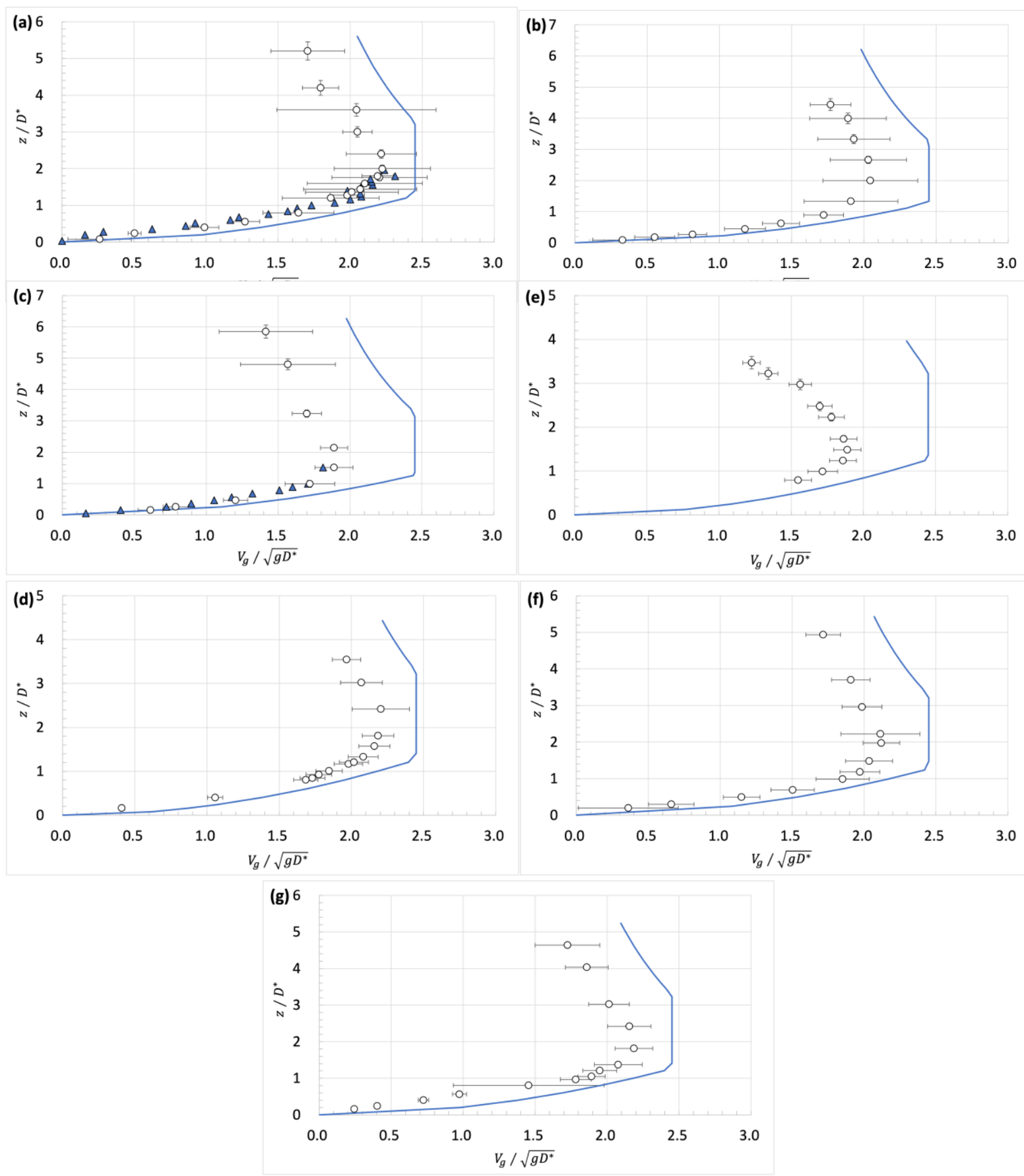

Figure 24. Dimensionless mean gas velocity $\left(V_{g} / \sqrt{g D^{*}}\right)$ as a function of dimensionless axial distance above the burner $\left(z / D^{*}\right)$, compared with Baum and McCaffrey plume theory (solid line) in the pool fires; (a) the acetone fire, (b) the ethanol fire, (c) the methanol fire, (d) the heptane fire, (e) the methane gas fire, (f) the $21 \mathrm{~kW}$ propane gas fire, and (g) the $34 \mathrm{~kW}$ propane gas fire. The hollow circle and solid triangle symbols represent the present study and Weckman's results $[8,32]$. The error bars indicate the uncertainty, representing a $95 \%$ confidence interval.

This publication is available free of charge from: https://doi.org/10.6028/NIST.TN.2162 
Table 4 lists the value and location of the measured peak upward axial velocity. The results showed that the largest fires (in terms of heat release rate) had the largest peak velocity and that the smallest fires had the smallest peak velocity. Although there are correlations that provides an estimate of the value of the peak velocity above the pool centerline, they are not employed here because the inputs for those correlation are not accurately known for the fires studied here. The needed information includes the position of the virtual origin of the fires, the combustion efficiency, the radiative fraction to the surroundings (including the fuel surface), the fractional heat losses to the burner, and the fractional enthalpy that convectively heats the fuel surface [34]. There are many correlations that provide the virtual origin, which differ significantly, particularly for low Froude number pool fires such as those studied here.

Table 4. Summary of value and location of the measured peak upward axial velocity.

\begin{tabular}{ccccc}
\hline Fuel & $\begin{array}{c}\boldsymbol{D} \\
{[\mathbf{m}]}\end{array}$ & $\begin{array}{c}\dot{\boldsymbol{Q}} \\
{[\mathbf{k W}]}\end{array}$ & $\begin{array}{c}\text { Peak } \overline{\boldsymbol{V}}_{\boldsymbol{g}} \\
{[\mathbf{m} / \mathbf{s}]}\end{array}$ & $\begin{array}{c}\text { Peak location } \\
{[\mathbf{c m}]}\end{array}$ \\
\hline Methanol & 0.30 & $18.7^{\mathrm{a}}$ & 2.6 & $29-41$ \\
Ethanol & 0.30 & $28.2^{\mathrm{a}}$ & 3.0 & 45 \\
Acetone & 0.30 & $37.1^{\mathrm{a}}$ & 3.5 & 50 \\
Heptane & 0.30 & 100 & 3.8 & 60 \\
Methane & 0.37 & 34.4 & 3.4 & 60 \\
Propane & 0.37 & 20 & 3.0 & $40-45$ \\
Propane & 0.37 & 34 & 3.4 & 45 \\
\hline
\end{tabular}

${ }^{a}$ Represents average of many studies; see: https://github.com/MaCFP/macfpdb/blob/master/Liquid_Pool_Fires/NIST_Pool_Fires/Documentation/README.md

\subsection{Radiative Fraction}

The radiative fraction determined for the $30 \mathrm{~cm}$ diameter methanol pool fire was estimated from a single location measurement heat flux, assuming fire symmetry and radiative isotropy. The measurements are compared to previous measurements including those based on both single and multi-heat flux gauges.

\subsubsection{Single location radiative fraction measurements in the $30 \mathrm{~cm}$ methanol fire}

Table 5 shows the results of four experiments in which measurements of the heat flux were made at distances greater than 10 radii from the pool burner center. Two heat flux gauges positioned at different distances from the fire were used to measure the fire heat flux during each of the experiments. The results are used to estimate the radiative fraction. As expected, the radiative fraction estimate was about the same regardless of distance from the fire for these measurements made at distances from 10 to 16.7 radii from the fire. Considering both the single location and multi-location heat flux measurements, the average radiative fraction is found to be equal to $0.225 \pm 6 \%$. This result is consistent with previous measurements as seen in Table 6 . The expanded combined uncertainty (representing a $95 \%$ confidence interval) of the radiative fraction $\left(U_{c}\left(\chi_{\text {rad }}\right)\right)$ is $19 \%$. 
Table 5. Mass loss, ideal heat release rate, heat flux gauge locations, fluxes and calculated radiative fractions for four tests with gauges various radial distances $(r)$ directed towards the fire and located at a vertical position, $z=15 \mathrm{~cm}$. The uncertainties are expressed as standard deviations (SD) of the measurements.

\begin{tabular}{ccc|cccc|cc}
\hline Test \# & $\begin{array}{c}\dot{\boldsymbol{m}} \\
{[\mathbf{g} / \mathbf{s}]}\end{array}$ & $\begin{array}{c}\dot{\boldsymbol{Q}} \\
{[\mathbf{k W}]}\end{array}$ & $\begin{array}{c}\boldsymbol{r}_{\mathbf{1}} \\
{[\mathbf{m}]}\end{array}$ & $\begin{array}{c}\boldsymbol{r}_{\mathbf{2}} \\
{[\mathbf{m}]}\end{array}$ & $\begin{array}{c}\dot{\boldsymbol{q}}_{\mathbf{1}}{ }^{\prime \prime} \\
{\left[\mathbf{k W} / \mathbf{m}^{2}\right]}\end{array}$ & $\begin{array}{c}\dot{\boldsymbol{q}}_{\mathbf{2}}{ }^{\prime \prime} \\
{\left[\mathbf{k W} / \mathbf{m}^{2}\right]}\end{array}$ & $\begin{array}{c}\chi_{\text {rad }_{\mathbf{1}}} \\
{[-]}\end{array}$ & $\begin{array}{c}\chi_{\text {rad }_{\mathbf{2}}} \\
{[-]}\end{array}$ \\
\hline 7 & 0.909 & 18.1 & 1.5 & 2.503 & 0.138 & 0.0562 & 0.216 & 0.224 \\
8 & 0.918 & 18.3 & 1.915 & 2.503 & 0.087 & 0.0513 & 0.22 & 0.211 \\
9 & 0.908 & 18.1 & 1.915 & 2.503 & 0.098 & 0.0547 & 0.25 & 0.233 \\
10 & 0.867 & 17.3 & 1.915 & 2.503 & 0.084 & 0.0563 & 0.224 & 0.241 \\
\hline Average \pm SD & $0.900 \pm 3 \%$ & $17.9 \pm 3 \%$ & & & & & $0.225 \pm 6 \%$ \\
\hline
\end{tabular}

Table 6 presents a summary of previous measurements reported on the radiative fraction $\left(\chi_{\text {rad }}\right)$ determined using single and multi-location measurements and the fractional energy radiated to the surroundings $\left(\chi_{r}\right)$ in steadily burning, $30 \mathrm{~cm}$ methanol pool fires with $0.5 \mathrm{~cm}$ and $1 \mathrm{~cm}$ lip heights. Some studies provided measurements of one, or sometimes two of the parameters of interest. It is possible to estimate the value of $\chi_{\text {rad }}$ for the $30 \mathrm{~cm}$ methanol fire from the measurement of $\chi_{r}$ using the relationship between these parameters determined from the measurements described in Ref. [5], which shows that:

$$
\chi_{\text {rad }}=1.13 \chi_{r}
$$

The average value of $\chi_{\text {rad }}$, considering the single and multi-location measurements from the literature and the measurement from this study are listed in Table 5 and is equal to $0.22 \pm 0.02$ (where the uncertainty represents the standard deviation of the measurement results).

Table 6. Summary of previous measurements of $\chi_{\text {rad }}$ from single and multi-location measurements and $\chi_{r}$ in $30 \mathrm{~cm}$ methanol pool fires.

\begin{tabular}{c|c|c|c}
\hline$\chi_{r}$ & $\begin{array}{c}\chi_{\text {rad }} \\
\text { (multi-location) }\end{array}$ & $\begin{array}{c}\chi_{\text {rad }} \\
\text { (single-location) }\end{array}$ & References \\
\hline- & - & $0.23 \pm 19 \%^{*}$ & Table 5 (this study) \\
0.18 & $0.20^{*}$ & 0.20 & Hamins et al. [35] \\
- & $0.23^{* *}$ & - & Hamins et al. [9] \\
$0.20^{\dagger}$ & 0.23 & - & Klassen and Gore [10] \\
0.22 & $0.24^{*}$ & - & Buch et al. [36] \\
0.19 & 0.24 & - & Kim et al. [5] \\
\hline $0.20 \pm 0.02$ & \multicolumn{2}{|c|}{$0.22 \pm 0.02$} & Average \pm SD \\
\hline
\end{tabular}

* expanded combined uncertainty representing a $95 \%$ confidence interval.

* Eq. 10 was used to estimated $\chi_{\text {rad }}$ from the reported measurement of $\chi_{r}$.

** Results from Ref. [9] were recalculated, correcting error in $\Delta H_{c}$ and assumptions about $\dot{Q}_{s r}$ [19].

${ }^{\dagger}$ Recalculated $\chi_{r}$, using $\Delta H_{c}=19.90 \mathrm{~kJ} / \mathrm{g}$ [27], not $22.37 \mathrm{~kJ} / \mathrm{g}$ assuming gaseous water as a combustion product. 


\section{Summary and Conclusions}

A series of measurements was conducted to characterize medium-scale pool fires burning a variety of liquid and gaseous fuels. The upward velocity and the gas phase temperature was measured along the centerline in the flame and plume regions of medium-scale pool fires. Time-averaged local measurements of the upward velocity were conducted using a bidirectional probe in the plumes of methanol, ethanol, and acetone pool fires burning in a $30 \mathrm{~cm}$ diameter liquid pool burner and methane and propane gaseous pool fires established on a $37 \mathrm{~cm}$ diameter gas burner. The gas-phase temperature was measured using fine-wire, bare-bead, thermocouples with various bead diameters.

The upward component of the velocity on the plume centerline in the pool fires compared favorably to previous measurements. The results showed that the upward velocity increased with distance above the plume for about 1 to 2 diameters above the fuel surface and then decreased with distance, which followed the general trends of Baum and McCaffrey's plume theory. The gas-phase thermocouple temperatures were corrected considering radiative loss and thermal inertia effects. The corrected profiles of mean axial temperature in the methanol fire were shown to be similar to previous results when scaled by $\dot{Q}^{2 / 5}$. A single location radiative heat flux measurement was used to determine the radiative fraction in $30 \mathrm{~cm}$ diameter methanol pool fires. The results were favorably compared to previous measurements using multi-location and single-location heat flux measurements. Future measurements may consider configurations other than pool fires as well as fuel types that lead to fires with relatively large soot concentrations. 


\section{References}

1. Falkesntein-Smith, R., Sung, K., Chen, J., Harris, K. and Hamins, A., The Structure of Medium-Scale Pool Fires, NIST Technical Note 2082, National Institute of Standards and Technology, Gaithersburg, MD, February 2020, https://doi.org/10.6028/NIST.TN.2082.

2. McGrattan, K., Hostikka, S., Floyd, J., McDermott, R. and Vanella, M., Fire Dynamics Simulator Technical Reference Guide Volume 3: Validation, NIST special publication 1018-3, Sixth Ed., National Institute of Standards and Technology, Gaithersburg, MD, March 2020, http://dx.doi.org/10.6028/NIST.SP.1018.

3. Brown, A., Bruns, M., Gollner, M., Hewson, J., Maragkos, G., Marshall, A., McDermott, R., Merci, B., Rogaume, T., Stoliarov, S., Torero, J., Trouvé, A., Wang, Y. and Weckman, E., Proceedings of the First Workshop Organized by the Iafss Working Group on Measurement and Computation of Fire Phenomena (MaCFP), Fire Safety Journal, 101, 1-17, (2018), https://doi.org/10.1016/j.firesaf.2018.08.009.

4. Merci, B. and Trouvé, A., Call for Participation in the Second Workshop Organized by the Iafss Working Group on Measurement and Computation of Fire Phenomena, Fire Technology, 55, 19111917, (2019), 10.1007/s10694-019-00844-6.

5. Kim, S. C., Lee, K. Y. and Hamins, A., Energy Balance in Medium-Scale Methanol, Ethanol, and Acetone Pool Fires, Fire Safety Journal, 107, 44-53, (2019), https://doi.org/10.1016/j.firesaf.2019.01.004.

6. Corlett, R. and Fu, T., Some Recent Experiments with Pool Fires, Pyrodynamics, 1, 253-269, (1966).

7. Weckman, E. J. and Sobiesiak, A., The Oscillatory Behaviour of Medium-Scale Pool Fires, in Proceedings of the Combustion Institute, 22, pp1299-1310, (1989).

8. Weckman, E. J. and Strong, A. B., Experimental Investigation of the Turbulence Structure of Medium-Scale Methanol Pool Fires, Combustion and Flame, 105, 245-266, (1996), 10.1016/001021809500103-4.

9. Hamins, A., Fischer, S. J., Kashiwagi, T., Klassen, M. E. and Gore, J. P., Heat Feedback to the Fuel Surface in Pool Fires, Combustion Science and Technology, 97, 37-62, (1994), 10.1080/00102209408935367.

10. Klassen, M. and Gore, J., Structure and Radiation Properties of Pool Fires, NIST-GCR-94-651, National Institute of Standards and Technology, Gaithersburg, MD, June 1994.

11. Hogben, C. D. A., Young, C. N., Weckman, E. J. and Strong, A. B., Radiative Properties of Acetone Pool Fires, in $33^{\text {rd }}$ ASME National Heat Transfer Conference, Albuquerque, pp12, (1999).

12. Papadopoulos, G., Bryant, R. and Pitts, W., Flow Characterization of Flickering Methane/Air Diffusion Flames Using Particle Image Velocimetry, Experiments in Fluids, 33, 472-481, (2002), 10.1007/s00348-002-0483-y.

13. Tieszen, S. R., O’Hern, T. J., Schefer, R. W., Weckman, E. J. and Blanchat, T. K., Experimental Study of the Flow Field in and around a One Meter Diameter Methane Fire, Combustion and Flame, 129, 378-391, (2002), 10.1016/s0010-21800200352-8.

14. Devaud, C. B., Weisinger, J., Johnson, D. A. and Weckman, E. J., Experimental and Numerical Characterization of the Flowfield in the Large-Scale Uw Live Fire Research Facility, International Journal for Numerical Methods in Fluids, 60, 539-564, (2009), https://doi.org/10.1002/fld.1906. 
15. Welle, E. J., Roberts, W. L., Decroix, M. E., Carter, C. D. and Donbar, J. M., Simultaneous ParticleImaging Velocimetry and Oh Planar Laser-Induced Fluorescence Measurements in an Unsteady Counterflow Propane/Air Diffusion Flame, Proceedings of the Combustion Institute, 28, 2021-2027, (2000), https://doi.org/10.1016/S0082-07840080609-8.

16. Bouvier, M., Cabot, G., Yon, J. and Grisch, F., On the Use of Piv, Lii, Pah-Plif and Oh-Plif for the Study of Soot Formation and Flame Structure in a Swirl Stratified Premixed Ethylene/Air Flame, Proceedings of the Combustion Institute, (2020), https://doi.org/10.1016/j.proci.2020.10.002.

17. McCaffrey, B. J. and Heskestad, G., A Robust Bidirectional Low-Velocity Probe for Flame and Fire Application, Combustion and Flame, 26, 125-127, (1976), https://doi.org/10.1016/001021807690062-6.

18. McCaffrey, B. J., Purely Buoyant Diffusion Flames: Some Experimental Results, NBSIR 79-1910, National Bureau of Standards, Washington, D.C. 20234, October 1979.

19. Sung, K., Chen, J., Bundy, M., Fernandez, M. and Hamins, A., The Thermal Character of a $1 \mathrm{~m}$ Methanol Pool Fire, NIST Technical Note 2083, Rev.1, National Institute of Standards and Technology, Gaithersburg, MD, June 2021, https://doi.org/10.6028/NIST.TN.2083r1.

20. Grosshandler, W. L., RADCAL: A Narrow-Band Model for Radiation Calculations in a Combustion Environment, NIST Technical Note 1402, National Institute of Standards and Technology, Gaithersburg, MD, April 1993.

21. McGrattan, K., McDermott, R., Vanella, M., Hostikka, S. and Floyd, J., Fire Dynamics Simulator Technical Reference Guide Volume 1: Mathematical Model, NIST special publication 1018-1, Sixth Ed., National Institute of Standards and Technology, Gaithersburg, MD, March 2020, http://dx.doi.org/10.6028/NIST.SP.1018.

22. Ranz, W. and Marshall, W., Evaporation from Drops, Chem. eng. prog, 48, 141-146, (1952).

23. Çengel, Y. A. and Ghajar, A. J., Heat and Mass Transfer: Fundamentals and Applications, $7^{\text {th }}$ Ed., McGraw-Hill Education, 2020.

24. Shaddix, C. R., Correcting Thermocouple Measurements for Radiation Loss: A Critical Review, American Society of Mechanical Engineers, New York, NY (US); Sandia National Labs., Livermore, CA (US), 1999.

25. Jaeger, F. M. and Rosenbohm, E., The Exact Formulae for the True and Mean Specific Heats of Platinum between $0^{\circ}$ and $1600^{\circ} \mathrm{C}$, Physica, 6, 1123-1125, (1939), https://doi.org/10.1016/S003189143990111-4.

26. Modak, A. T., Thermal Radiation from Pool Fires, Combustion and Flame, 29, 177-192, (1977), https://doi.org/10.1016/0010-21807790106-7.

27. Design Institute for Physical Properties (DIPPR 801), American Institute of Chemical Engineers, 2017.

28. Hamins, A. and Lock, A., The Structure of a Moderate-Scale Methanol Pool Fire, NIST Technical Note 1928, National Institute of Standards and Technology, Gaithersburg, MD, November 2016, https://doi.org/10.6028/NIST.TN.1928.

29. Wang, Z., Tam, W. C., Lee, K. Y. and Hamins, A., Temperature Field Measurements Using Thin Filament Pyrometry in a Medium-Scale Methanol Pool Fire, NIST Technical Note 2031, National Institute of Standards and Technology, Gaithersburg, MD, November 2018, https://doi.org/10.6028/NIST.TN.2031. 
30. Sung, K., Chen, J., Bundy, M. and Hamins, A., The Characteristics of a 1 M Methanol Pool Fire, Fire Safety Journal, (2020), https://doi.org/10.1016/j.firesaf.2020.103121.

31. Fischer, S. J., Hardouin-Duparc, B. and Grosshandler, W. L., The Structure and Radiation of an Ethanol Pool Fire, Combustion and Flame, 70, 291-306, (1987), 10.1016/0010-21808790110-6.

32. Personal Communication, 9 July 2019 Email from Beth Weckman.

33. Baum, H. R. and McCaffrey, B. J., Fire Induced Flow Field-Theory and Experiment, in Proceedings of the Second International Symposium on Fire Safety Science, Hemisphere, New York, 2, pp129-148, (1989).

34. Heskestad, G., SFPE Handbook of Fire Protection Engineering, $5^{\text {th }}$ edition, Socierty of Fire Protection Engineers, Springer, 2016.

35. Hamins, A., Klassen, M., Gore, J. and Kashiwagi, T., Estimate of Flame Radiance via a Single Location Measurement in Liquid Pool Fires, Combustion and Flame, 86, 223-228, (1991), https://doi.org/10.1016/0010-21809190102-H.

36. Buch, R., Hamins, A., Konishi, K., Mattingly, D. and Kashiwagi, T., Radiative Emission Fraction of Pool Fires Burning Silicone Fluids, Combustion and Flame, 108, 118-126, (1997), https://doi.org/10.1016/S0010-21809600098-3.

37. National Instruments Inc., SCXI-1600 User Manual and Specifications, 2004.

38. Taylor, B. N. and Kuyatt, C. E., Guidelines for Evaluating and Expressing the Uncertainty of NIST Measurement Results, NIST Technical Note 1297, National Institute of Standards and Technology, Gaithersburg, MD, September 1994.

39. Pitts, W. M., Murthy, A. V., De Ris, J. L., Filtz, J.-R., Nygård, K., Smith, D. and Wetterlund, I., Round Robin Study of Total Heat Flux Gauge Calibration at Fire Laboratories, Fire Safety Journal, 41, 459-475, (2006), 10.1016/j.firesaf.2006.04.004.

40. Bryant, R., Johnsson, E., Ohlemiller, T. and Womeldorf, C., Estimates of the Uncertainty of Radiative Heat Flux Calculated from Total Heat Flux Measurements, in Proc. $9^{\text {th }}$ Interflam Conference in Edinburgh, Interscience Communications London, pp605-616, (2001).

This publication is available free of charge from: https://doi.org/10.6028/NIST.TN.2162 


\section{Appendices}

This publication is available free of charge from: https://doi.org/10.6028/NIST.TN.2162 


\section{A Thermophysical Properties}

Table A1. Thermochemical properties of liquid and gaseous fuels at $20^{\circ} \mathrm{C}$ [27].

\begin{tabular}{cccccc}
\hline Fuel & $\begin{array}{c}\text { Chemical } \\
\text { Formula }\end{array}$ & $\begin{array}{c}\text { Density } \\
{\left[\mathbf{k g} / \mathbf{m}^{3}\right]}\end{array}$ & $\begin{array}{c}\text { MW } \\
{[\mathbf{g} / \mathbf{m o l}]}\end{array}$ & $\begin{array}{c}\text { Boiling } \\
\text { Temperature } \\
{\left[{ }^{\circ} \mathbf{C}\right]}\end{array}$ & $\begin{array}{c}\Delta \boldsymbol{H}_{\boldsymbol{c}} \\
{[\mathbf{k J} / \mathbf{g}]}\end{array}$ \\
\hline Methanol & $\mathrm{CH}_{3} \mathrm{OH}$ & $794 \pm<1 \%$ & 32.04 & $64.7 \pm<1 \%$ & $19.90 \pm<1 \%$ \\
Ethanol & $\mathrm{C}_{2} \mathrm{H}_{6} \mathrm{O}$ & $789 \pm<1 \%$ & 46.07 & $78.3 \pm<1 \%$ & $26.82 \pm<1 \%$ \\
Acetone & $\mathrm{C}_{3} \mathrm{H}_{6} \mathrm{O}$ & $791 \pm<1 \%$ & 58.08 & $56.1 \pm<1 \%$ & $28.52 \pm<1 \%$ \\
Heptane & $\mathrm{C}_{7} \mathrm{H}_{16}$ & $680 \pm<1 \%$ & 100.20 & $98.4 \pm<1 \%$ & $44.56 \pm<1 \%$ \\
Methane & $\mathrm{CH}_{4}$ & $0.66 \pm<1 \%$ & 16.04 & $-161.6 \pm<1 \%$ & $50.03 \pm<1 \%$ \\
Propane & $\mathrm{C}_{3} \mathrm{H}_{8}$ & $1.84 \pm<1 \%$ & 44.10 & $-42.2 \pm<1 \%$ & $46.33 \pm<1 \%$ \\
\hline
\end{tabular}

Table A2. Thermophysical properties of platinum as a function of temperature.

\begin{tabular}{ccc}
\hline Temperature $[\mathbf{K}]$ & ${\text { Specific heat }[\mathbf{J} / \mathbf{g}-\mathbf{K}]^{\mathbf{a}}}^{\mathbf{a}}$ & ${\text { Emissivity }[-]^{\mathbf{b}}}^{\mathbf{2}}$ \\
473 & 0.14 & 0.00 \\
573 & 0.14 & 0.03 \\
673 & 0.14 & 0.05 \\
773 & 0.14 & 0.07 \\
873 & 0.15 & 0.09 \\
973 & 0.15 & 0.10 \\
1073 & 0.15 & 0.12 \\
1173 & 0.15 & 0.13 \\
1273 & 0.16 & 0.14 \\
1373 & 0.16 & 0.15 \\
1473 & 0.16 & 0.17 \\
1573 & 0.16 & 0.18 \\
1673 & 0.17 & 0.19 \\
\hline
\end{tabular}

${ }^{a}$ Ref. [25]

${ }^{\mathrm{b}}$ Ref. [24]

Polynomial fits for the temperature dependent specific heat $\left(c_{p, b}\right)$ and emissivity $\left(\epsilon_{b}\right)$ of platinum:

$$
\begin{aligned}
& c_{p, b}=0.13+2.56 T \\
& \epsilon_{b}=-0.1+3.24 \cdot 10^{-4} T-1.25 \cdot 10^{-7} T^{2}+2.18 \cdot 10^{-11} T^{3}
\end{aligned}
$$


Table A3. Thermophysical properties of air as a function of temperature [23].

\begin{tabular}{cccccc}
\hline $\begin{array}{c}\text { Temperature } \\
{\left[{ }^{\circ} \mathbf{C}\right]}\end{array}$ & $\begin{array}{c}\text { Density } \\
{\left[\mathbf{k g} / \mathbf{m}^{3}\right]}\end{array}$ & $\begin{array}{c}\text { Specific Heat } \\
{[\mathbf{J} / \mathbf{k g} / \mathbf{K}]}\end{array}$ & $\begin{array}{c}\text { Thermal } \\
\text { Conductivity } \\
{[\mathbf{W} / \mathbf{m} / \mathbf{K}]}\end{array}$ & $\begin{array}{c}\text { Dynamic } \\
\text { Viscosity } \\
{[\mathbf{k g} / \mathbf{m} / \mathbf{s}]}\end{array}$ & $\begin{array}{c}\text { Prandtl } \\
\text { Number } \\
{[-]}\end{array}$ \\
\hline 300 & 0.616 & 1044 & 0.044 & $2.93 \mathrm{E}-05$ & 0.694 \\
350 & 0.566 & 1056 & 0.047 & $3.10 \mathrm{E}-05$ & 0.694 \\
400 & 0.524 & 1069 & 0.050 & $3.26 \mathrm{E}-05$ & 0.695 \\
450 & 0.488 & 1081 & 0.053 & $3.42 \mathrm{E}-05$ & 0.697 \\
500 & 0.457 & 1093 & 0.056 & $3.56 \mathrm{E}-05$ & 0.699 \\
600 & 0.404 & 1115 & 0.061 & $3.85 \mathrm{E}-05$ & 0.704 \\
700 & 0.363 & 1135 & 0.066 & $4.11 \mathrm{E}-05$ & 0.709 \\
800 & 0.329 & 1153 & 0.070 & $4.36 \mathrm{E}-05$ & 0.715 \\
900 & 0.301 & 1169 & 0.075 & $4.60 \mathrm{E}-05$ & 0.721 \\
1000 & 0.277 & 1184 & 0.079 & $4.83 \mathrm{E}-05$ & 0.726 \\
1500 & 0.199 & 1234 & 0.096 & $5.82 \mathrm{E}-05$ & 0.748 \\
2000 & 0.155 & 1264 & 0.111 & $6.63 \mathrm{E}-05$ & 0.754 \\
\hline
\end{tabular}

Polynomial fits for the temperature dependent density $(\rho)$, specific heat $\left(c_{p}\right)$, thermal conductivity $(\lambda)$, and dynamic viscosity $(\mu)$ of the air yield the following:

$$
\begin{aligned}
& \rho=351.90(T+272.99)^{-0.9996} \\
& c_{p}=948.38+0.36 T-1.43 \mathrm{E}-4 \cdot T^{2}+2.20 \mathrm{E}-8 \cdot T^{3} \\
& \lambda=0.024+7.56 \mathrm{E}-5 \cdot T-2.52 \mathrm{E}-8 \cdot T^{2}+4.64 \mathrm{E}-12 \cdot T^{3} \\
& \mu=1.74 \mathrm{E}-5+4.463 \mathrm{E}-8 \cdot T-2.40 \mathrm{E}-11 \cdot T^{3}+1.05 \mathrm{E}-14 \cdot T^{3}-1.99 \mathrm{E}-18 \cdot T^{4}
\end{aligned}
$$




\section{B Pressure Transducer Information}

Table B1. Calibration factors of the pressure transducers.

\begin{tabular}{cccc}
\hline Pressure transducer & $\begin{array}{c}\text { Maximum Measurement } \\
\text { Range }[\mathbf{k P a}]\end{array}$ & $\begin{array}{c}\text { Calibration factor } \\
{[\mathbf{P a} / \mathbf{V}]}\end{array}$ & $\begin{array}{c}\text { Response time } \\
\boldsymbol{\tau}_{\boldsymbol{p}}[\mathrm{ms}]\end{array}$ \\
\hline Setra-717 & 0.025 & 10.225 & $19.5 \pm 1.6^{\dagger}$ \\
MKS-220D & 0.13 & 13.33 & $160.5 \pm 3.8^{\dagger}$ \\
MKS-226A & 0.027 & 2.742 & $21.3 \pm 0.6^{\dagger}$ \\
Setra-568 & 0.25 & 101.764 & $9.6 \pm 2.8^{\dagger}$ \\
\hline
\end{tabular}

${ }^{\dagger}$ the uncertainty represents a $95 \%$ confidence interval.

\section{B.1 Pressure Transducer Response Time}

The response time of the pressure transducer $\left(\tau_{p}\right)$ is defined as:

$$
\tau_{p}=\frac{t_{1}}{1.9}
$$

where $t_{1}$ is the time at which the transducer signal is reduced from $95 \%$ to $10 \%$ of its initial value when a step change of pressure is applied. Response time measurements were repeated three times using a data acquisition system (DAQ, Model: SCXI-1600, National Instrument Inc) with the data sampling rate of $500 \mathrm{~Hz}$.

According to its specifications, the measurement accuracy of the pressure transducer and DAQ are $1.0 \%$ and $0.076 \%$ [37] in the application range of interest, respectively. The measurement uncertainties are considered in the combined uncertainty of the measured pressure difference $\left(u_{c}(\Delta P)\right)$. Here, the combined uncertainty of the response time of the pressure transducer, $u_{c}\left(\tau_{p}\right)$, is estimated as:

$$
u_{c}\left(\tau_{p}\right)=\sqrt{\sigma_{R}\left(\tau_{p}\right)^{2}+u_{c}(D A Q)^{2}+u_{c}(\text { Probe })^{2}}
$$

where $\sigma_{R}\left(\tau_{p}\right)$ is the repeatability defined by taking the standard deviation of the repeat measurements. $u_{c}(D A Q)$ and $u_{c}$ (Probe) are the measurement uncertainties of the bidirectional probe and the DAQ, respectively. Figure B1 shows the normalized pressure difference measured with Setra-717 as a function of time in Test 2 . The pressure difference was normalized with mean initial pressure $\left(\overline{\Delta P}_{i}\right)$. The parameter $t_{1}$ was $37 \mathrm{~ms}$ and $\tau_{p}$ was $19.5 \mathrm{~ms}$. The mean and expanded combined uncertainty of the response time are $19.5 \mathrm{~ms} \pm 1.6 \mathrm{~ms}$ for three repeat measurements.

This publication is available free of charge from: https://doi.org/10.6028/NIST.TN.2162 


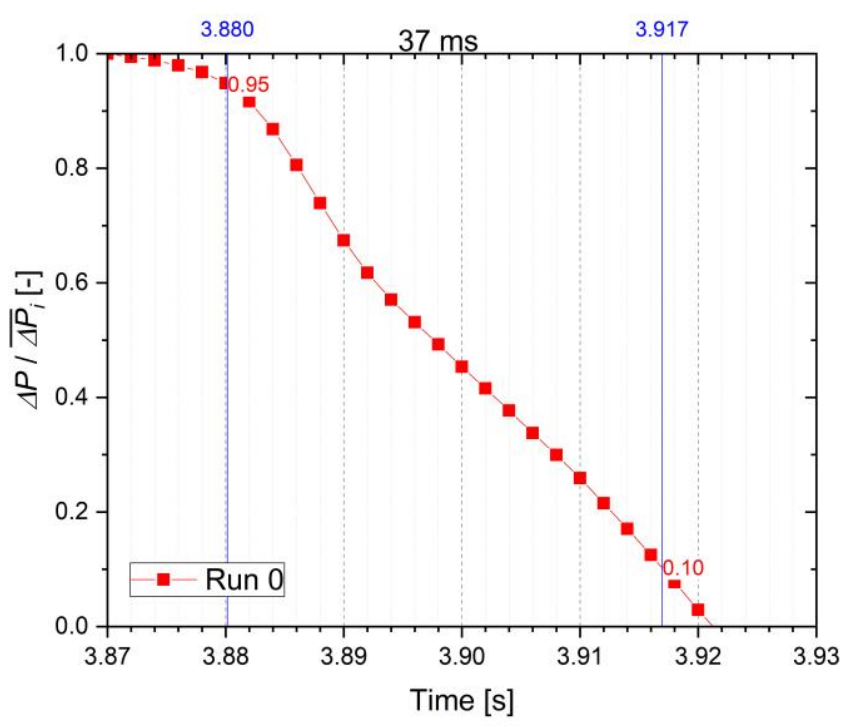

Figure B1. Normalized pressure difference measured with Setra-717 as a function of time.

\section{Thermocouple Information}

Table C1. Thermocouple type, and wire and bead diameters.

\begin{tabular}{cccc}
\hline Thermocouple No. & Type & $\begin{array}{c}\text { Wire diameter } \\
\boldsymbol{d}_{\boldsymbol{w}}[\boldsymbol{\mu \mathrm { m }}]\end{array}$ & $\begin{array}{c}\text { Bead diameter } \\
\boldsymbol{d}_{\boldsymbol{b}}[\boldsymbol{\mu m}]\end{array}$ \\
\hline TC 1 & $\mathrm{~S}$ & 25 & 199 \\
TC 2 & $\mathrm{~S}$ & 12.5 & 52.1 \\
TC 3 & $\mathrm{~S}$ & 25 & 119 \\
TC 4 & $\mathrm{R}$ & 25 & 102.7 \\
TC 5 & $\mathrm{~S}$ & 25 & 125 \\
TC 6 & $\mathrm{~S}$ & 50 & 150 \\
\hline
\end{tabular}

${ }^{\dagger}$ during experiments using TC 5 , the thermocouple was positioned about $5 \mathrm{~mm}$ upstream of the bidirectional probe.

\section{Effect of Bidirectional Probe on Temperature Measurements}

To calculate the temperature-dependent gas properties in Eqs. 4 - 6, time series temperature measurements were conducted using a Type S, $25 \mu \mathrm{m}$ wire diameter, bare -bead, thermocouple (TC5) positioned $5 \mathrm{~mm}$ upstream of the bidirectional probe (see Figure 4 in Section 2.4).

The thermocouple position was based on being as close to the probe as practical while preventing damage to the fine thermocouple by the fire, which tended to move the thermocouple downstream towards the bidirectional probe when inserted into the upward moving fire plume. In this section, the mean of the thermocouple bead temperature with and without the bidirectional probe at the same measurement positions were compared to understand the effect of the presence of the bidirectional probe on the temperature measurement results. 
Table D1 shows the mean gas temperatures measured using thermocouples without the bidirectional probe $\left(T_{g, \text { alone }}\right)$ present and with the thermocouple positioned below the bidirectional probe $\left(T_{g, T C 5}\right)$ in methanol, acetone and ethanol pool fires. Deviation of the mean gas temperature, defined as the relative difference: $\left|\bar{T}_{g, T C 5}-\bar{T}_{g, \text { alone }}\right| / \bar{T}_{g, \text { alone }}$, is compared to the expanded combined uncertainty of the mean gas temperature measured using thermocouples without the bidirectional probe $\left(U_{c}\left(T_{g, \text { alone }}\right)\right)$ present. The percentage temperature difference between the mean gas temperature measurements with and without the bidirectional probe is $4 \%$ on-average, which is less than the mean of the expanded combined uncertainty of the mean gas temperature measured using thermocouples without the presence of the bidirectional probe.

Table D1. Mean gas temperature measured using thermocouples without the bidirectional probe ( $\left.T_{g, \text { alone }}\right)$ present and with the thermocouple positioned below the bidirectional probe $\left(T_{g, T C 5}\right)$ in methanol, acetone and ethanol pool fires. The deviation of the mean gas temperature at each position is compared to the expanded combined uncertainty of the mean gas temperature measured using thermocouples without the bidirectional probe present $\left(U_{c}\left(T_{g, a l o n e}\right)\right)$.

\begin{tabular}{cccccc}
\hline Fuel & $\begin{array}{c}\boldsymbol{Z} \\
{[\mathbf{c m}]}\end{array}$ & $\begin{array}{c}\overline{\boldsymbol{T}}_{\boldsymbol{g}, \boldsymbol{a l o n e}} \\
{[\mathbf{K}]}\end{array}$ & $\begin{array}{c}\overline{\boldsymbol{T}}_{\boldsymbol{g}, \boldsymbol{T C 5}} \\
{[\mathbf{K}]}\end{array}$ & $\begin{array}{c}\boldsymbol{U}_{\boldsymbol{c}}\left(\overline{\boldsymbol{T}}_{\boldsymbol{g}, \boldsymbol{a l o n e} \boldsymbol{e}}\right) \\
{[\mathbf{\%}]}\end{array}$ & $\begin{array}{c}\text { Deviation of } \overline{\boldsymbol{T}}_{\boldsymbol{g}} \\
{[-]}\end{array}$ \\
\hline Acetone & 2 & 702 & 653 & $35 \%$ & $7 \%$ \\
Acetone & 6 & 910 & 894 & $24 \%$ & $2 \%$ \\
Acetone & 10 & 1079 & 1066 & $13 \%$ & $1 \%$ \\
Acetone & 14 & 1200 & 1148 & $2 \%$ & $4 \%$ \\
Acetone & 20 & 1232 & 1187 & $9 \%$ & $4 \%$ \\
Acetone & 40 & 1142 & 1072 & $29 \%$ & $6 \%$ \\
Acetone & 45 & 1081 & 1034 & $14 \%$ & $4 \%$ \\
Acetone & 50 & 1048 & 1007 & $39 \%$ & $4 \%$ \\
Acetone & 60 & 918 & 890 & $22 \%$ & $3 \%$ \\
Ethanol & 2 & 969 & 933 & $7 \%$ & $4 \%$ \\
Ethanol & 4 & 1132 & 1109 & $4 \%$ & $2 \%$ \\
Ethanol & 6 & 1206 & 1221 & $6 \%$ & $1 \%$ \\
Ethanol & 10 & 1281 & 1260 & $3 \%$ & $2 \%$ \\
Ethanol & 14 & 1291 & 1265 & $5 \%$ & $2 \%$ \\
Ethanol & 20 & 1261 & 1217 & $5 \%$ & $3 \%$ \\
Ethanol & 30 & 1097 & 984 & $5 \%$ & $10 \%$ \\
Ethanol & 45 & 813 & 759 & $3 \%$ & $7 \%$ \\
Ethanol & 60 & 615 & 598 & $3 \%$ & $3 \%$ \\
Methanol & 3 & 1183 & 1236 & $2 \%$ & $4 \%$ \\
Methanol & 5 & 1251 & 1316 & $5 \%$ & $5 \%$ \\
\hline Average & & & $12 \%$ & $4 \%$ \\
\hline
\end{tabular}




\section{E Uncertainty Analysis}

Estimates of uncertainty are evaluated using the method descried by Taylor and Kuyatt [38]. A series of measurements, denoted by $y$, can be expressed as a function of its associated independent variables, $x_{i}$. The function $f$ in Eq. E1 contains all quantities that significantly contribute to the measurement:

$$
y=f\left(x_{1}, x_{2}, x_{3}, \cdots, x_{N}\right)
$$

In the case that all input parameters are uncorrelated, the combined standard uncertainty is given by Eq. $\mathrm{E} 2$, referred to as the law of propagation of uncertainty.

$$
u_{c}(y)=\sqrt{\sum_{i=1}^{N}\left(s_{i} \cdot u\left(x_{i}\right)\right)^{2}}
$$

where $u_{c}(y)$ is the combined standard uncertainty and $u\left(x_{i}\right)$ is the standard uncertainty of each input parameter. The parameter, $s_{i}$, is the non-dimensional sensitivity coefficient, defined as:

$$
s_{i}=\frac{\partial f}{\partial x_{i}} \frac{x_{i}}{y}
$$

A series of measurements allows computation of statistics of their uncertainties during steady burning and the standard deviation of the output estimate, $\sigma_{y}$, is considered an uncertainty component. The expanded combined uncertainty, $U_{c}(y)$, is defined as:

$$
U_{c}(y)=k \sqrt{u_{c}(y)^{2}+\sigma_{y}^{2}}
$$

where the coverage factor, $k$, is taken as equal to 2 , so that the expanded combined uncertainty, $U_{c}$, defines an interval representing approximately a $95 \%$ confidence level. Appendices E. 1 and E.2 below describe the uncertainty of the gas velocity and temperature measurements, respectively.

\section{E.1 Gas Velocity Uncertainty Methodology}

The instantaneous gas velocity in the upward direction $\left(V_{g}(t)\right)$ is estimated from measurement of the pressure difference across a bidirectional probe and the gas temperature near the downward face of the probe, applying the velocity model for a bidirectional probe [17] given by Eq. 4 and reproduced here:

$$
V_{g}(t)=\frac{1}{k_{p}(t)} \sqrt{\frac{2 \Delta P_{c}(t)}{\rho(t)}}
$$

where $\Delta P_{c}(t)$ and $\rho(t)$ are the instantaneous corrected pressure difference and gas density, respectively. The gas density $\rho(t)$ is determined from the thermocouple temperature measurement using a fine, barebead, Type $S$ thermocouple corrected for radiative loss and the assumption that the gas constant corresponds to that of air. In this study, the instantaneous gas velocity for every measured data point is

This publication is available free of charge from: https://doi.org/10.6028/NIST.TN.2162 
calculated with the time series of instantaneous measurements of the parameters in Eq. E5. The temperature-dependent gas properties are taken as those of air [23]. The temperatures of the temperaturedependent thermophysical properties are determined based on the instantaneous temperature determined from thermocouple measurements corrected for radiative loss $\left(T_{r}\right)$, using the polynomials presented in Appendix A.

In this study, a number of experiments were conducted, acquiring time series data of the gas velocity were acquired at each measurement location, using multiple pressure transducers. These measurements were typically repeated 2 to 3 times and as often as 10 times.

- The pooled mean gas velocity at a particular measurement position $\left(\bar{V}_{g}\right)$ is estimated by averaging the mean gas velocities from all pressure transducers: $\bar{V}_{g}=\sum_{n=1}^{N} \bar{V}_{g, n} / N$, where $n$ is the index of the pressure transducers and $N$ is the total number of pressure transducers used at a particular measurement location. The uncertainty of the gas velocity associated with the standard deviation of the results from the $N$ pressure transducers is estimated as: $\operatorname{SD}\left(\bar{V}_{g, n} / \bar{V}_{g}\right)$, where SD is the standard deviation. This term is denoted as $u_{c}(P T)$, which contributes to the combined uncertainty defined by Eq. E6 below.

- The mean gas velocity of the $n^{\text {th }}$ pressure transducer $\left(\bar{V}_{g, n}\right)$ is estimated by averaging its value during repeat measurements: $\bar{V}_{g, n}=\sum_{m=1}^{M} \bar{V}_{g, m} / M$, where $M$ is the total number of measurements repeated at a particular measurement location. The repeatability of $\bar{V}_{g, n}$ is quantified by the relative standard deviation of the measurements: $\operatorname{SD}\left(\bar{V}_{g, m}\right) / \bar{V}_{g, n}$. This term is denoted as $\sigma_{R}\left(\bar{V}_{g, n}\right)$, which contributes to the combined uncertainty in Eq. E6 below.

The expanded combined uncertainty of the mean gas velocity (with an expansion factor of 2) measure using $n^{\text {th }}$ pressure transducer at each measurement position, $U_{c}\left(\bar{V}_{g, n}\right)$, is estimated as:

$$
U_{c}\left(\bar{V}_{g, n}\right)=2 \sqrt{\left(\frac{1}{2} u_{c}\left(\Delta P_{c}\right)\right)^{2}+\left(\frac{1}{2} u_{c}\left(\rho_{g}\right)\right)^{2}+u_{c}\left(k_{p}\right)^{2}+u_{c}(P T)^{2}+\sigma_{R}\left(\bar{V}_{g, n}\right)^{2}}
$$

where the first three terms on the right side of the equation are the propagated error from the various terms in Eq. E5. The term $u_{c}(P T)$ represents the uncertainty of the gas velocity measured using the $N$ pressure transducers and $\sigma_{R}\left(\bar{V}_{g, n}\right)$ is the repeatability. Finally, the expanded combined uncertainty of the mean gas velocity at a particular measurement position, $U_{c}\left(\bar{V}_{g}\right)$, is estimated by considering the repeat measurements:

$$
U_{c}\left(\bar{V}_{g}\right)=\operatorname{RMS}\left[U_{c}\left(\bar{V}_{g, n}\right)\right]=\sqrt{\frac{1}{N} \sum_{n=1}^{N} U_{c}\left(\bar{V}_{g, n}\right)^{2}}
$$

where $N$ is the number of total number of pressure transducers used at a particular measurement position. In Eq. E6, the combined uncertainty of bidirectional probe constant, $u_{c}\left(k_{p}\right)$, is estimated as: 


$$
u_{c}\left(k_{p, n}\right)=\sqrt{\left(S_{\operatorname{Re}_{p, n}} \cdot u_{c}\left(\operatorname{Re}_{p, n}\right)\right)^{2}+u_{c}(\text { model })^{2}+\sigma_{R}\left(k_{p, n}\right)^{2}}
$$

where $S_{\mathrm{Re}_{p, n}}$ is the sensitivity coefficient of the Reynolds number of the bidirectional probe. The combined uncertainty of the empirical model between the probe constant $\left(k_{p}\right)$ and the Reynolds number is $5 \%$ [17], denoted as $u_{c}$ (model). The term $\sigma_{R}\left(k_{p, n}\right)$ is the repeatability, quantified by the standard deviation of the mean values in repeat measurements. The combined uncertainty of the corrected pressure difference, $u_{c}\left(\Delta P_{c, n}\right)$, is estimated as:

$$
u_{c}\left(\Delta P_{c, n}\right)=\sqrt{u_{c}(\Delta P)^{2}+u_{c}\left(\tau_{p, n}\right)^{2}+u_{c}\left(\frac{d \Delta P_{n}}{d t}\right)^{2}+\sigma_{R}\left(\Delta P_{c, n}\right)^{2}}
$$

where the response time of the pressure transducer $\left(\tau_{p}\right)$ was measured as discussed in Appendix B, which provides the mean and expanded combined uncertainty of the response time for each pressure transducer. The uncertainty of the time derivative of the pressure difference $\left(u_{c}\left(d \Delta P_{n} / d t\right)\right)$ is estimated as $5 \%$, based on the curve fitting described in Ref. [19]. The term $\sigma_{R}\left(\Delta P_{c, n}\right)$ is the repeatability, quantified by the standard deviation of the mean values of the repeat measurements.

The temperature-dependent gas properties in Eqs. E6 and E9, are taken as those of air [23]. The thermophysical properties, including the density $\left(\rho_{g}\right)$, dynamic viscosity $\left(\mu_{g}\right)$, thermal conductivity $\left(\lambda_{g}\right)$ and specific heat $\left(c_{p, g}\right)$, are based on the instantaneous temperature determined from thermocouple measurements corrected for radiative loss $\left(T_{r}\right)$ using the polynomials presented in Appendix A.

The uncertainty of each thermophysical property $(x)$ is estimated as:

$$
u_{c}\left(x_{n}\right)=\sqrt{\left(S_{x_{n}} \cdot u_{c}\left(T_{r, n}\right)\right)^{2}+\sigma_{R}\left(x_{n}\right)^{2}}
$$

where $S_{x}$ is the sensitivity coefficient of the thermophysical property $\left(x_{n}\right)$ and $\sigma_{R}\left(x_{n}\right)$ is the repeatability, quantified by the standard deviation of the mean values in repeat measurements. The uncertainty of the radiative loss correction temperature $\left(u_{c}\left(T_{r, n}\right)\right)$ is estimated based on the energy balance at the thermocouple bead as:

$$
u_{c}\left(T_{r, n}\right)=\sqrt{u_{c}\left(T_{b}\right)^{2}+u_{c}\left(T_{r a d, n}\right)^{2}+\sigma_{R}\left(T_{r, n}\right)}
$$

where $u_{c}\left(T_{b}\right)$ and $u_{c}\left(T_{r a d, n}\right)$ are the uncertainties of the thermocouple bead temperature and the radiative loss correction term in the energy balance at the thermocouple bead described by Eq. 1 in Section 2.3.1. The term $\sigma_{R}\left(T_{r, n}\right)$ is the repeatability, quantified by the standard deviation of the mean values in repeat measurements. The sections below present the results of the uncertainty analysis for each of the fires considered in this report. 


\section{E.1.1 Methanol Fire}

Table E1 shows the pooled mean gas velocity $\left(\bar{V}_{g}\right)$ and standard deviation $\left(\sigma_{V_{g}}\right)$ as a function of axial distance above the burner in the $30 \mathrm{~cm}$ methanol pool fire. The expanded combined uncertainty of the mean gas velocity $\left(U_{c}\left(\bar{V}_{g}\right)\right)$ is also shown in which the uncertainty represents a $95 \%$ confidence interval.

Table E1. Pooled mean gas velocity $\left(\bar{V}_{g}\right)$ and standard deviation $\left(\sigma_{V_{g}}\right)$ as a function of axial distance above the burner in the $30 \mathrm{~cm}$ methanol pool fire. The expanded combined uncertainty of the mean gas velocity $\left(U_{c}\left(\bar{V}_{g}\right)\right)$ is also shown in which the uncertainty represents a $95 \%$ confidence interval.

\begin{tabular}{ccccccc}
\hline $\begin{array}{c}\boldsymbol{z} \\
{[\mathbf{c m}]}\end{array}$ & $\begin{array}{c}\boldsymbol{r} \\
{[\mathbf{c m}]}\end{array}$ & $\begin{array}{c}\overline{\boldsymbol{V}}_{\boldsymbol{g}} \\
{[\mathbf{m} / \mathbf{s}]}\end{array}$ & $\begin{array}{c}\boldsymbol{\sigma}_{\boldsymbol{V}_{\boldsymbol{g}}} \\
{[\mathbf{m} / \mathbf{s}]}\end{array}$ & $\begin{array}{c}\boldsymbol{U}_{\boldsymbol{c}}\left(\overline{\boldsymbol{V}}_{\boldsymbol{g}}\right) \\
{[\%]}\end{array}$ & $\begin{array}{c}\text { Pressure } \\
\text { Transducer, } \\
\boldsymbol{N}\end{array}$ & $\begin{array}{c}\text { Repeated } \\
\text { Measurements, } \\
\boldsymbol{M}\end{array}$ \\
\hline 3 & 0 & 0.84 & 0.32 & 14 & 3 & 1 \\
5 & 0 & 1.08 & 0.37 & 11 & 3 & 1 \\
9 & 0 & 1.65 & 0.36 & 7 & 3 & 3 \\
19 & 0 & 2.36 & 0.45 & 10 & 3 & 3 \\
29 & 0 & 2.59 & 0.53 & 7 & 3 & 3 \\
41 & 0 & 2.59 & 0.53 & 5 & 3 & 1 \\
62 & 0 & 2.33 & 0.48 & 6 & 3 & 3 \\
92 & 0 & 2.15 & 0.42 & 21 & 3 & 4 \\
112 & 0 & 1.94 & 0.42 & 23 & 3 & 2 \\
\hline
\end{tabular}

\section{E.1.2 Ethanol Fire}

Table E2 shows the pooled mean gas velocity $\left(\bar{V}_{g}\right)$ and standard deviation $\left(\sigma_{V_{g}}\right)$ as a function of axial distance above the burner in the $30 \mathrm{~cm}$ ethanol pool fire. The expanded combined uncertainty of the mean gas velocity $\left(U_{c}\left(\bar{V}_{g}\right)\right)$ is also shown in which the uncertainty represents a $95 \%$ confidence interval.

Table E2. Pooled mean gas velocity $\left(\bar{V}_{g}\right)$ and standard deviation $\left(\sigma_{V_{g}}\right)$ as a function of axial distance above the burner in the $30 \mathrm{~cm}$ ethanol pool fire. The expanded combined uncertainty of the mean gas velocity $\left(U_{c}\left(\bar{V}_{g}\right)\right)$ is also shown in which the uncertainty represents a $95 \%$ confidence interval.

\begin{tabular}{|c|c|c|c|c|c|c|}
\hline $\begin{array}{c}z \\
{[\mathrm{~cm}]}\end{array}$ & $\begin{array}{c}r \\
{[\mathrm{~cm}]}\end{array}$ & $\begin{array}{c}\bar{V}_{g} \\
{[\mathbf{m} / \mathbf{s}]}\end{array}$ & $\begin{array}{c}\sigma_{V_{g}} \\
{[\mathrm{~m} / \mathrm{s}]}\end{array}$ & $\begin{array}{c}\boldsymbol{U}_{\boldsymbol{c}}\left(\overline{\boldsymbol{V}}_{\boldsymbol{g}}\right) \\
{[\%]}\end{array}$ & $\begin{array}{c}\text { Pressure } \\
\text { Transducer, } \\
N_{N}\end{array}$ & $\begin{array}{c}\text { Repeated } \\
\text { Measurements, } \\
M\end{array}$ \\
\hline 2 & 0 & 0.49 & 0.20 & 63 & 2 & 3 \\
\hline 4 & 1 & 0.82 & 0.27 & 25 & 2 & 5 \\
\hline 6 & 2 & 1.21 & 0.35 & 13 & 3 & 5 \\
\hline 10 & 3 & 1.75 & 0.33 & 13 & 3 & 6 \\
\hline 14 & 4 & 2.12 & 0.32 & 9 & 3 & 7 \\
\hline 20 & 5 & 2.56 & 0.36 & 8 & 3 & 7 \\
\hline
\end{tabular}

----- Table E2 Continued on Next Page ----- 


\begin{tabular}{ccccccc}
\hline $\begin{array}{c}\boldsymbol{Z} \\
{[\mathbf{c m}]}\end{array}$ & $\begin{array}{c}\boldsymbol{r} \\
{[\mathbf{c m}]}\end{array}$ & $\begin{array}{c}\overline{\boldsymbol{V}}_{\boldsymbol{g}} \\
{[\mathbf{m} / \mathbf{s}]}\end{array}$ & $\begin{array}{c}\boldsymbol{\sigma}_{\boldsymbol{V}_{\boldsymbol{g}}} \\
{[\mathbf{m} / \mathbf{s}]}\end{array}$ & $\begin{array}{c}\boldsymbol{U}_{\boldsymbol{c}}\left(\overline{\boldsymbol{V}}_{\boldsymbol{g}}\right) \\
{[\boldsymbol{\%}]}\end{array}$ & $\begin{array}{c}\text { Pressure } \\
\text { Transducer, } \\
\boldsymbol{N}\end{array}$ & $\begin{array}{c}\text { Repeated } \\
\text { Measurements, } \\
\boldsymbol{M}\end{array}$ \\
\hline 30 & 6 & 2.84 & 0.46 & 17 & 3 & 7 \\
45 & 7 & 3.04 & 0.49 & 16 & 3 & 7 \\
60 & 8 & 3.02 & 0.45 & 14 & 3 & 7 \\
75 & 9 & 2.87 & 0.43 & 13 & 3 & 7 \\
90 & 10 & 2.81 & 0.40 & 14 & 3 & 5 \\
100 & 11 & 2.63 & 0.41 & 8 & 3 & 2 \\
\hline
\end{tabular}

\section{E.1.3 Acetone Fire}

Table E3 shows the pooled mean gas velocity $\left(\bar{V}_{g}\right)$ and standard deviation $\left(\sigma_{V_{g}}\right)$ as a function of axial distance above the burner in the $30 \mathrm{~cm}$ acetone pool fire. The expanded combined uncertainty of the mean gas velocity $\left(U_{c}\left(\bar{V}_{g}\right)\right)$ is also shown in which the uncertainty represents a $95 \%$ confidence interval.

Table E3. Pooled mean gas velocity $\left(\bar{V}_{g}\right)$ and standard deviation $\left(\sigma_{V_{g}}\right)$ as a function of axial distance above the burner in the $30 \mathrm{~cm}$ acetone pool fire. The expanded combined uncertainty of the mean gas velocity $\left(U_{c}\left(\bar{V}_{g}\right)\right)$ is also shown in which the uncertainty represents a $95 \%$ confidence interval.

\begin{tabular}{|c|c|c|c|c|c|c|}
\hline $\begin{array}{c}Z \\
{[\mathbf{c m}]}\end{array}$ & $\begin{array}{c}r \\
{[\mathrm{~cm}]}\end{array}$ & $\begin{array}{c}\bar{V}_{g} \\
{[\mathrm{~m} / \mathrm{s}]}\end{array}$ & $\begin{array}{c}\sigma_{V_{g}} \\
{[\mathbf{m} / \mathbf{s}]}\end{array}$ & $\begin{array}{c}U_{\boldsymbol{c}}\left(\overline{\boldsymbol{V}}_{\boldsymbol{g}}\right) \\
{[\%]}\end{array}$ & $\begin{array}{c}\text { Pressure } \\
\text { Transducer, } \\
N_{N}\end{array}$ & $\begin{array}{c}\text { Repeated } \\
\text { Measurements, } \\
M\end{array}$ \\
\hline 2 & 0 & 0.41 & 0.17 & 84 & 2 & 1 \\
\hline 6 & 0 & 0.79 & 0.25 & 9 & 2 & 1 \\
\hline 10 & 0 & 1.55 & 0.33 & 10 & 3 & 2 \\
\hline 14 & 0 & 1.99 & 0.31 & 8 & 3 & 2 \\
\hline 20 & 0 & 2.57 & 0.28 & 15 & 3 & 2 \\
\hline 30 & 0 & 2.92 & 0.46 & 18 & 3 & 2 \\
\hline 32 & 0 & 3.10 & 0.44 & 6 & 3 & 2 \\
\hline 34 & 0 & 3.15 & 0.44 & 16 & 3 & 2 \\
\hline 36 & 0 & 3.24 & 0.47 & 19 & 3 & 2 \\
\hline 40 & 0 & 3.29 & 0.53 & 19 & 3 & 2 \\
\hline 44 & 0 & 3.45 & 0.54 & 15 & 3 & 2 \\
\hline 45 & 0 & 3.43 & 0.52 & 5 & 3 & 1 \\
\hline 50 & 0 & 3.48 & 0.59 & 15 & 3 & 2 \\
\hline 60 & 0 & 3.47 & 0.63 & 11 & 3 & 2 \\
\hline 75 & 0 & 3.21 & 0.70 & 5 & 3 & 2 \\
\hline 90 & 0 & 3.20 & 0.59 & 27 & 3 & 2 \\
\hline 105 & 0 & 2.81 & 0.56 & 7 & 3 & 2 \\
\hline 130 & 0 & 2.67 & 0.52 & 15 & 3 & 2 \\
\hline
\end{tabular}




\section{E.1.4 Heptane Fire}

Table E4 shows the pooled mean gas velocity $\left(\bar{V}_{g}\right)$ and standard deviation $\left(\sigma_{V_{g}}\right)$ as a function of axial distance above the burner in the $30 \mathrm{~cm}$ heptane pool fire. The expanded combined uncertainty of the mean gas velocity $\left(U_{c}\left(\bar{V}_{g}\right)\right)$ is also shown in which the uncertainty represents a $95 \%$ confidence interval.

Table E4. Pooled mean gas velocity $\left(\bar{V}_{g}\right)$ and standard deviation $\left(\sigma_{V_{g}}\right)$ as a function of axial distance above the burner in the $30 \mathrm{~cm}$ heptane pool fire. The expanded combined uncertainty of the mean gas velocity $\left(U_{c}\left(\bar{V}_{g}\right)\right)$ is also shown in which the uncertainty represents a $95 \%$ confidence interval.

\begin{tabular}{ccccccc}
\hline $\begin{array}{c}\boldsymbol{Z} \\
{[\mathbf{c m}]}\end{array}$ & $\begin{array}{c}\boldsymbol{r} \\
{[\mathbf{c m}]}\end{array}$ & $\begin{array}{c}\overline{\boldsymbol{V}}_{\boldsymbol{g}} \\
{[\mathbf{m} / \mathbf{s}]}\end{array}$ & $\begin{array}{c}\boldsymbol{\sigma}_{\boldsymbol{V}_{\boldsymbol{g}}} \\
{[\mathbf{m} / \mathbf{s}]}\end{array}$ & $\begin{array}{c}\boldsymbol{U}_{\boldsymbol{c}}\left(\overline{\boldsymbol{V}}_{\boldsymbol{g}}\right) \\
{[\boldsymbol{\%}]}\end{array}$ & $\begin{array}{c}\text { Pressure } \\
\text { Transducer, } \\
\boldsymbol{N}\end{array}$ & $\begin{array}{c}\text { Repeated } \\
\text { Measurements, } \\
\boldsymbol{M}\end{array}$ \\
\hline 32 & 0 & 3.08 & 0.31 & 6 & 3 & 2 \\
40 & 1 & 3.42 & 0.44 & 6 & 3 & 3 \\
50 & 2 & 3.70 & 0.54 & 5 & 3 & 1 \\
60 & 3 & 3.76 & 0.70 & 5 & 3 & 1 \\
70 & 4 & 3.71 & 0.80 & 5 & 3 & 1 \\
90 & 5 & 3.54 & 0.79 & 5 & 3 & 1 \\
100 & 6 & 3.38 & 0.75 & 5 & 3 & 1 \\
120 & 7 & 3.11 & 0.96 & 5 & 3 & 1 \\
130 & 8 & 2.67 & 0.83 & 5 & 3 & 1 \\
140 & 9 & 2.44 & 0.68 & 5 & 3 & 1 \\
\hline
\end{tabular}

\section{E.1.5 Methane Fire}

Table E5 shows the pooled mean gas velocity $\left(\bar{V}_{g}\right)$ and standard deviation $\left(\sigma_{V_{g}}\right)$ as a function of axial distance above the burner in the $37 \mathrm{~cm}$ methane gas fire. The expanded combined uncertainty of the mean gas velocity $\left(U_{c}\left(\bar{V}_{g}\right)\right)$ is also shown in which the uncertainty represents a $95 \%$ confidence interval.

Table E5. Pooled mean gas velocity $\left(\bar{V}_{g}\right)$ and standard deviation $\left(\sigma_{V_{g}}\right)$ as a function of axial distance above the burner in the methane gas fire. The expanded combined uncertainty of the mean gas velocity $\left(U_{c}\left(\bar{V}_{g}\right)\right)$ is also shown in which the uncertainty represents a $95 \%$ confidence interval.

\begin{tabular}{ccccccc}
\hline $\begin{array}{c}\boldsymbol{Z} \\
{[\mathbf{c m}]}\end{array}$ & $\begin{array}{c}\boldsymbol{r} \\
{[\mathbf{c m}]}\end{array}$ & $\begin{array}{c}\overline{\boldsymbol{V}}_{\boldsymbol{g}} \\
{[\mathbf{m} / \mathbf{s}]}\end{array}$ & $\begin{array}{c}\boldsymbol{\sigma}_{\boldsymbol{V}_{\boldsymbol{g}}} \\
{[\mathbf{m} / \mathbf{s}]}\end{array}$ & $\begin{array}{c}\boldsymbol{U}_{\boldsymbol{c}}\left(\overline{\boldsymbol{V}}_{\boldsymbol{g}}\right) \\
{[\boldsymbol{\%}]}\end{array}$ & $\begin{array}{c}\text { Pressure } \\
\text { Transducer, }\end{array}$ & $\begin{array}{c}\text { Repeated } \\
\text { Measurements, } \\
\boldsymbol{M}\end{array}$ \\
\hline 4 & 0 & 0.64 & 0.21 & 5 & 1 & 1 \\
10 & 0 & 1.65 & 0.33 & 5 & 1 & 1 \\
20 & 0 & 2.63 & 0.46 & 5 & 1 & 1 \\
21 & 0 & 2.70 & 0.48 & 5 & 1 & 1 \\
23 & 0 & 2.77 & 0.50 & 5 & 1 & 1 \\
\hline
\end{tabular}

----- Table E5 Continued on Next Page ----- 


\begin{tabular}{ccccccc}
\hline $\begin{array}{c}\boldsymbol{Z} \\
{[\mathbf{c m}]}\end{array}$ & $\begin{array}{c}\boldsymbol{r} \\
{[\mathbf{c m}]}\end{array}$ & $\begin{array}{c}\overline{\boldsymbol{V}}_{\boldsymbol{g}} \\
{[\mathbf{m} / \mathbf{s}]}\end{array}$ & $\begin{array}{c}\boldsymbol{\sigma}_{\boldsymbol{V}_{\boldsymbol{g}}} \\
{[\mathbf{m} / \mathbf{s}]}\end{array}$ & $\begin{array}{c}\boldsymbol{U}_{\boldsymbol{c}}\left(\overline{\boldsymbol{V}}_{\boldsymbol{g}}\right) \\
{[\boldsymbol{\%}]}\end{array}$ & $\begin{array}{c}\text { Pressure } \\
\text { Transducer, } \\
\boldsymbol{N}\end{array}$ & $\begin{array}{c}\text { Repeated } \\
\text { Measurements, } \\
\boldsymbol{M}\end{array}$ \\
\hline 25 & 0 & 2.88 & 0.55 & 5 & 1 & 1 \\
29 & 0 & 3.09 & 0.51 & 5 & 1 & 1 \\
30 & 0 & 3.15 & 0.63 & 5 & 1 & 1 \\
33 & 0 & 3.25 & 0.51 & 5 & 1 & 1 \\
39 & 0 & 3.37 & 0.54 & 5 & 1 & 1 \\
45 & 0 & 3.41 & 0.46 & 5 & 1 & 1 \\
60 & 0 & 3.44 & 0.51 & 9 & 1 & 2 \\
75 & 0 & 3.23 & 0.56 & 7 & 1 & 2 \\
88 & 0 & 3.07 & 0.57 & 5 & 1 & 1 \\
\hline
\end{tabular}

\section{E.1.6 Propane Fires}

\section{E.1.6.1 The $21 \mathrm{~kW}$ Fire}

Table E6 shows the pooled mean gas velocity $\left(\bar{V}_{g}\right)$ and standard deviation $\left(\sigma_{V_{g}}\right)$ as a function of axial distance above the burner in the $21 \mathrm{~kW}$ propane gas fire. The expanded combined uncertainty of the mean gas velocity $\left(U_{c}\left(\bar{V}_{g}\right)\right)$ is also shown in which the uncertainty represents a $95 \%$ confidence interval.

Table E6. Pooled mean gas velocity $\left(\bar{V}_{g}\right)$ and standard deviation $\left(\sigma_{V_{g}}\right)$ as a function of axial distance above the burner in the $21 \mathrm{~kW}$ propane gas fire. The expanded combined uncertainty of the mean gas velocity $\left(U_{c}\left(\bar{V}_{g}\right)\right)$ is also shown in which the uncertainty represents a $95 \%$ confidence interval.

\begin{tabular}{ccccccc}
\hline $\begin{array}{c}\boldsymbol{z} \\
{[\mathbf{c m}]}\end{array}$ & $\begin{array}{c}\boldsymbol{r} \\
{[\mathbf{c m}]}\end{array}$ & $\begin{array}{c}\overline{\boldsymbol{V}}_{\boldsymbol{g}} \\
{[\mathbf{m} / \mathbf{s}]}\end{array}$ & $\begin{array}{c}\boldsymbol{\sigma}_{\boldsymbol{V}_{\boldsymbol{g}}} \\
{[\mathbf{m} / \mathbf{s}]}\end{array}$ & $\begin{array}{c}\boldsymbol{U}_{\boldsymbol{c}}\left(\overline{\boldsymbol{V}}_{\boldsymbol{g}}\right) \\
{[\boldsymbol{\%}]}\end{array}$ & $\begin{array}{c}\text { Pressure } \\
\text { Transducer, }\end{array}$ & $\begin{array}{c}\text { Repeated } \\
\text { Measurements, } \\
\boldsymbol{M}\end{array}$ \\
\hline 4 & 0 & 0.51 & 0.25 & 96 & 3 & 2 \\
6 & 0 & 0.93 & 0.27 & 24 & 3 & 2 \\
10 & 0 & 1.62 & 0.24 & 12 & 3 & 2 \\
14 & 0 & 2.12 & 0.24 & 10 & 3 & 2 \\
20 & 0 & 2.61 & 0.31 & 11 & 3 & 3 \\
24 & 0 & 2.78 & 0.37 & 7 & 1 & 3 \\
30 & 0 & 2.87 & 0.45 & 9 & 3 & 3 \\
40 & 0 & 2.99 & 0.52 & 6 & 3 & 10 \\
45 & 0 & 2.98 & 0.52 & 13 & 3 & 9 \\
60 & 0 & 2.80 & 0.49 & 7 & 3 & 6 \\
75 & 0 & 2.69 & 0.44 & 7 & 3 & 4 \\
100 & 0 & 2.42 & 0.39 & 7 & 3 & \\
\hline
\end{tabular}




\section{E.1.6.2 The $34 \mathrm{~kW}$ Fire}

Table E7 shows the pooled mean gas velocity $\left(\bar{V}_{g}\right)$ and standard deviation $\left(\sigma_{V_{g}}\right)$ as a function of axial distance above the burner in the $34 \mathrm{~kW}$ propane gas fire. The expanded combined uncertainty of the mean gas velocity $\left(U_{c}\left(\bar{V}_{g}\right)\right)$ is also shown in which the uncertainty represents a $95 \%$ confidence interval.

Table E7. Pooled mean gas velocity $\left(\bar{V}_{g}\right)$ and standard deviation $\left(\sigma_{V_{g}}\right)$ as a function of axial distance above the burner in the $34 \mathrm{~kW}$ propane gas fire. The expanded combined uncertainty of the mean gas velocity $\left(U_{c}\left(\bar{V}_{g}\right)\right)$ is also shown in which the uncertainty represents a $95 \%$ confidence interval.

\begin{tabular}{ccccccc}
\hline $\begin{array}{c}\boldsymbol{z} \\
{[\mathbf{c m}]}\end{array}$ & $\begin{array}{c}\boldsymbol{r} \\
{[\mathbf{c m}]}\end{array}$ & $\begin{array}{c}\overline{\boldsymbol{V}}_{\boldsymbol{g}} \\
{[\mathbf{m} / \mathbf{s}]}\end{array}$ & $\begin{array}{c}\boldsymbol{\sigma}_{\boldsymbol{V}_{\boldsymbol{g}}} \\
{[\mathbf{m} / \mathbf{s}]}\end{array}$ & $\begin{array}{c}\boldsymbol{U}_{\boldsymbol{c}}\left(\overline{\boldsymbol{V}}_{\boldsymbol{g}}\right) \\
{[\boldsymbol{\%}]}\end{array}$ & $\begin{array}{c}\text { Pressure } \\
\text { Transducer, }\end{array}$ & $\begin{array}{c}\text { Repeated } \\
\text { Measurements, } \\
\boldsymbol{M}\end{array}$ \\
\hline 4 & 0 & 0.38 & 0.17 & 5 & 1 & 1 \\
6 & 1 & 0.63 & 0.21 & 5 & 1 & 1 \\
10 & 2 & 1.13 & 0.18 & 5 & 1 & 1 \\
14 & 3 & 1.52 & 0.20 & 5 & 1 & 1 \\
20 & 4 & 2.27 & 0.72 & 37 & 1 & 3 \\
24 & 5 & 2.78 & 0.53 & 6 & 2 & 8 \\
26 & 6 & 2.95 & 0.34 & 5 & 1 & 6 \\
30 & 7 & 3.04 & 0.84 & 6 & 1 & 6 \\
34 & 8 & 3.24 & 0.53 & 8 & 2 & 7 \\
45 & 9 & 3.41 & 0.60 & 6 & 2 & 8 \\
60 & 10 & 3.36 & 0.66 & 7 & 2 & 5 \\
75 & 11 & 3.14 & 0.59 & 7 & 3 & 5 \\
100 & 12 & 2.90 & 0.72 & 9 & 3 & 10 \\
115 & 13 & 2.69 & 0.67 & 14 & 3 & \\
\hline
\end{tabular}

\section{E.2 Gas Temperature Uncertainty Methodology}

The measured instantaneous thermocouple bead temperature $\left(T_{b}(t)\right)$ is corrected to determine the gas temperature, considering the thermal inertia and radiative loss of the thermocouple. The gas temperature $\left(T_{g}(t)\right)$ is related to the sum of the thermocouple measurement $\left(T_{b}(t)\right)$, the thermal inertia correction term $\left(T_{\text {the }}(t)\right)$ and the radiative loss correction term $\left(T_{\text {rad }}(t)\right)$ :

$$
T_{g}(t)=T_{b}(t)+T_{\text {the }}(t)+T_{\text {rad }}(t)=T_{b}(t)+\tau \frac{d T_{b}(t)}{d t}+\frac{\epsilon \sigma}{h}\left(T_{b}^{4}(t)-T_{\text {surr }}^{4}\right)
$$

The thermal inertia correction term has a negligible influence on the mean gas temperature, but does amplify the value of the instantaneous temperature extremes and impact the RMS calculation [8, 30]. For these reasons, the uncertainties of the mean and RMS of the gas temperature are independently analyzed. Details of the uncertainty methodology for the gas temperature are described in Ref. [19]. Here, a summary is provided. 
In this study, the gas temperature was measured using many kinds of fine-wire, bare-bead, platinum thermocouples with different data acquisition rates as listed in Table 1. The measurements were typically repeated 2 to 3 times and as often as 10 times.

- The pooled mean gas temperature at a particular measurement position $\left(\bar{T}_{g}\right)$ is estimated by averaging the mean temperatures from all of the thermocouple measurements: $\bar{T}_{g}=\sum_{n=1}^{N} \bar{T}_{g, n} / N$, where $n$ is the index of the thermocouple and $N$ is the total number of thermocouple measurements at the particular measurement location.

- The pooled RMS of the gas temperature $\left(\sigma_{T_{g}}\right)$ is estimated by taking the RMS of the $N$ standard deviation values of the gas temperature time series datasets at a particular measurement location: $\sigma_{T_{g}}=\left[1 /{ }_{N} \sum_{n=1}^{N} \sigma_{T_{g, n}}^{2}\right]^{1 / 2}$.

The expanded combined uncertainty of the pooled mean gas temperature, $U_{c}\left(\bar{T}_{g}\right)$, is estimated as:

$$
U_{c}\left(\bar{T}_{g}\right)=2 \sqrt{u_{c}\left(\bar{T}_{b}\right)^{2}+u_{c}\left(\bar{T}_{\text {rad }}\right)^{2}+\sigma_{R}\left(\bar{T}_{g}\right)^{2}}
$$

where the uncertainty from the thermal inertia correction term was not considered since its contribution to the mean gas temperature is negligible. The expanded combined uncertainty of the pooled RMS of the corrected gas temperature, $U_{c}\left(\sigma_{T_{g}}\right)$, is estimated as:

$$
U_{c}\left(\sigma_{T_{g}}\right)=2 \sqrt{u_{c}\left(\sigma_{T_{\text {the }}}\right)^{2}+\sigma_{R}\left(\sigma_{T_{g}}\right)^{2}}
$$

In Eqs. E13 and E14, the term $\left(\sigma_{R}\right)$ represents the repeatability of each parameter in the replicate measurements, which is quantified by the standard deviation of the $N$ time series measurements of the mean $\left(\bar{T}_{g}\right)$ or the standard deviation $\left(\sigma_{T_{g}}\right)$ of the gas temperature, respectively. The uncertainties of $u_{c}\left(T_{b}\right), u_{c}\left(\bar{T}_{\text {rad }}\right)$ and $u_{c}\left(\sigma_{T_{\text {the }}}\right)$ are estimated considering the propagated error from the various terms in Eq. E12. Details of the uncertainty methodology for the gas temperature are described in Ref. [19]. The sections below present the results of the uncertainty analysis for each of fires considered in this report.

\section{E.2.1 Methanol Fire}

Table E8. Pooled mean and RMS of the gas temperature as a function of the axial distance above the burner in the $30 \mathrm{~cm}$ methanol pool fire; those expanded combined uncertainties are also shown in which uncertainty represents a $95 \%$ confidence interval.

\begin{tabular}{ccccccccc}
\hline $\begin{array}{c}\boldsymbol{Z} \\
{[\mathbf{c m}]}\end{array}$ & $\begin{array}{c}\boldsymbol{r} \\
{[\mathbf{c m}]}\end{array}$ & $\begin{array}{c}\overline{\boldsymbol{T}}_{\boldsymbol{b}} \\
{[\mathbf{K}]}\end{array}$ & $\begin{array}{c}\boldsymbol{\sigma}_{\boldsymbol{T}_{\boldsymbol{b}}} \\
{[\mathbf{K}]}\end{array}$ & $\begin{array}{c}\overline{\boldsymbol{T}}_{\boldsymbol{g}} \\
{[\mathbf{K}]}\end{array}$ & $\begin{array}{c}\boldsymbol{\sigma}_{\boldsymbol{T}_{\boldsymbol{g}}} \\
{[\mathbf{K}]}\end{array}$ & $\begin{array}{c}\boldsymbol{U}_{\boldsymbol{c}}\left(\overline{\boldsymbol{T}}_{\boldsymbol{g}}\right) \\
{[\boldsymbol{\%}]}\end{array}$ & $\begin{array}{c}\boldsymbol{U}_{\boldsymbol{c}}\left(\boldsymbol{\sigma}_{\boldsymbol{T}_{\boldsymbol{g}}}\right) \\
{[\boldsymbol{\%}]}\end{array}$ & $\begin{array}{c}\mathbf{T C s} \\
\boldsymbol{N}\end{array}$ \\
\hline-1 & 0 & 335 & 2 & 335 & 8 & 2 & 69 & 1 \\
0 & 0 & 919 & 266 & 922 & 293 & 8 & 39 & 1 \\
1 & 0 & 1062 & 266 & 1090 & 371 & 12 & 49 & 2 \\
2 & 0 & 1127 & 206 & 1145 & 370 & 7 & 50 & 1 \\
\hline
\end{tabular}

----- Table E8 Continued on Next Page ----- 


\begin{tabular}{|c|c|c|c|c|c|c|c|c|}
\hline $\begin{array}{c}z \\
{[\mathrm{~cm}]}\end{array}$ & $\begin{array}{c}r \\
{[\mathrm{~cm}]}\end{array}$ & $\begin{array}{c}\overline{\boldsymbol{T}}_{b} \\
{[\mathbf{K}]}\end{array}$ & $\begin{array}{l}\sigma_{T_{b}} \\
{[\mathrm{~K}]}\end{array}$ & $\begin{array}{c}\bar{T}_{g} \\
{[\mathbf{K}]}\end{array}$ & $\begin{array}{l}\sigma_{T_{g}} \\
{[\mathbf{K}]}\end{array}$ & $\begin{array}{c}U_{c}\left(\bar{T}_{g}\right) \\
{[\%]}\end{array}$ & $\begin{array}{c}U_{c}\left(\sigma_{T_{g}}\right) \\
{[\%]}\end{array}$ & $\begin{array}{c}\text { TCs } \\
N\end{array}$ \\
\hline 3 & 0 & 1196 & 308 & 1210 & 528 & 1 & 49 & 2 \\
\hline 4 & 0 & 1248 & 197 & 1273 & 340 & 3 & 43 & 1 \\
\hline 5 & 0 & 1268 & 321 & 1284 & 531 & 2 & 48 & 2 \\
\hline 6 & 0 & 1288 & 183 & 1315 & 312 & 3 & 37 & 1 \\
\hline 7 & 0 & 1280 & 337 & 1290 & 405 & 1 & 33 & 1 \\
\hline 9 & 0 & 1330 & 322 & 1355 & 685 & 2 & 53 & 1 \\
\hline 10 & 0 & 1266 & 269 & 1283 & 363 & 3 & 36 & 2 \\
\hline 13 & 0 & 1230 & 309 & 1238 & 393 & 2 & 36 & 1 \\
\hline 14 & 0 & 1223 & 270 & 1238 & 375 & 10 & 39 & 2 \\
\hline 19 & 0 & 1098 & 363 & 1112 & 791 & 9 & 70 & 1 \\
\hline 20 & 0 & 1085 & 281 & 1094 & 399 & 18 & 44 & 2 \\
\hline 29 & 0 & 856 & 341 & 862 & 729 & 2 & 79 & 1 \\
\hline 30 & 0 & 883 & 262 & 887 & 383 & 8 & 49 & 2 \\
\hline 33 & 0 & 836 & 299 & 838 & 404 & 2 & 51 & 1 \\
\hline 40 & 0 & 719 & 265 & 720 & 369 & 7 & 56 & 1 \\
\hline 41 & 0 & 626 & 245 & 628 & 529 & 1 & 75 & 1 \\
\hline 45 & 0 & 628 & 137 & 629 & 245 & 6 & 46 & 1 \\
\hline 50 & 0 & 594 & 208 & 595 & 285 & 6 & 56 & 1 \\
\hline 60 & 0 & 501 & 127 & 501 & 193 & 6 & 46 & 2 \\
\hline 62 & 0 & 449 & 124 & 450 & 268 & 5 & 57 & 1 \\
\hline 63 & 0 & 484 & 131 & 484 & 182 & 12 & 43 & 1 \\
\hline 90 & 0 & 403 & 67 & 403 & 97 & 5 & 37 & 1 \\
\hline 92 & 0 & 385 & 55 & 385 & 118 & 10 & 41 & 1 \\
\hline 110 & 0 & 377 & 45 & 377 & 63 & 2 & 34 & 1 \\
\hline 112 & 0 & 362 & 38 & 363 & 81 & 4 & 37 & 1 \\
\hline
\end{tabular}

Table E9. Pooled mean temperature as a function of the radial distance from the burner at $z=40 \mathrm{~cm}, 50$ $\mathrm{cm}$ and $60 \mathrm{~cm}$ in the $30 \mathrm{~cm}$ methanol pool fire. The expanded combined uncertainty is also shown in which uncertainty represents a $95 \%$ confidence interval.

\begin{tabular}{ccccccc}
\hline $\begin{array}{c}\boldsymbol{Z} \\
{[\mathbf{c m}]}\end{array}$ & $\begin{array}{c}\boldsymbol{r} \\
{[\mathbf{c m}]}\end{array}$ & $\begin{array}{c}\overline{\boldsymbol{T}}_{\boldsymbol{b}} \\
{[\mathbf{K}]}\end{array}$ & $\begin{array}{c}\boldsymbol{\sigma}_{\boldsymbol{T}_{\boldsymbol{b}}} \\
{[\mathbf{K}]}\end{array}$ & $\begin{array}{c}\overline{\boldsymbol{T}}_{\boldsymbol{g}} \\
{[\mathbf{K}]}\end{array}$ & $\begin{array}{c}\boldsymbol{U}_{\boldsymbol{c}}\left(\overline{\boldsymbol{T}}_{\boldsymbol{g}}\right) \\
{[\boldsymbol{\%}]}\end{array}$ & $\begin{array}{c}\mathbf{T C s}, \\
\boldsymbol{N}\end{array}$ \\
\hline 40 & -4 & 656 & 256 & 659 & 1 & 1 \\
40 & -2 & 727 & 258 & 730 & 1 & 1 \\
40 & 2 & 730 & 221 & 732 & 1 & 1 \\
40 & 4 & 655 & 213 & 657 & 1 & 1 \\
40 & 6 & 586 & 209 & 588 & 1 & 1 \\
40 & 8 & 530 & 179 & 530 & 1 & 1 \\
40 & 10 & 504 & 179 & 504 & 1 & 1 \\
\hline
\end{tabular}

----- Table E9 Continued on Next Page -----

45

This publication is available free of charge from: https://doi.org/10.6028/NIST.TN.2162 


\begin{tabular}{|c|c|c|c|c|c|c|}
\hline $\begin{array}{c}z \\
{[\mathrm{~cm}]}\end{array}$ & $\begin{array}{c}r \\
{[\mathrm{~cm}]}\end{array}$ & $\begin{array}{c}\overline{\boldsymbol{T}}_{\boldsymbol{b}} \\
{[\mathbf{K}]}\end{array}$ & $\begin{array}{l}\sigma_{T_{b}} \\
{[\mathbf{K}]}\end{array}$ & $\begin{array}{c}\overline{\boldsymbol{T}}_{\boldsymbol{g}} \\
{[\mathbf{K}]}\end{array}$ & $\begin{array}{c}U_{c}\left(\bar{T}_{g}\right) \\
{[\%]}\end{array}$ & $\begin{array}{c}\text { TCs, } \\
N\end{array}$ \\
\hline 40 & 12 & 461 & 153 & 462 & 1 & 1 \\
\hline 40 & 14 & 455 & 162 & 455 & 1 & 1 \\
\hline 40 & 16 & 404 & 133 & 404 & 1 & 1 \\
\hline 40 & 18 & 384 & 121 & 384 & 1 & 1 \\
\hline 50 & -4 & 558 & 178 & 559 & 1 & 1 \\
\hline 50 & -2 & 620 & 196 & 621 & 1 & 1 \\
\hline 50 & 2 & 602 & 169 & 603 & 1 & 1 \\
\hline 50 & 4 & 573 & 173 & 574 & 1 & 1 \\
\hline 50 & 6 & 539 & 162 & 539 & 1 & 1 \\
\hline 50 & 8 & 495 & 146 & 495 & 1 & 1 \\
\hline 50 & 10 & 458 & 135 & 458 & 1 & 1 \\
\hline 50 & 12 & 473 & 146 & 473 & 1 & 1 \\
\hline 50 & 14 & 416 & 120 & 416 & 1 & 1 \\
\hline 50 & 16 & 406 & 119 & 406 & 1 & 1 \\
\hline 60 & -4 & 486 & 142 & 487 & 1 & 1 \\
\hline 60 & -2 & 521 & 135 & 522 & 1 & 1 \\
\hline 60 & 2 & 532 & 135 & 533 & 1 & 1 \\
\hline 60 & 4 & 520 & 130 & 520 & 1 & 1 \\
\hline 60 & 6 & 489 & 132 & 489 & 1 & 1 \\
\hline 60 & 8 & 469 & 117 & 470 & 1 & 1 \\
\hline 60 & 10 & 440 & 103 & 440 & 1 & 1 \\
\hline 60 & 12 & 421 & 94 & 421 & 1 & 1 \\
\hline 60 & 14 & 394 & 83 & 394 & 1 & 1 \\
\hline 60 & 16 & 377 & 74 & 377 & 1 & 1 \\
\hline
\end{tabular}

\section{E.2.2 Acetone Fire}

Table E10. Pooled mean temperature as a function of the axial distance above the burner in the $30 \mathrm{~cm}$ acetone pool fire. The expanded combined uncertainty is also shown in which uncertainty represents a $95 \%$ confidence interval.

\begin{tabular}{ccccccc}
\hline $\begin{array}{c}\boldsymbol{z} \\
{[\mathbf{c m}]}\end{array}$ & $\begin{array}{c}\boldsymbol{r} \\
{[\mathbf{c m}]}\end{array}$ & $\begin{array}{c}\overline{\boldsymbol{T}}_{\boldsymbol{b}} \\
{[\mathbf{K}]}\end{array}$ & $\begin{array}{c}\boldsymbol{\sigma}_{\boldsymbol{T}_{\boldsymbol{b}}} \\
{[\mathbf{K}]}\end{array}$ & $\begin{array}{c}\overline{\boldsymbol{T}}_{\boldsymbol{g}} \\
{[\mathbf{K}]}\end{array}$ & $\begin{array}{c}\boldsymbol{U}_{\boldsymbol{c}}\left(\overline{\boldsymbol{T}}_{\boldsymbol{g}}\right) \\
{[\boldsymbol{\%}]}\end{array}$ & $\begin{array}{c}\mathbf{T C s} \\
\boldsymbol{N}\end{array}$ \\
\hline 2 & 0 & 684 & 87 & 686 & 13 & 3 \\
4 & 0 & 818 & 141 & 821 & 21 & 2 \\
6 & 0 & 901 & 145 & 905 & 10 & 3 \\
8 & 0 & 916 & 136 & 949 & 8 & 1 \\
10 & 0 & 1068 & 154 & 1075 & 11 & 3 \\
14 & 0 & 1165 & 162 & 1174 & 6 & 2 \\
15 & 0 & 1158 & 134 & 1168 & 7 & 1
\end{tabular}




\begin{tabular}{ccccccc}
\hline $\begin{array}{c}\boldsymbol{Z} \\
{[\mathbf{c m}]}\end{array}$ & $\begin{array}{c}\boldsymbol{r} \\
{[\mathbf{c m}]}\end{array}$ & $\begin{array}{c}\overline{\boldsymbol{T}}_{\boldsymbol{b}} \\
{[\mathbf{K}]}\end{array}$ & $\begin{array}{c}\boldsymbol{\sigma}_{\boldsymbol{T}_{\boldsymbol{b}}} \\
{[\mathbf{K}]}\end{array}$ & $\begin{array}{c}\overline{\boldsymbol{T}}_{\boldsymbol{g}} \\
{[\mathbf{K}]}\end{array}$ & $\begin{array}{c}\boldsymbol{U}_{\boldsymbol{c}}\left(\overline{\boldsymbol{T}}_{\boldsymbol{g}}\right) \\
{[\boldsymbol{\%}]}\end{array}$ & $\begin{array}{c}\text { TCs } \\
\boldsymbol{N}\end{array}$ \\
\hline 20 & 0 & 1204 & 139 & 1215 & 8 & 3 \\
30 & 0 & 1163 & 186 & 1172 & 13 & 3 \\
32 & 0 & 1121 & 250 & 1131 & 2 & 1 \\
34 & 0 & 1114 & 253 & 1124 & 13 & 1 \\
36 & 0 & 1103 & 261 & 1113 & 18 & 1 \\
40 & 0 & 1098 & 243 & 1107 & 19 & 2 \\
44 & 0 & 1015 & 277 & 1023 & 7 & 1 \\
45 & 0 & 1050 & 242 & 1058 & 7 & 2 \\
50 & 0 & 1020 & 253 & 1028 & 23 & 2 \\
60 & 0 & 906 & 234 & 911 & 15 & 3 \\
75 & 0 & 687 & 213 & 689 & 1 & 1 \\
90 & 0 & 604 & 159 & 605 & 22 & 1 \\
100 & 0 & 598 & 129 & 598 & 6 & 1 \\
105 & 0 & 502 & 95 & 503 & 5 & 1 \\
130 & 0 & 429 & 54 & 429 & 10 & 1 \\
\hline
\end{tabular}

\section{E.2.3 Ethanol Fire}

Table E11. Pooled mean temperature as a function of the axial distance above the burner in the $30 \mathrm{~cm}$ ethanol pool fire. The expanded combined uncertainty is also shown in which uncertainty represents a $95 \%$ confidence interval.

\begin{tabular}{|c|c|c|c|c|c|c|}
\hline $\begin{array}{c}z \\
{[\mathrm{~cm}]}\end{array}$ & $\begin{array}{c}r \\
{[\mathrm{~cm}]}\end{array}$ & $\begin{array}{c}\overline{\boldsymbol{T}}_{\boldsymbol{b}} \\
{[\mathbf{K}]}\end{array}$ & $\begin{array}{l}\sigma_{T_{b}} \\
{[\mathbf{K}]}\end{array}$ & $\begin{array}{c}\bar{T}_{g} \\
{[\mathbf{K}]}\end{array}$ & $\begin{array}{c}U_{c}\left(\bar{T}_{g}\right) \\
{[\%]}\end{array}$ & $\begin{array}{c}\text { TCs } \\
N\end{array}$ \\
\hline 1 & 0 & 839 & 185 & 845 & 3 & 1 \\
\hline 2 & 0 & 945 & 188 & 951 & 4 & 2 \\
\hline 4 & 0 & 1108 & 181 & 1121 & 11 & 2 \\
\hline 6 & 0 & 1197 & 186 & 1214 & 7 & 2 \\
\hline 10 & 0 & 1252 & 176 & 1271 & 7 & 2 \\
\hline 14 & 0 & 1260 & 174 & 1278 & 5 & 2 \\
\hline 20 & 0 & 1222 & 200 & 1239 & 4 & 2 \\
\hline 30 & 0 & 1031 & 237 & 1041 & 16 & 2 \\
\hline 45 & 0 & 783 & 212 & 786 & 15 & 2 \\
\hline 60 & 0 & 606 & 146 & 607 & 14 & 2 \\
\hline 75 & 0 & 503 & 99 & 503 & 11 & 1 \\
\hline 90 & 0 & 454 & 63 & 454 & 8 & 1 \\
\hline 100 & 0 & 430 & 50 & 430 & 3 & 1 \\
\hline
\end{tabular}




\section{E.2.4 Heptane Fire}

Table E12. Pooled mean gas temperature near the downstream face of the probe as a function of axial distance above the burner in the $30 \mathrm{~cm}$ heptane pool fire. The expanded combined uncertainty is also shown in which the uncertainty represents a $95 \%$ confidence interval.

\begin{tabular}{ccccccc}
\hline $\begin{array}{c}\boldsymbol{Z} \\
{[\mathbf{c m}]}\end{array}$ & $\begin{array}{c}\boldsymbol{r} \\
{[\mathbf{c m}]}\end{array}$ & $\begin{array}{c}\overline{\boldsymbol{T}}_{\boldsymbol{b}} \\
{[\mathbf{K}]}\end{array}$ & $\begin{array}{c}\boldsymbol{\sigma}_{\boldsymbol{T}_{\boldsymbol{b}}} \\
{[\mathbf{K}]}\end{array}$ & $\begin{array}{c}\overline{\boldsymbol{T}}_{\boldsymbol{g}} \\
{[\mathbf{K}]}\end{array}$ & $\begin{array}{c}\boldsymbol{U}_{\boldsymbol{c}}\left(\overline{\boldsymbol{T}}_{\boldsymbol{g}}\right) \\
{[\boldsymbol{\%}]}\end{array}$ & $\begin{array}{c}\text { TCs } \\
\boldsymbol{N}\end{array}$ \\
\hline 32 & 0 & 1190 & 183 & 1202 & 4 & 1 \\
40 & 0 & 1156 & 228 & 1166 & 3 & 1 \\
50 & 0 & 1128 & 257 & 1138 & 1 & 1 \\
60 & 0 & 1034 & 300 & 1042 & 1 & 1 \\
70 & 0 & 968 & 318 & 975 & 1 & 1 \\
90 & 0 & 787 & 234 & 790 & 1 & 1 \\
100 & 0 & 689 & 187 & 691 & 1 & 1 \\
120 & 0 & 562 & 153 & 563 & 1 & 1 \\
130 & 0 & 499 & 121 & 500 & 1 & 1 \\
140 & 0 & 460 & 96 & 460 & 1 & 1 \\
\hline
\end{tabular}

\section{E.2.5 Methane Fire}

Table E13. Pooled mean temperature as a function of the axial distance above the burner in the methane gas fire. The expanded combined uncertainty is also shown in which uncertainty represents a $95 \%$ confidence interval.

\begin{tabular}{|c|c|c|c|c|c|c|}
\hline $\begin{array}{c}z \\
{[\mathrm{~cm}]}\end{array}$ & $\begin{array}{c}r \\
{[\mathrm{~cm}]}\end{array}$ & $\begin{array}{c}\bar{T}_{b} \\
{[\mathbf{K}]}\end{array}$ & $\begin{array}{l}\sigma_{T_{b}} \\
{[\mathbf{K}]}\end{array}$ & $\begin{array}{c}\bar{T}_{g} \\
{[\mathbf{K}]}\end{array}$ & $\begin{array}{c}U_{c}\left(\bar{T}_{g}\right) \\
{[\%]}\end{array}$ & $\begin{array}{c}\text { TCs } \\
N\end{array}$ \\
\hline 1 & 0 & 784 & 227 & 787 & 5 & 2 \\
\hline 2 & 0 & 969 & 255 & 975 & 1 & 2 \\
\hline 4 & 0 & 1108 & 247 & 1118 & 2 & 3 \\
\hline 6 & 0 & 1200 & 237 & 1211 & 2 & 2 \\
\hline 10 & 0 & 1314 & 228 & 1330 & 2 & 3 \\
\hline 14 & 0 & 1334 & 223 & 1347 & 3 & 2 \\
\hline 20 & 0 & 1321 & 230 & 1336 & 4 & 3 \\
\hline 21 & 0 & 1274 & 200 & 1290 & 1 & 1 \\
\hline 23 & 0 & 1235 & 221 & 1249 & 1 & 1 \\
\hline 25 & 0 & 1198 & 241 & 1212 & 1 & 1 \\
\hline 29 & 0 & 1165 & 248 & 1176 & 1 & 1 \\
\hline 30 & 0 & 1204 & 309 & 1214 & 2 & 2 \\
\hline 33 & 0 & 1102 & 258 & 1111 & 1 & 1 \\
\hline 39 & 0 & 993 & 270 & 1000 & 1 & 1 \\
\hline 45 & 0 & 930 & 300 & 934 & 5 & 3 \\
\hline 47 & 0 & 920 & 266 & 925 & 1 & 1 \\
\hline
\end{tabular}

Table E13 Continued on Next Page -----

48

This publication is available free of charge from: https://doi.org/10.6028/NIST.TN.2162 


\begin{tabular}{ccccccc}
\hline $\begin{array}{c}\boldsymbol{Z} \\
{[\mathbf{c m}]}\end{array}$ & $\begin{array}{c}\boldsymbol{r} \\
{[\mathbf{c m}]}\end{array}$ & $\begin{array}{c}\overline{\boldsymbol{T}}_{\boldsymbol{b}} \\
{[\mathbf{K}]}\end{array}$ & $\begin{array}{c}\boldsymbol{\sigma}_{\boldsymbol{T}_{\boldsymbol{b}}} \\
{[\mathbf{K}]}\end{array}$ & $\begin{array}{c}\overline{\boldsymbol{T}}_{\boldsymbol{g}} \\
{[\mathbf{K}]}\end{array}$ & $\begin{array}{c}\boldsymbol{U}_{\boldsymbol{c}}\left(\overline{\boldsymbol{T}}_{\boldsymbol{g}}\right) \\
{[\boldsymbol{\%}]}\end{array}$ & $\begin{array}{c}\mathbf{T C s} \\
\boldsymbol{N}\end{array}$ \\
\hline 60 & 0 & 740 & 279 & 743 & 14 & 3 \\
62 & 0 & 719 & 267 & 721 & 1 & 1 \\
75 & 0 & 598 & 187 & 600 & 11 & 2 \\
88 & 0 & 536 & 146 & 537 & 1 & 1 \\
\hline
\end{tabular}

\section{E.2.6 Propane Fires}

\section{E.2.6.1 The $21 \mathrm{~kW}$ Fire}

Table E14. Pooled mean gas temperature near the downstream face of the probe as a function of axial distance above the burner in the $21 \mathrm{~kW}$ propane gas fire. The expanded combined uncertainty is also shown in which the uncertainty represents a $95 \%$ confidence interval.

\begin{tabular}{ccccccc}
\hline $\begin{array}{c}\boldsymbol{Z} \\
{[\mathbf{c m}]}\end{array}$ & $\begin{array}{c}\boldsymbol{r} \\
{[\mathbf{c m}]}\end{array}$ & $\begin{array}{c}\overline{\boldsymbol{T}}_{\boldsymbol{b}} \\
{[\mathbf{K}]}\end{array}$ & $\begin{array}{c}\boldsymbol{\sigma}_{\boldsymbol{T}_{\boldsymbol{b}}} \\
{[\mathbf{K}]}\end{array}$ & $\begin{array}{c}\overline{\boldsymbol{T}}_{\boldsymbol{g}} \\
{[\mathbf{K}]}\end{array}$ & $\begin{array}{c}\boldsymbol{U}_{\boldsymbol{c}}\left(\overline{\boldsymbol{T}}_{\boldsymbol{g}}\right) \\
{[\boldsymbol{\%}]}\end{array}$ & $\begin{array}{c}\mathbf{T C s} \\
\boldsymbol{N}\end{array}$ \\
\hline 4 & 0 & 1028 & 229 & 1037 & 4 & 1 \\
6 & 0 & 1192 & 227 & 1206 & 3 & 1 \\
10 & 0 & 1319 & 200 & 1339 & 3 & 1 \\
14 & 0 & 1356 & 190 & 1376 & 2 & 1 \\
20 & 0 & 1284 & 240 & 1301 & 6 & 1 \\
24 & 0 & 1201 & 257 & 1216 & 6 & 1 \\
30 & 0 & 1008 & 286 & 1017 & 7 & 1 \\
40 & 0 & 851 & 268 & 855 & 2 & 1 \\
45 & 0 & 761 & 237 & 764 & 8 & 1 \\
60 & 0 & 579 & 149 & 580 & 5 & 1 \\
75 & 0 & 494 & 92 & 495 & 4 & 1 \\
100 & 0 & 418 & 51 & 419 & 4 & 1
\end{tabular}

\section{E.2.6.2 The $34 \mathrm{~kW}$ Fire}

Table E15. Pooled mean gas temperature near the downstream face of the probe as a function of axial distance above the burner in the $34 \mathrm{~kW}$ propane gas fire. The expanded combined uncertainty is also shown in which the uncertainty represents a $95 \%$ confidence interval.

\begin{tabular}{ccccccc}
\hline $\begin{array}{c}\boldsymbol{Z} \\
{[\mathbf{c m}]}\end{array}$ & $\begin{array}{c}\boldsymbol{r} \\
{[\mathbf{c m}]}\end{array}$ & $\begin{array}{c}\overline{\boldsymbol{T}}_{\boldsymbol{b}} \\
{[\mathbf{K}]}\end{array}$ & $\begin{array}{c}\boldsymbol{\sigma}_{\boldsymbol{T}_{\boldsymbol{b}}} \\
{[\mathbf{K}]}\end{array}$ & $\begin{array}{c}\overline{\boldsymbol{T}}_{\boldsymbol{g}} \\
{[\mathbf{K}]}\end{array}$ & $\begin{array}{c}\boldsymbol{U}_{\boldsymbol{c}}\left(\overline{\boldsymbol{T}}_{\boldsymbol{g}}\right) \\
{[\boldsymbol{\%}]}\end{array}$ & $\begin{array}{c}\mathbf{T C s} \\
\boldsymbol{N}\end{array}$ \\
\hline 4 & 0 & 850 & 197 & 854 & 1 & 1 \\
6 & 0 & 1041 & 246 & 1051 & 1 & 1 \\
10 & 0 & 1156 & 231 & 1168 & 1 & 1 \\
14 & 0 & 1243 & 215 & 1258 & 1 & 1 \\
20 & 0 & 1300 & 212 & 1317 & 5 & 1 \\
24 & 0 & 1254 & 225 & 1269 & 4 & 1 \\
\hline
\end{tabular}

Table E15 Continued on Next Page -----

49

This publication is available free of charge from: https://doi.org/10.6028/NIST.TN.2162 


\begin{tabular}{ccccccc}
\hline $\begin{array}{c}\boldsymbol{Z} \\
{[\mathbf{c m}]}\end{array}$ & $\begin{array}{c}\boldsymbol{r} \\
{[\mathbf{c m}]}\end{array}$ & $\begin{array}{c}\overline{\boldsymbol{T}}_{\boldsymbol{b}} \\
{[\mathbf{K}]}\end{array}$ & $\begin{array}{c}\boldsymbol{\sigma}_{\boldsymbol{T}_{\boldsymbol{b}}} \\
{[\mathbf{K}]}\end{array}$ & $\begin{array}{c}\overline{\boldsymbol{T}}_{\boldsymbol{g}} \\
{[\mathbf{K}]}\end{array}$ & $\begin{array}{c}\boldsymbol{U}_{\boldsymbol{c}}\left(\overline{\boldsymbol{T}}_{\boldsymbol{g}}\right) \\
{[\boldsymbol{\%}]}\end{array}$ & $\begin{array}{c}\mathbf{T C s} \\
\boldsymbol{N}\end{array}$ \\
\hline 26 & 0 & 1250 & 227 & 1265 & 3 & 1 \\
30 & 0 & 1196 & 262 & 1210 & 4 & 1 \\
34 & 0 & 1148 & 284 & 1160 & 8 & 1 \\
45 & 0 & 1001 & 320 & 1010 & 2 & 1 \\
60 & 0 & 780 & 299 & 785 & 4 & 1 \\
75 & 0 & 610 & 222 & 612 & 7 & 1 \\
100 & 0 & 493 & 116 & 494 & 8 & 1 \\
115 & 0 & 446 & 75 & 446 & 6 & 1 \\
\hline
\end{tabular}

\section{E.3 Uncertainty of Ideal Heat Release Rate}

The expanded combined uncertainty of the ideal heat release rate calculated from the burning rate is estimated as:

$$
U_{c}(\dot{Q})=2 \sqrt{u(\dot{Q})^{2}+\sigma_{R}(\overline{\dot{Q}})^{2}+u_{c}(\dot{m})^{2}}
$$

where $u(\dot{Q})$ is the standard uncertainty of the ideal heat release rate and $\sigma_{R}(\overline{\dot{Q}})$ is the repeatability of the measurement. $u_{c}(\dot{m})$ is the combined uncertainty of the ideal mass burning rate. The mean and expanded combined uncertainty of the ideal heat release rate is listed in Table 2.

\section{E.4 Uncertainty of the Radiative Fraction Estimate Based on a Single Point Measurement}

The expanded combined uncertainty of the radiative fraction estimate is estimated, considering Eq. 8 in Section 2.5:

$$
U_{c}\left(\chi_{\text {rad }}\right)=2 \sqrt{u_{c}(\dot{m})^{2}+u_{c}\left(\dot{q}^{\prime \prime}\right)^{2}+u_{c}\left(\dot{Q}_{\text {rad }, \text { model }}\right)^{2}+\left(2 u_{c}(r)\right)^{2}+\sigma_{R}\left(\chi_{\text {rad }}\right)}
$$

where the term $u_{c}(\dot{m})$ is the combined uncertainty of the burning rate and the term $\sigma_{R}\left(\chi_{r a d}\right)$ is the repeatability in repeated measurements. The term $u_{c}(r)$ is the positioning uncertainty of the radial distance, which is $1 \%$ in general.

Modak [26] suggests that a distance five times the diameter of a fire is adequately far enough away to use a single point location measurement of the total radiative flux, assuming isotropy. The results show the flame radiative power output assuming radiative isotropy tends to underestimate the total radiative energy emitted by the flame with a bias of about $2 \%$ at $r / D=5$. This is treated in Eq. E16 as uncertainty in the single point radiation estimate method, $u_{c}\left(\dot{Q}_{\text {rad,model }}\right)$.

The heat flux slightly increased during the steady burning period as the fire slowly heated up the surroundings continuously. The measured (uncorrected) heat flux can be affected by the temperature of surroundings (walls, calorimeter hood and so on). Background heat flux is subtracted from the measured heat flux and the details of the background heat flux estimate are described in Ref. [19]. In Eq. E16, the combined uncertainty of the corrected heat flux, $u_{c}\left(\dot{q}^{\prime \prime}\right)$, is estimated as:

This publication is available free of charge from: https://doi.org/10.6028/NIST.TN.2162 


$$
u_{c}\left(\dot{q}^{\prime \prime}\right)=\sqrt{u_{c}\left(\dot{q}_{b}^{\prime \prime}\right)^{2}+u_{c}(\text { cal. })^{2}+u_{c}(D A Q)^{2}}
$$

where the term $u_{c}\left(\dot{q}_{b}{ }^{\prime \prime}\right)$ is the heat flux background subtraction uncertainty of $5 \%$. The heat flux gauges were calibrated using a secondary standard gauge in a well-characterized calibration facility [39]. The calibration method and apparatus are described in Ref. [40]; the systematic uncertainty for the calibration, $u_{c}$ (cal), is estimated as $4.5 \%$ [39]. The measurement accuracy of the data acquisition system (DAQ, Model: SCXI-1600), $u_{c}(D A Q)$, is $0.076 \%$ in the application range [37].

In this study, the radiative fraction was estimated using the heat flux data measured at the three radial positions such as $r=1.5 \mathrm{~m}, 1.915 \mathrm{~m}$ and $2.503 \mathrm{~m}$, as seen in Table 5 (see Section 3.4). Uncertainty budget of the combined uncertainty of the radiative fraction estimate based on a single point measurement, $u_{c}\left(\chi_{\mathrm{rad}}\right)$, is presented in Table E16. The mean and expanded combined uncertainty of the radiative fraction are $0.23 \pm 19 \%$, representing a $95 \%$ confidence interval.

Table E16. Uncertainty budget of the combined uncertainty of the radiative fraction estimate based on a single point measurement $\left(u_{c}\left(\chi_{\text {rad }}\right)\right)$, considering the heat flux measurements using gauges various radial distances $(r)$ directed towards the fire and located at a vertical position of $z=15 \mathrm{~cm}$.

\begin{tabular}{cccc}
\hline Parameter & $\boldsymbol{s}_{\boldsymbol{i}}(\boldsymbol{x})$ & Combined uncertainty & contributions \\
$\boldsymbol{x}$ & {$[-]$} & $\boldsymbol{u}_{\boldsymbol{c}}(\boldsymbol{x})[-]$ & {$[-]$} \\
\hline Burning rate, $\dot{m}$ & 1 & $2.5 \%$ & $7 \%$ \\
Heat flux, $\dot{q}^{\prime \prime}$ & 1 & $6.7 \%$ & $49 \%$ \\
Repeatability, $\sigma_{R}$ & 1 & $5.8 \%$ & $36 \%$ \\
Model & 1 & $2.0 \%$ & $4 \%$ \\
Radial distance, $r$ & 2 & $1.0 \%$ & $4 \%$ \\
\hline$\chi_{\text {rad }}$ & & $9.6 \%$ & $100 \%$ \\
\hline
\end{tabular}

